HENRIQUE TAKACHI MORIYA

CONTRIBUIÇÕES NÃO-LINEARES E APROXIMAÇÃO NO DOMÍNIO DO TEMPO DO MODELO DE FASE CONSTANTE NA MECÂNICA RESPIRATÓRIA EM CAMUNDONGOS

\footnotetext{
Tese apresentada à Escola Politécnica da Universidade de São Paulo para obtenção do Título de Doutor em Engenharia.
}

São Paulo 
HENRIQUE TAKACHI MORIYA

\section{CONTRIBUIÇÕES NÃO-LINEARES E APROXIMAÇÃO NO DOMÍNIO DO TEMPO DO MODELO DE FASE CONSTANTE NA MECÂNICA RESPIRATÓRIA EM CAMUNDONGOS}

Tese apresentada à Escola Politécnica da Universidade de São Paulo para obtenção do Título de Doutor em Engenharia. 


\section{CONTRIBUIÇÕES NÃO-LINEARES E APROXIMAÇÃO NO DOMÍNIO DO TEMPO DO MODELO DE FASE CONSTANTE NA MECÂNICA RESPIRATÓRIA EM CAMUNDONGOS}

Tese apresentada à Escola Politécnica da Universidade de São Paulo para obtenção do Título de Doutor em Engenharia.

Área de Concentração:

Sistemas Eletrônicos

Opção:

Engenharia Biomédica

Orientador:

José Carlos Teixeira de Barros Moraes 
Moriya, Henrique Takachi

Contribuições não-lineares e aproximação no domínio do tempo do modelo de fase constante na mecânica respiratória em camundongos / Henrique Takachi Moriya. -- São Paulo, 2003. $112 \mathrm{p}$.

Tese (Doutorado) - Escola Politécnica da Universidade de São Paulo. Departamento de Engenharia de Telecomunicações e Controle.

1.Engenharia biomédica 2.Sistema respiratório I. Universidade de São Paulo. Escola Politécnica. Departamento de Engenharia de Telecomunicações e Controle II. $t$ 
Para aqueles que bancaram meus sonhos e sempre acreditaram mais do que eu, Takachi e Tokico, Luciana e Giovana. 
"E então quando tudo estiver terminado, é necessário lembrarmos o quanto foi difícil aqui termos chegado. E que em nossas próximas ações, lembremos do passado, como algo que tenha que inevitavelmente ficar em nossos corações."

Autor desconhecido 


\section{AGRADECIMENTOS}

A Deus por todas as oportunidades.

Ao orientador Prof. Dr. José Carlos Teixeira de Barros Moraes pela dedicação e pelo voto de confiança.

Ao co-orientador Jason H. T. Bates, Ph.D., D.Sc. pela enorme aposta e por me guiar e ensinar em um mundo novo.

À Lara Brandani e equipe por toda ajuda e orientação.

A todos do Laboratório de Engenharia Biomédica da EPUSP pela amizade e paciência.

A todos do Vermont Lung Center da Universidade de Vermont - EUA pela imensa hospitalidade e amizade.

À amiga e mestre Sonia Khirani e ao amigo Leonard Xasfyljé Meredith pela ajuda valiosa.

Ao Prof. Dr. Antonio Giannella Neto pela indicação de meu co-orientador.

Aos Dr. Daniel Deheinzelin, Dr. Laerte Pastore Júnior, mestranda Maria Eudóxia Pilloto de Carvalho e equipe de médicos da UTI do Hospital do Câncer da Fundação Antônio Prudente pela oportunidade de aplicar em minha pátria parte dos conhecimentos que aprendi e por me ensinarem mais sobre o assunto.

Ao Prof. Dr. Milton de Arruda Martins e as mestres Fernanda D. T. Q. S. Lopes e Fernanda M. A. Costa por terem permitido que colocasse em prática parte dos ensinamentos que aprendi e por me ensinarem mais sobre o assunto.

Aos estudantes Marcio Caetano Turbuk e Leandro Gaspari Lenz pelas conversas e lições.

A todos que, direta ou indiretamente, colaboraram na execução deste trabalho.

Ao CNPq pelo apoio financeiro. 


\section{ERRATA}

Nome: Henrique Takachi Moriya

Título da tese: Contribuições não-lineares e aproximação no domínio do tempo do modelo de fase constante na mecânica respiratória em camundongos

Área de concentração: Sistemas Eletrônicos

Opção: Engenharia Biomédica

\begin{tabular}{|l|l|l|}
\hline LOCAL & ONDE SE LE & LEIA-SE \\
\hline Todo texto & patologia & doença \\
\hline Todo texto & severa & grave \\
\hline
\end{tabular}

\begin{tabular}{|l|l|l|l|}
\hline PÁGINA & LINHA & ONDE SE LÊE & LEIA-SE \\
\hline 73 & $11^{\text {a }}$ & $\begin{array}{l}\text { "...que chega ao máximo } \\
\text { de } 5,5 \% \text { no caso de } \\
\text { melhor ajuste..." }\end{array}$ & $\begin{array}{l}\text { "..que chega ao máximo de } \\
5,5 \% \text { considerando média } \\
\text { mais desvio-padrão, no caso } \\
\text { de melhor ajuste..." }\end{array}$ \\
\hline 75 & $6^{\text {a }}$ & $\begin{array}{l}\text { "Os valores dos } \\
\text { parâmetros } R_{a w}, G_{t} e H_{t} \\
\text { estimados pelo modelo de } \\
\text { fase constante..." }\end{array}$ & $\begin{array}{l}\text { Os valores dos parâmetros } \\
R_{a w}, G_{t}, H_{t} \text { e } \alpha \text { estimados } \\
\text { pelo modelo de fase } \\
\text { constante..." }\end{array}$ \\
\hline
\end{tabular}

\begin{tabular}{|l|l|l|}
\hline PÁGINA & LOCAL & ANEXAR \\
\hline 76 & $\begin{array}{l}\text { Após } \\
\text { Tabela 4.4 }\end{array}$ & Tabela 4.4.1 \\
\hline
\end{tabular}

Tabela 4.4.1. Valores de $\alpha$ (média \pm desvio padrão) para o modelo de fase constante.

\begin{tabular}{|c|c|c|c|c|}
\hline $\begin{array}{c}\text { Amplitude } \\
\text { perturbação } \\
\downarrow\end{array}$ & PEEP $0 \mathrm{cmH}_{2} \mathrm{O}$ & PEEP $3 \mathrm{cmH}_{2} \mathrm{O}$ & PEEP $6 \mathrm{cmH}_{2} \mathrm{O}$ & $P E E P 9 \mathrm{cmH}_{2} \mathrm{O}$ \\
\hline $0,1 \mathrm{~mL}$ & $0,898 \pm 0,007$ & $0,896 \pm 0,015$ & $0,897 \pm 0,007$ & $0,934 \pm 0,009$ \\
\hline $0,2 \mathrm{~mL}$ & $0,897 \pm 0,006$ & $0,912 \pm 0,010$ & $0,927 \pm 0,010$ & $0,958 \pm 0,010$ \\
\hline $0,3 \mathrm{~mL}$ & $0,907 \pm 0,014$ & $0,921 \pm 0,009$ & $0,960 \pm 0,016$ & $0,970 \pm 0,005$ \\
\hline $0,4 \mathrm{~mL}$ & $0,911 \pm 0,011$ & $0,936 \pm 0,015$ & $0,987 \pm 0,010$ & $0,953 \pm 0,009$ \\
\hline
\end{tabular}




\begin{tabular}{|l|l|l|}
\hline PÁGINA & LOCAL & ANEXAR \\
\hline 83 & $\begin{array}{l}\text { Após a } \\
5^{\text {a }} \text { linha }\end{array}$ & Tabela 4.8 \\
\hline
\end{tabular}

Tabela 4.8. Valores de $R_{2}\left(\mathrm{cmH}_{2} \mathrm{O} / \mathrm{mL}^{2} / \mathrm{s}^{2}\right)$ (média \pm desvio padrão) para a variação não-linear da aproximação no domínio do tempo do modelo de fase constante com resistência dependente do fluxo.

\begin{tabular}{|c|c|c|c|c|}
\hline $\begin{array}{c}\text { Amplitude } \\
\text { perturbação } \\
\downarrow\end{array}$ & $P E E P 0 \mathrm{cmH}_{2} \mathrm{O}$ & PEEP $3 \mathrm{cmH}_{2} \mathrm{O}$ & PEEP $6 \mathrm{cmH}_{2} \mathrm{O}$ & $P E E P 9 \mathrm{cmH}_{2} \mathrm{O}$ \\
\hline $0,1 \mathrm{~mL}$ & $0,287 \pm 0,947$ & $-0,107 \pm 0,072$ & $-0,316 \pm 0,149$ & $-0,784 \pm 0,301$ \\
\hline $0,2 \mathrm{~mL}$ & $0,099 \pm 0,118$ & $-0,009 \pm 0,122$ & $-0,133 \pm 0,114$ & $-0,737 \pm 0,112$ \\
\hline $0,3 \mathrm{~mL}$ & $0,065 \pm 0,249$ & $0,008 \pm 0,137$ & $-0,039 \pm 0,097$ & $-0,592 \pm 0,132$ \\
\hline $0,4 \mathrm{~mL}$ & $0,046 \pm 0,207$ & $0,036 \pm 0,146$ & $-0,074 \pm 0,075$ & $-0,724 \pm 0,205$ \\
\hline
\end{tabular}

\begin{tabular}{|c|c|c|c|}
\hline PÁGINA & LINHA & ONDE SE LÊ & LEIA-SE \\
\hline 91 & $11^{\mathrm{a}}$ & $\begin{array}{l}\text { "...o valor de } H_{t} \text { foi } \\
\text { mínimo em um valor } \\
\text { intermediário de } P E E P . . .\end{array}$ & $\begin{array}{l}\text { "...o valor de } H_{t} \text { foi mínimo, } \\
\text { considerando os valores } \\
\text { médios, em um valor } \\
\text { intermediário de } P E E P . . . "\end{array}$ \\
\hline 91 & $16^{\mathrm{a}}$ & $\begin{array}{l}\text { "O parâmetro } G_{t} \\
\text { apresenta um padrão } \\
\text { similar ao apresentado por } \\
H_{t} . . .\end{array}$ & $\begin{array}{l}\text { "O parâmetro } \mathrm{G}_{\mathrm{t}} \text { apresenta } \\
\text { um padrão bastante similar } \\
\text { ao apresentado por } H_{t}(\mathrm{com} \\
\text { valores médios mínimos com } \\
\text { nível de PEEP de } 6 \\
\left.\mathrm{cmH}_{2} \mathrm{O}\right) \text {..." }\end{array}$ \\
\hline
\end{tabular}


SUMÁRIO

LISTA DE TABELAS

LISTA DE FIGURAS

LISTA DE ABREVIATURAS E SIGLAS

LISTA DE SÍMBOLOS

RESUMO

ABSTRACT

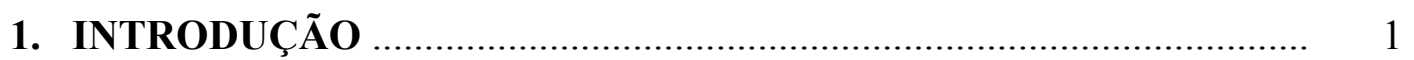

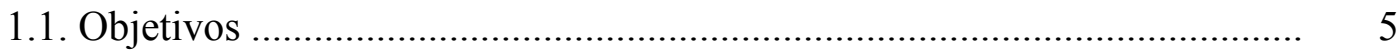

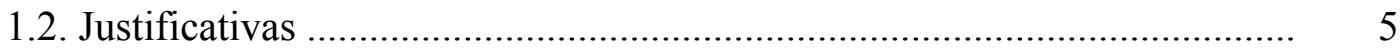

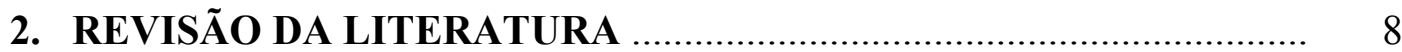

2.1. Método quasi-estático ................................................................ 10

2.2. Método dinâmico ................................................................................... 15

2.2.1. Modelo multicompartimentais .......................................................... 20

2.2.1.1. Excitação para modelos multicompartimentais ................................. 20

2.2.1.2. Análise no domínio do tempo ....................................................... 23

2.2.1.3. Análise no domínio da freqüência ................................................ 30

2.2.2. Modelos não-lineares .................................................................. 37

2.3. Método de escolha do modelo a ser utilizado ........................................... 42

2.4. Modelos computacionais .................................................................. 43

2.5. Estado atual da avaliação da mecânica respiratória .................................... 43

3. MATERIAIS E MÉTODOS …....................................................... 46

3.1. Procedimentos experimentais ............................................................... 46 
3.2. Geração da perturbação em volume

3.3. Análise dos dados experimentais ...................................................... 53

3.4. Comparação entre os modelos .................................................................. 62

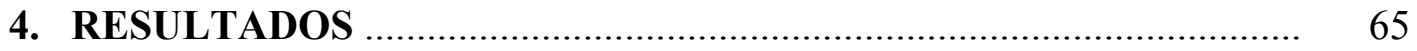

4.1. Desenvolvimento do modelo matemático ............................................... 65

4.2. Estudo da importância da inertância .......................................................... 71

4.3. Comparação entre o modelo de fase constante e sua aproximação no domínio do tempo ..............................................................................

4.4. Índice de não-linearidade do sistema respiratório modelado .................... 80

4.5. Extensões não-lineares da aproximação no domínio do tempo do modelo de fase constante

4.6. Comparação entre a aproximação no domínio do tempo do modelo de fase constante e suas variações não-lineares ............................................... 82

4.7. Artigos publicados e aceitos para publicação internacional ...................... 86

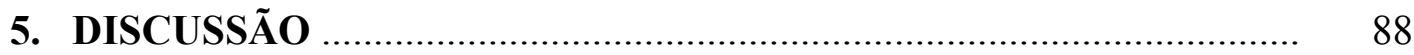

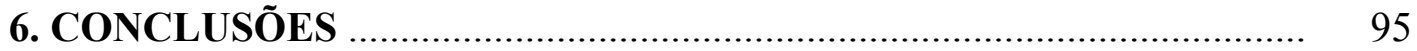

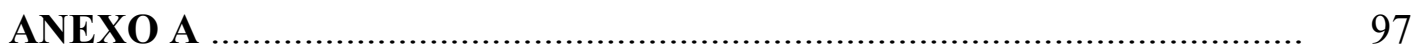

LISTA DE REFERÊNCIAS _.......................................................... 101

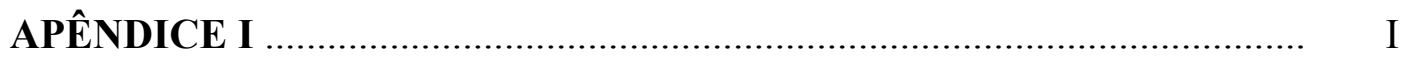

APÊNDICE II ……............................................................... V 


\section{LISTA DE TABELAS}

Tabela 4.1 Valores de $I_{a w}\left(\mathrm{cmH}_{2} \mathrm{O} / \mathrm{mL} / \mathrm{s}^{2}\right)$ (média \pm desvio-padrão)

Tabela 4.2 Valores de $R_{a w}\left(\mathrm{cmH}_{2} \mathrm{O} / \mathrm{mL} / \mathrm{s}\right)$ (média \pm desvio-padrão) para o modelo de fase constante

Tabela 4.3 Valores de $G_{t}\left(\mathrm{cmH}_{2} \mathrm{O} / \mathrm{mL} / \mathrm{s}^{(1-\alpha)}\right)$ (média \pm desvio-padrão) para o modelo de fase constante

Tabela 4.4 Valores de $H_{t}\left(\mathrm{cmH}_{2} \mathrm{O} / \mathrm{mL} / \mathrm{s}^{(1-\alpha)}\right)$ (média \pm desvio-padrão) para o modelo de fase constante

Tabela 4.5 Valores de $R_{a w}\left(\mathrm{cmH}_{2} \mathrm{O} / \mathrm{mL} / \mathrm{s}\right)$ (média \pm desvio-padrão) para a aproximação no domínio do tempo do modelo de fase constante

Tabela 4.6 Valores de $G_{t}\left(\mathrm{cmH}_{2} \mathrm{O} / \mathrm{mL} / \mathrm{s}^{(1-\alpha)}\right)$ (média \pm desvio-padrão) para a aproximação no domínio do tempo do modelo de fase constante

Tabela 4.7 Valores de $H_{t}\left(\mathrm{cmH}_{2} \mathrm{O} / \mathrm{mL} / \mathrm{s}^{(1-\alpha)}\right)$ (média \pm desvio-padrão) para a aproximação no domínio do tempo do modelo de fase constante 


\section{LISTA DE FIGURAS}

Figura 1.1 Esquema da montagem utilizada para avaliação da mecânica respiratória em pacientes humanos ventilados mecanicamente (Bates, 1998)

Figura 2.1 Exemplo de curva $P V$ típica (Haas, 2000)

Figura 2.2 Modelo linear de um compartimento constituído por tubo (resistência) e balão (elastância)

Figura 2.3 Representação mecânica do modelo linear de um compartimento 16

Figura 2.4 Modelo paralelo de redistribuição gasosa. (A) Representação anatômica. (B) Representação mecânica

Figura 2.5 Modelo em série de redistribuição gasosa. (A) Representação anatômica. (B) Representação mecânica

Figura 2.6 Modelo viscoelástico. (A) Representação anatômica. (B) Representação mecânica

Figura 2.7 Dois modos equivalentes de arranjar três elementos de um corpo de Kelvin para representar um material viscoelástico

Figura 2.8 Representação mecânica do modelo plastoelástico

Figura 2.9 Exemplo de aplicação do modelo de fase constante para modelamento da impedância de entrada do sistema respiratório de um camundongo

Figura 3.1 Camundongo sendo ventilado

Figura 3.2 Foto do flexiVent utilizado nesta pesquisa

Figura 3.3 Diagrama esquemático do flexiVent 
Figura 3.4 Perturbação em volume utilizada, dimensionada para ter $0,3 \mathrm{~mL}$ pico-a-pico

Figura 3.5 Equivalente elétrico do modelo flexiVent-camundongo (Bates et al., 1997)

Figura 4.1 Exemplo de aplicação da aproximação no domínio do tempo do modelo de fase constante (Equação 4.17) aos dados experimentais obtidos (camundongo número 2, PEEP de 3 $\mathrm{cmH}_{2} \mathrm{O}$ e amplitude de $0,2 \mathrm{~mL}$ )

Figura 4.2 Exemplo de aplicação da aproximação no domínio do tempo do modelo de fase constante com a adição do termo relativo à inertância (Equação 4.18) aos dados experimentais obtidos (camundongo número 2, PEEP de $3 \mathrm{cmH}_{2} \mathrm{O}$ e amplitude de 0,2 $\mathrm{mL})$

Figura 4.3 Comportamento de $\triangle E N V$ com a adição do termo referente à inertância $\left(I_{a w}\right)$ em relação à aproximação no domínio do tempo do modelo de fase constante

Figura 4.4 Exemplo de aplicação do modelo de fase constante (Equação 2.18) no domínio da freqüência aos valores calculados da impedância (camundongo número 2, PEEP de $3 \mathrm{cmH}_{2} \mathrm{O}$ e amplitude de 0,2 $\mathrm{mL}$ )

Figura 4.5 Diferenças percentuais entre os valores de resistência $\left(R_{a w}\right)$ estimados pelo modelo de fase constante no domínio da freqüência (Equação 2.18) e a aproximação do modelo de fase constante no domínio do tempo (Equação 4.17) 
Figura 4.6 Diferenças percentuais entre os valores de $G_{t}$ estimados pelo modelo de fase constante no domínio da freqüência (Equação 2.18) e a aproximação do modelo de fase constante no domínio do tempo (Equação 4.17)

Figura 4.7 Diferenças percentuais entre os valores de $H_{t}$ estimados pelo modelo de fase constante no domínio da freqüência (Equação 2.18) e a aproximação do modelo de fase constante no domínio do tempo (Equação 4.17)

Figura 4.8 Índice de não-linearidade $k_{d}$ (Equação 3.11) para as diversas amplitudes de perturbação e níveis de PEEP estudados

Figura 4.9 Exemplo de aplicação da variação não-linear da aproximação no domínio do tempo do modelo de fase constante com a resistência dependente do fluxo (Equação 4.19) aos dados experimentais obtidos (camundongo número 2, PEEP $3 \mathrm{cmH}_{2} \mathrm{O}$ e amplitude de $0,2 \mathrm{~mL}$ )

Figura 4.10 Comportamento de $\triangle E N V$ com a adição do termo referente à resistência dependente do fluxo em relação à aproximação no domínio do tempo do modelo de fase constante

Figura 4.11 Exemplo de aplicação da variação não-linear da aproximação no domínio do tempo do modelo de fase constante com a elastância dependente do volume (Equação 4.20) aos dados experimentais obtidos (camundongo número 2, PEEP de $3 \mathrm{cmH}_{2} \mathrm{O}$ e amplitude de $0,2 \mathrm{~mL}$ ) 
Figura 4.12 Comportamento de $\triangle E N V$ com a adição do termo referente à elastância dependente do volume em relação à aproximação no domínio do tempo do modelo de fase constante 


\section{LISTA DE ABREVIATURAS E SIGLAS}

\begin{tabular}{|c|c|}
\hline ANOVA & Análise de Variância \\
\hline$A T S$ & American Thoracic Society \\
\hline$B M E S$ & Biomedical Engineering Society \\
\hline$C A$ & Estado norte-americano da Califórnia \\
\hline$C N P q$ & $\begin{array}{l}\text { Conselho Nacional de Desenvolvimento Científico e } \\
\text { Tecnológico }\end{array}$ \\
\hline$C P T$ & Capacidade Pulmonar Total \\
\hline$C R F$ & Capacidade Residual Funcional \\
\hline$E U A$ & Estados Unidos da América \\
\hline$G A$ & Estado norte-americano da Georgia \\
\hline$I L$ & Estado norte-americano de Illinois \\
\hline$L V D T$ & $\begin{array}{l}\text { Transdutor Diferencial Variável Linear do inglês Linear } \\
\text { Variable Differential Transducer }\end{array}$ \\
\hline$M A$ & Estado norte-americano de Massachusetts \\
\hline$N C$ & Estado norte-americano da Carolina do Norte \\
\hline$N S N D$ & Não-Soma-Não-Diferença do inglês No-Sum-No-Difference \\
\hline$O V W$ & $\begin{array}{l}\text { Forma Ventilatória Ótima do inglês Optimal Ventilator } \\
\text { Waveform }\end{array}$ \\
\hline$P C$ & Computador Pessoal do inglês Personal Computer \\
\hline PEEP & $\begin{array}{l}\text { Pressão Positiva de Final de Expiração do inglês Positive End } \\
\text { Expiratory Pressure }\end{array}$ \\
\hline$P V$ & Pressão-Volume \\
\hline$Q C$ & Província canadense de Quebéc \\
\hline$S D R A$ & Síndrome do Desconforto Respiratório Agudo \\
\hline$V T$ & Estado norte-americano de Vermont \\
\hline
\end{tabular}




\section{LISTA DE SÍMBOLOS}

1. Constante na equação proposta por Salazar e Knowles (1964) (Equação 2.1)

2. Constante nas equações dos Capítulos 3 e 4 e no ANEXO A

Constante na equação proposta por Salazar e Knowles (1964)

(Equação 2.1)

C

Elemento de Coulomb

$\mathrm{cmH}_{2} \mathrm{O}$

centímetros de água

$D F T_{x}$

Transformada discreta de Fourier do sinal $x$

$d(t)$

Função de Heaviside

$f$

Freqüência cíclica

E

1. Elastância para o modelo linear de um compartimento

2. Elastância dependente do volume na variação não-linear da aproximação no domínio do tempo do modelo de fase constante com elastância dependente do volume

$e$

Base dos logaritmos naturais

$E_{1}$

1. Elastância para o compartimento número 1 do modelo paralelo de redistribuição gasosa

2. Elastância do compartimento proximal do modelo em série de redistribuição gasosa

3. Elastância do corpo de Prandtl do modelo plastoelástico

4. Elastância não dependente do volume nas Equações $2.21 \mathrm{e}$ 


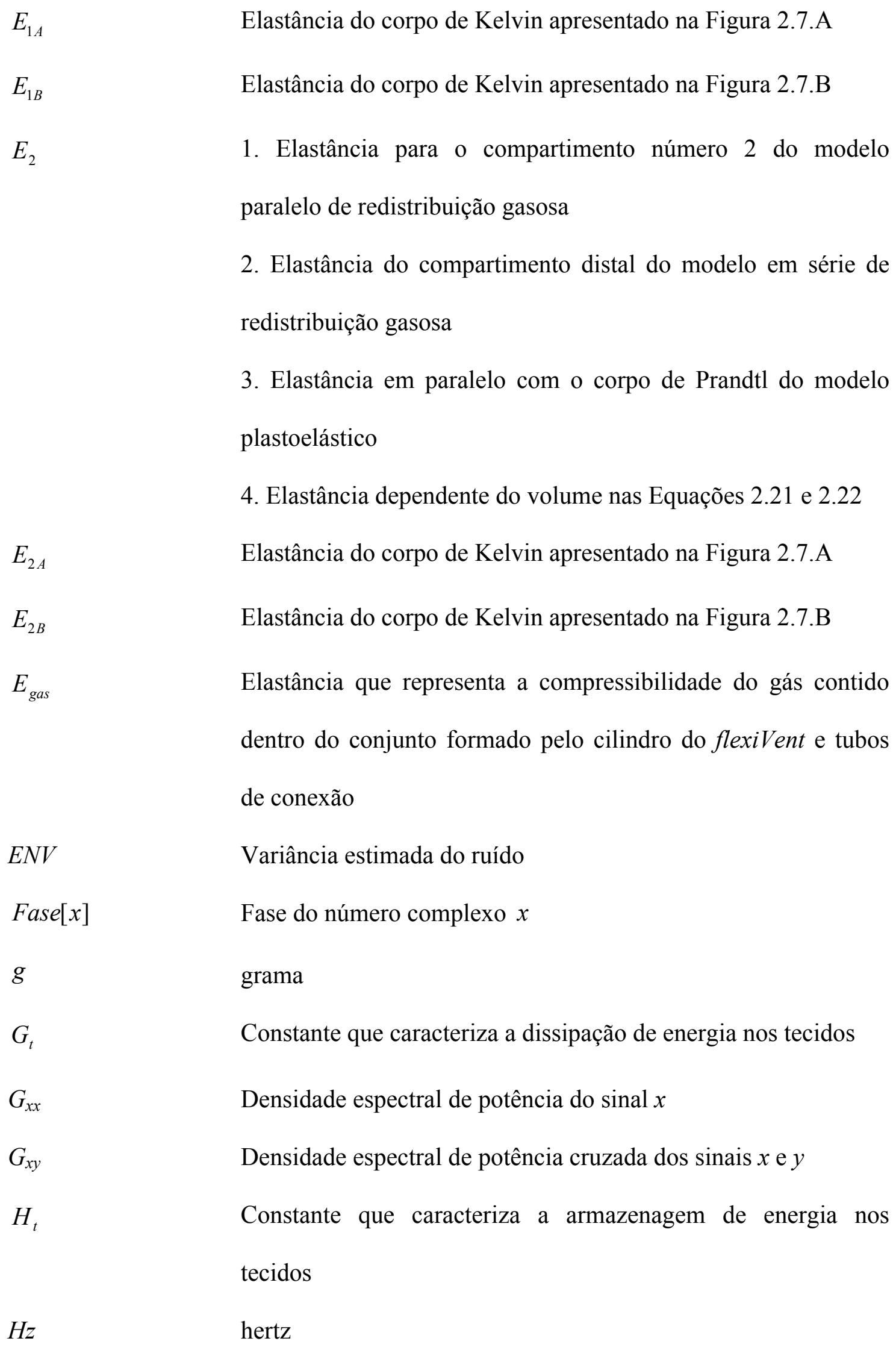




\begin{tabular}{|c|c|}
\hline$I_{a w}$ & Inertância das vias aéreas \\
\hline $\operatorname{Im}[x]$ & Parte imaginária do número complexo $x$ \\
\hline$I_{\text {tubo }}$ & Inertância devido às tubulações e à cânula \\
\hline$j$ & Unidade imaginária \\
\hline$K$ & $\begin{array}{l}\text { Constante na equação proposta por Salazar e Knowles (1964) } \\
\text { (Equação 2.1) }\end{array}$ \\
\hline$k$ & $1-\alpha$ \\
\hline$k g$ & kilograma \\
\hline$K_{1}$ & Coeficiente de Rohrer dependente da viscosidade do gás \\
\hline$K_{2}$ & Coeficiente de Rohrer dependente da densidade do gás \\
\hline$k_{d}$ & Índice de não-linearidade do sistema respiratório modelado \\
\hline $\ln t$ & Logaritmo neperiano do tempo \\
\hline$m g$ & miligrama \\
\hline$m L$ & mililitro \\
\hline$P$ & Pressão \\
\hline$\dot{P}$ & Aceleração da pressão \\
\hline$P_{0}$ & Valor que $P$ assume quando $\dot{V}$ e $V$ são iguais a zero \\
\hline$P_{\text {aberto }}$ & $\begin{array}{l}\text { Pressão dentro do cilindro do flexiVent enquanto a cânula estava } \\
\text { aberta para o ar ambiente }\end{array}$ \\
\hline$P_{a o}$ & Pressão na saída das vias aéreas \\
\hline$P_{c y l}$ & Pressão dentro do cilindro do flexiVent \\
\hline$P_{D}$ & Pressão após uma mudança em degrau do volume do modelo \\
\hline
\end{tabular}


multicompartimental descrito pela Equação 2.9

$P_{e s}$

$P_{N I}$

$P_{\text {ocluido }}$

$P_{t i}$

$P_{\text {TOT }}$

$P_{t p}$

$R$

$R_{1}$

número 1 do modelo paralelo de redistribuição gasosa
2. Resistência da traquéia do modelo em série de redistribuição
gasosa
3. Resistência do modelo plastoelástico
4. Resistência não-dependente do fluxo na variação não-linear
da aproximação no domínio do tempo do modelo de fase
constante com resistência dependente do fluxo
Resistência do corpo de Kelvin apresentado na Figura 2.7.B
1. Resistência da via aérea que conecta o compartimento
número 2 do modelo paralelo de redistribuição gasosa
2. Resistência de via aérea do modelo em série de redistribuição
gasosa

Potência de $P_{a o}$ nas freqüências que não estão presentes no sinal de entrada $\dot{V}_{a o}$

Pressão dentro do cilindro do flexiVent enquanto a cânula estava

completamente obstruída

Pressão nos tecidos

Potência total de $P_{a o}$

Pressão transpulmonar

Resistência para o modelo linear de um compartimento

1. Resistência da via aérea que conecta o compartimento número 1 do modelo paralelo de redistribuição gasosa

Resistência da traquéia do modelo em série de redistribuição
Pressão esofagiana 
3. Resistência dependente do fluxo na variação não-linear da aproximação no domínio do tempo do modelo de fase constante com resistência dependente do fluxo

$R_{2 A}$

$R_{a w}$

$R_{c}$

$R_{\text {tubo }}$

$\operatorname{Re}[x]$

$S$

$t$

V

$\dot{V}$

$|\dot{V}|$

$\ddot{V}$

$V_{\text {aberto }}$

$V_{a o_{a b e r o}}$

$V_{c y l}$

$V_{D}$
Resistência do corpo de Kelvin apresentado na Figura 2.7.A

Resistência das vias aéreas

Resistência da traquéia no modelo paralelo de redistribuição gasosa

Resistência devido às tubulações e à cânula

Parte real do número complexo $x$

1. Segundos

2. Operador da transformada de Laplace no ANEXO A

Tempo

Volume

Fluxo

Módulo do fluxo

Aceleração do volume

Posicionamento do pistão do flexiVent enquanto a cânula estava aberta para o ar ambiente

Volume que realmente sai pela cânula quando ela estava completamente aberta para o ar ambiente

Posicionamento do pistão do flexiVent, medida indireta do volume fornecido

Mudança em degrau do volume do modelo multicompartimental 
descrito pela Equação 2.9

$V_{\text {ocluido }}$

Posicionamento do pistão do flexiVent enquanto a cânula estava

completamente obstruída

Z

Impedância mecânica

$Z_{a w}$

Impedância devido às vias aéreas

$Z_{\text {in }}$

Impedância de entrada

$Z_{r s}$

Impedância do sistema respiratório

$Z_{t i}$

Impedância devido aos tecidos

$z_{t i}$

Anti-transformada de Fourier de $Z_{t i}$

$Z_{t r}$

Impedância de transferência

$\alpha$

$\frac{2}{\pi} \cdot \operatorname{arctg}\left(\frac{H_{t}}{G_{t}}\right)$

$\triangle E N V$

Percentual de melhora da $E N V$

$\Gamma(\alpha)$

Função gama de $\alpha$

$\gamma^{2}$

Função de coerência

$\pi$

pi 


\section{RESUMO}

A avaliação das propriedades mecânicas do sistema respiratório é tipicamente realizada oscilando-se um fluxo nos pulmões através da traquéia, medindo-se a pressão resultante gerada na traquéia e relacionando-se os dois sinais em termos de alguns modelos matemáticos. Se o sinal de fluxo de perturbação tem seu espectro em banda larga e não apresenta uma amplitude muito elevada, assume-se que o sistema respiratório está se comportando de forma linear e calcula-se sua impedância de entrada. Alternativamente, alguns pesquisadores tem utilizado sinais de fluxo que apresentam um espectro em banda estreita, mas com altos valores de amplitude, e aplicam modelos paramétricos não-lineares para quantificar as relações entre fluxo e pressão. Pouco tem sido feito, entretanto, para considerar dados relativos ao sistema respiratório quando a excitação é de banda larga e o sistema reflete não-linearidades. Nesta pesquisa, esta categoria de dados foi considerada realizando-se experimentos com camundongos. Para interpretar estes dados, desenvolveu-se uma aproximação no domínio do tempo de um modelo muito empregado para descrever a impedância respiratória de entrada. Este modelo foi então estendido para incluir termos de resistência e elastância não-lineares. Descobriu-se que o modelo com termo de elastância não-linear estima melhor os dados experimentais quando amplitudes altas são utilizadas, relativamente ao modelo linear e ao modelo com termo resistivo nãolinear. Este modelo pode também ser útil para detecção de hiperinsuflação dos pulmões durante a ventilação mecânica. 


\begin{abstract}
The assessment of the mechanical properties of the respiratory system is typically done by oscillating flow into the lungs via the trachea, measuring the resulting pressure generated at the trachea, and relating these two signals to each other in terms of some suitable mathematical model. If the perturbing flow signal is broadband and not too large in amplitude, linear behavior is usually assumed and the input impedance calculated. Alternatively, some researchers have used flow signals that are narrow band but large in amplitude, and invoked nonlinear lumpedparameter models to account for the relationship between flow and pressure. There has been little attempt, however, to deal with respiratory data that is both broadband and reflective of system nonlinearities. In the present study, it was collected such data from mice. To interpret these data, it was first developed a time-domain approximation to a widely used model of respiratory input impedance. It was then extended this model to include nonlinear resistive and elastic terms. It was found that the nonlinear elastic term fit the data better than the linear model or the nonlinear resistance model when amplitudes were large. This model may also be useful for detecting overinflation of the lung during mechanical ventilation.
\end{abstract}




\section{INTRODUÇÃO}

A respiração pode ser considerada como o conjunto de fenômenos e processos que fornece oxigênio ao metabolismo intracelular e elimina um dos produtos finais decorrente deste metabolismo, o gás carbônico. Para que esta troca gasosa possa ocorrer, são necessários processos químicos e mecânicos. A avaliação da mecânica respiratória engloba todos os aspectos pertinentes aos processos mecânicos realizados durante a respiração.

A avaliação da mecânica respiratória pode ser realizada tanto durante a ventilação espontânea como durante a assistência ventilatória mecânica. Esta pesquisa tem seu enfoque na avaliação da mecânica respiratória sob assistência ventilatória invasiva.

Esta pesquisa foi realizada em dois locais distintos graças a uma bolsa de doutorado-sanduíche fornecida pelo CNPq. De março de 1999 a agosto de 2000 e de outubro de 2001 a janeiro de 2003, as atividades foram realizadas no Laboratório de Engenharia Biomédica da Escola Politécnica da Universidade de São Paulo - Brasil sob orientação do Prof. Dr. José Carlos Teixeira de Barros Moraes. Outras atividades foram realizadas no Vermont Lung Center do College of Medicine da University of Vermont - EUA de setembro de 2000 a setembro de 2001 sob orientação de Jason H. T. Bates, Ph.D., D.Sc..

A monitoração da mecânica respiratória em pacientes sob assistência ventilatória invasiva pode constituir-se em uma importante ferramenta para auxílio na avaliação do estado de pacientes e na escolha do melhor modo de ventilação e do 
melhor procedimento terapêutico a ser adotado (Avanzolini et al., 1997); (Bates, 1998).

Atualmente, a avaliação da mecânica respiratória baseia-se na medição e posterior análise das pressões, fluxos e volumes envolvidos na respiração. Para pacientes ventilados mecanicamente, a montagem tipicamente utilizada para realizar esta medição é esquematizada na Figura 1.1. Pode-se também monitorar pacientes traqueostomizados e, neste caso, tem-se uma cânula ao invés de um tubo endotraqueal.

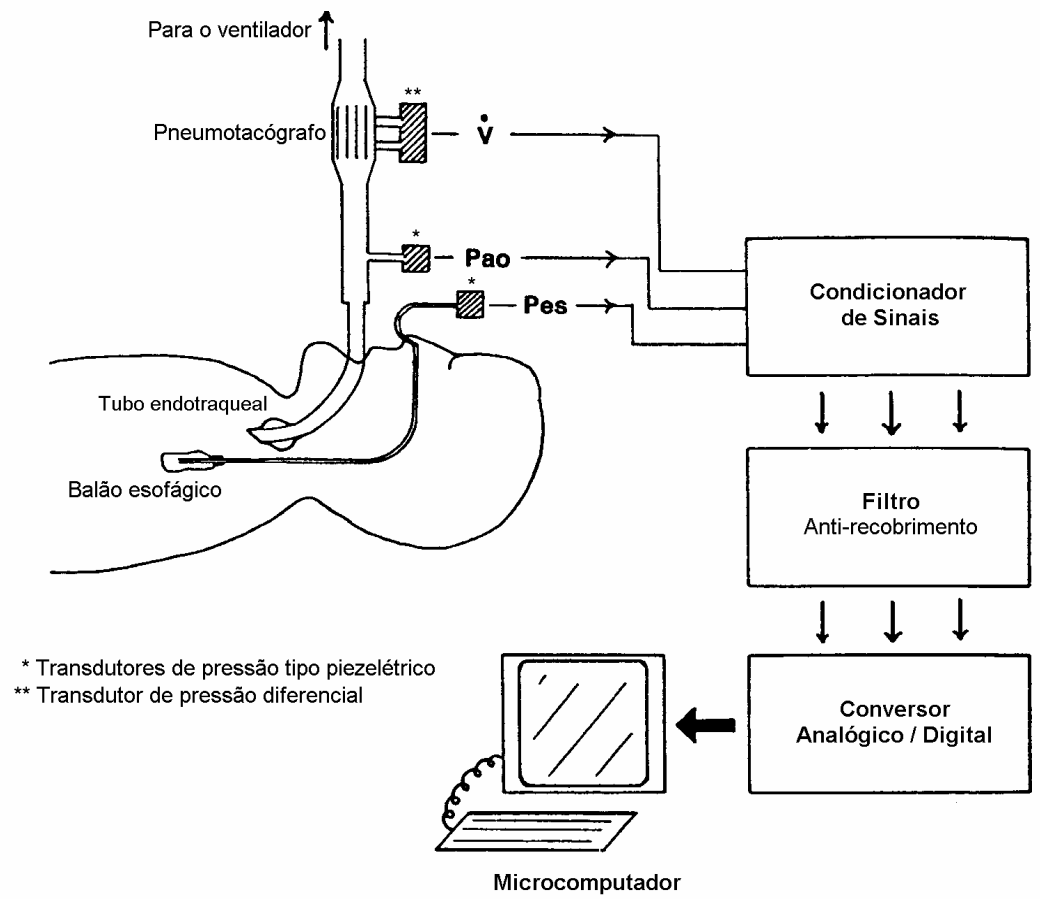

Figura 1.1. Esquema da montagem utilizada para avaliação da mecânica respiratória em pacientes humanos ventilados mecanicamente (Bates, 1998).

O conjunto formado por um pneumotacógrafo conectado a um transdutor de pressão diferencial é utilizado para registrar o fluxo na entrada do tubo endotraqueal $(\dot{V})$. O volume pulmonar $(V)$ relativo à capacidade residual funcional $(C R F)$ é 
obtido pela integração numérica desse fluxo (Bates, 1998). A pressão na saída do tubo endotraqueal $\left(P_{a o}\right)$ é medida por um transdutor de pressão do tipo piezelétrico, sendo também medida a pressão esofagiana $\left(P_{e s}\right)$ através de um balão esofágico conectado a um transdutor de pressão do tipo piezelétrico. Esta pressão é utilizada como uma estimativa da pressão na caixa torácica (D'Angelo, 1999).

Os sinais provenientes dos transdutores seguem para um subsistema responsável pelo condicionamento e, posteriormente, para um subsistema de filtragem para evitar o efeito de recobrimento. Após a filtragem, os sinais são enviados a um conversor analógico-digital, seguindo então para um microcomputador para realização de análises matemáticas/computacionais.

Como ocorre na maioria dos estudos biológicos, diversas pesquisas sobre avaliação da mecânica respiratória tem sido realizadas em animais (Gomes et al., 2000). O sistema de medição utilizado em animais se assemelha muito ao esquematizado na Figura 1.1, sendo que a diferença principal é a não medição de $P_{e s}$ em certos animais (como camundongos) devido à impossibilidade de utilizar-se um balão esofágico.

Segundo Bates e colaboradores (1989), a compreensão do comportamento mecânico do sistema respiratório é invariavelmente realizada através da utilização de modelos que são análogos teóricos ao sistema respiratório, cujos comportamentos se assemelham ao do sistema real, dentro de um certo grau de precisão, e cujos parâmetros apresentam algum significado fisiológico.

De acordo com Avanzolini e colaboradores (1997), diversos modelos para avaliação da mecânica respiratória foram propostos, pois havia a necessidade de satisfazer diferentes aspectos, tais como: aplicação clínica em tempo real, redução do 
ruído/distorção introduzida pelo sistema de medição, tipo de respiração (mecânica, espontânea ou mista), tipo de dados medidos e condições de pacientes.

Atualmente, a avaliação das propriedades mecânicas do sistema respiratório é tipicamente realizada oscilando-se um fluxo conhecido nos pulmões através da traquéia, medindo-se a pressão resultante gerada na traquéia e relacionando os dois sinais em termos de resistência respiratória e elastância dos tecidos. O termo complacência também é bastante utilizado e é matematicamente definido como sendo o inverso da elastância. O fluxo utilizado para excitar o sistema respiratório ou é de ar ambiente ou de uma outra mistura gasosa conhecida, sendo que esta mistura, geralmente, é enriquecida com uma maior porcentagem de oxigênio do que a existente no ar ambiente.

Tanto a resistência como a elastância são notadamente dependentes da freqüência de oscilação e esta dependência é mais pronunciada no intervalo correspondente às freqüências respiratórias. Esta dependência da freqüência mostra a multicompartimentabilidade do sistema respiratório. Conseqüentemente, análises multifreqüênciais da mecânica respiratória são necessárias.

Uma das análises multifreqüênciais mais utilizadas é realizada no domínio da freqüência através da avaliação da impedância mecânica de entrada do sistema respiratório. Esta impedância é convenientemente determinada através da chamada técnica de oscilações forçadas, pela qual os pulmões são perturbados com um sinal excitatório, geralmente de fluxo, em banda larga, tipicamente de valores de décimos até dezenas de hertz, dependendo da aplicação desejada.

A determinação da impedância de entrada é realizada assumindo-se que o sistema respiratório apresenta um comportamento linear (Michaelson et al., 1975), 
uma suposição que é usualmente satisfeita utilizando-se valores baixos de amplitude de fluxo.

Lutchen e colaboradores (1993b) desenvolveram um novo processo de medição e aplicaram um fluxo em banda larga com uma forma de onda préestabelecida que denominaram de "forma ventilatória ótima" ( $O V W$, do inglês Optimal Ventilator Waveform). Os fluxos tipo $O V W$ podem ventilar os pulmões de uma maneira suficiente para manter as trocas gasosas, enquanto, ao mesmo tempo, permitem a determinação da impedância de entrada do sistema respiratório até aproximadamente $8 \mathrm{~Hz}$. Como os fluxos tipo $O V W$ utilizam valores altos de amplitude para poder ventilar os pulmões, a suposição do comportamento linear do sistema respiratório nem sempre é satisfeita quando estes fluxos são empregados.

\subsection{OBJETIVOS}

Esta pesquisa visou desenvolver e ensaiar experimentalmente, em camundongos, modelos matemáticos no domínio do tempo capazes de considerar os efeitos das não-linearidades quando amplitudes altas de fluxos tipo $O V W$ forem aplicadas no sistema respiratório.

\subsection{JUSTIFICATIVAS}

O sistema respiratório geralmente é estudado como sendo um modelo linear. Entretanto, a modelagem linear para descrição do sistema respiratório é apenas uma aproximação da realidade, válida somente sob certas circunstâncias. Em alguns casos, como na presença de patologias ou quando da utilização de altos valores de 
volume corrente e "pressão positiva de final de expiração" (PEEP, do inglês Positive End Expiratory Pressure), o comportamento não-linear do sistema respiratório passa a ser relevante e não pode ser menosprezado na modelagem.

Para realizar de modo satisfatório a ventilação, as amplitudes pico-a-pico dos fluxos tipo $O V W$ não podem ser muito baixas. Entretanto, quanto maior a amplitude do fluxo submetido aos pulmões, maiores as chances do sistema respiratório responder de forma não-linear, inviabilizando o cálculo da impedância de entrada (Michaelson et al., 1975).

A distorção harmônica que obtém-se quando um sistema não-linear é excitado por uma entrada em banda-larga pode ser minimizada desde que as freqüências presentes no fluxo excitatório satisfaçam certos critérios, tal como o da não-soma-não-diferença (NSND, do inglês No-Sum-No-Difference) proposto por Suki e Lutchen (1992). Entretanto, esta condição implica que todas as outras componentes de freqüência que não satisfazem o critério $N S N D$, e estão presentes no sinal de pressão obtido devido ao fluxo excitatório e às não-linearidades, sejam descartadas e não utilizadas para o cálculo da impedância de entrada. As análises atualmente realizadas em fluxos tipo $O V W$ geralmente utilizam critérios como o NSND.

Nesta pesquisa, buscou-se desenvolver e avaliar experimentalmente um método que não descartasse os efeitos das não-linearidades no caso de aplicação de fluxos tipo $O V W$, pois, se o sistema for altamente não-linear, as harmônicas descartadas por critérios como o NSND podem representar uma fração significativa da potência total do sinal de pressão obtido. 
Embora, em princípio, a análise das influências das não-linearidades possa ser realizada no domínio da freqüência, esta abordagem geralmente envolve a aplicação de séries de integrais de difícil compreensão físiológica como, por exemplo, as séries de Volterra (Korenberg e Hunter, 1996); (Suki e Bates, 1991) e (Zhang et al., 1999).

Algumas abordagens no domínio do tempo já foram realizadas anteriormente com o intuito de investigar a influência de não-linearidades na avaliação da mecânica respiratória (Suki et al., 1995) e (Maksym e Bates, 1997). Entretanto, mais uma vez, a interpretação de todos estes modelos em termos fisiológicos não é óbvia.

Devido aos fatos anteriormente mencionados e considerando-se fundamentalmente a adoção de modelos que permitam uma interpretação fisiológica, optou-se nesta pesquisa por realizar a análise no domínio do tempo, utilizando-se modelos com parâmetros possuindo algum significado fisiológico e que pudessem considerar tanto o comportamento não-linear como a multicompartimentabilidade do sistema respiratório.

Os modelos matemáticos e paramétricos no domínio do tempo desenvolvidos nesta pesquisa não foram ainda citados na literatura e constituem uma inovação na área da avaliação da mecânica respiratória.

Vários resumos relacionados com esta pesquisa foram apresentados e publicados nos anais de congressos internacionais (Moriya et al., 2001); (Kaminsky et al., 2001); (Kaminsky et al., 2002) e (Bates et al., 2002), um artigo foi publicado (Wagers et al., 2002) e outro aceito para publicação internacional (Moriya et al., no prelo), conforme será apresentado no final do Capítulo 4 desta tese. 


\section{REVISÃO DA LITERATURA}

Segundo Otis (1986), a história da avaliação da mecânica respiratória teve seus primórdios nos primeiros estudos de anatomia e fisiologia respiratória. Inicialmente a mecânica respiratória foi avaliada através da análise da disposição dos órgãos e da ação de músculos individuais, sendo esta análise baseada em um detalhado conhecimento anatômico obtido através da observação visual.

Com o aparecimento dos conceitos relativos aos fenômenos físicos e às correspondentes leis físicas, a avaliação da mecânica respiratória passou a ser mais abstrata e matemática, sendo esta avaliação baseada na medição de forças e fluxos, considerando suas magnitudes, e mais usualmente, pressões, volumes e suas variações com o tempo (Otis, 1986).

Em 1915, Fritz Rohrer foi o primeiro a iniciar um estudo conceitualmente mais quantitativo e abstrato da mecânica respiratória através do exame do problema da resistência à passagem de fluxo pelas vias aéreas.

Karl Wirz e Kurt von Neegaard, associados ao laboratório de Rohrer, realizaram importantes estudos sobre a elasticidade do pulmão e a resistência à passagem de fluxo na década de 1920.

Rohrer, Wirz e von Neegaard foram os pioneiros em tentar explicar os complexos movimentos e as forças envolvidas na respiração através da análise de duas importantes variáveis: pressão e volume (Otis, 1986).

A avaliação da mecânica respiratória tem evoluído muito desde as primeiras experiências de Rohrer e seus discípulos. De acordo com Bates (1998), a literatura acumulada pode dar ao leigo a impressão de que a avaliação da mecânica respiratória 
é muito vasta e complexa. Entretanto, a aparente grande quantidade de métodos diferentes para se avaliar a mecânica respiratória é invariavelmente reduzida a casos especiais de um pequeno número de enfoques distintos que podem ser unificados dentro da teoria de Identificação de Sistemas. Dessa forma, a avaliação da mecânica respiratória é essencialmente um exercício de Identificação de Sistemas.

A Identificação de Sistemas visa solucionar o problema de construir modelos matemáticos de sistemas com base em dados observados de entrada e saída (Ljung, 1999). No caso da mecânica respiratória, aplicam-se excitações no sistema respiratório e medem-se as correspondentes saídas, tentando-se então relacionar as entradas e saídas do sistema em termos de modelos matemáticos paramétricos ou não-paramétricos (Yuan et al., 1999). Pode-se excitar o sistema respiratório através da imposição de variações de pressão na entrada das vias aéreas (Michaelson et al., 1975) ou na caixa torácica (Marchal et al., 1996); (Peslin e Duvivier, 1998) obtendose um fluxo correspondente nas vias aéreas. A excitação também pode ser realizada impondo-se um fluxo e obtendo-se uma diferença de pressões resultante deste fluxo.

A construção de modelos matemáticos paramétricos pode ser divida em dois processos distintos: determinação estrutural e estimação de parâmetros.

A determinação estrutural se refere ao processo onde a estrutura do modelo é estabelecida. Este processo geralmente envolve a determinação de quantos compartimentos o modelo irá apresentar e como eles estarão conectados. Busca-se as equações matemáticas que regem o modelo e para esta atividade não há um procedimento universal (Bates, 1998). 
O processo subseqüente, a estimação de parâmetros, envolve a determinação numérica dos parâmetros do modelo através da associação do comportamento do modelo com os dados obtidos de experimentos.

A seguir serão apresentadas os dois métodos pelos quais a estimação de parâmetros da mecânica respiratória pode ser realizada: método quasi-estático e método dinâmico.

\subsection{MÉTODO QUASI-ESTÁTICO}

Neste tipo de estimação de parâmetros da mecânica respiratória tenta-se descrever as propriedades estáticas do sistema respiratório através das relações de pressão e volume quando não há movimento de ar e não há aceleração dos tecidos no sistema respiratório (Vassilakopoulos et al., 1998). Estas relações de pressão e volume são normalmente indicadas por meio das denominadas curvas $P V$.

Segundo Bates (1998), o termo quasi-estático é utilizado pois as condições empregadas aproximam condições estáticas, nas quais não há fluxo de gás em nenhum lugar dentro dos pulmões e todo o esforço de adaptação dentro dos tecidos já foi completado, ou seja, o regime transitório foi concluído. Para obter-se realmente condições estáticas, o volume pulmonar deveria teoricamente ser mantido exatamente constante por um intervalo de tempo infinitamente longo.

Rahn e colaboradores realizaram em 1946 uma das primeiras descrições experimentais das propriedades quasi-estáticas do sistema respiratório. Neste experimento, voluntários saudáveis foram solicitados a inspirar um determinado volume de ar de um espirômetro e depois relaxar por alguns segundos contra uma via aérea ocluída, mantendo a glote aberta. A pressão na boca foi medida e o volume 
inspirado foi observado pela indicação no espirômetro. A diferença entre a pressão na boca e a pressão atmosférica correspondeu à pressão adotada no sistema respiratório. Variando-se os volumes inspirados, foi possível a obtenção de uma relação pressão-volume do sistema respiratório (Vassilakopoulos et al., 1998).

Embora Rahn e colaboradores argumentassem que a pressão total medida na boca dos voluntários correspondesse à soma das pressões exercidas pelas propriedades elásticas da caixa torácica e dos pulmões, eles não foram capazes de medir tais pressões diretamente (Vassilakopoulos et al., 1998). A medição direta de tais grandezas só foi possível com a introdução da técnica do balão esofágico em 1949 (Milic-Emili et al., 1964), pois a pressão esofagiana pode ser considerada uma estimativa da pressão pleural (D'Angelo, 1999). Entretanto, é importante observar que o emprego adequado desta técnica requer a correta colocação do balão esofágico (Baydur et al., 1982); (Dechman et al., 1992). Tem havido um interesse crescente sobre a possibilidade de medir a pressão esofagiana usando-se um transdutor de pressão piezelétrico em miniatura colocado diretamente no esôfago (Chartrand et al., 1987).

O estudo das contribuições do abdome e dos músculos intercostais na mecânica respiratória começou a ser realizado por Agostoni e Rahn (1960) que desenvolveram um método de medição da pressão transdiafragmática através da diferença entre as pressões gástrica e esofagiana. Dessa forma, a pressão exercida pelas propriedades elásticas da caixa torácica pôde ser subdividida em pressão exercida pelo abdome (pressão gástrica) e pressão exercida pelos músculos intercostais (pressão esofagiana). 
Segundo Vassilakopoulos e colaboradores (1998), diversos modelos e técnicas para particionar as propriedades elásticas da caixa torácica em componentes devidos aos músculos intercostais e ao abdome foram propostos, mas o método de Kono e Mead (1967) é o mais aceito. Estes pesquisadores mediram os deslocamentos na superfície do abdome e da caixa torácica e lançaram a hipótese de que a caixa torácica apresenta dois graus de liberdade, podendo acomodar o volume dos pulmões pelo movimento dos músculos intercostais ou pelo movimento diafragma-abdome, sendo a soma dos dois deslocamentos monotonicamente relacionada às mudanças de volume nos pulmões.

A medição dos deslocamentos da caixa torácica tornou-se um método bastante útil para monitorar a ventilação de forma não-invasiva, com uma precisão de aproximadamente 10\% em relação às medições espirométricas (Vassilakopoulos et al., 1998).

Apesar dos diversos métodos existentes para realizar o particionamento das propriedades elásticas da caixa torácica, na maioria das vezes particiona-se a pressão nas vias aéreas $\left(P_{a o}\right)$ apenas nos componentes devidos à caixa torácica como um todo (pressão esofagiana, $\left.P_{e s}\right)$ e aos pulmões $\left(P_{a o}-P_{e s}\right)$, sendo esta última denominada pressão transpulmonar $\left(P_{t p}\right)$.

O ramo inspiratório da curva $P V$ pode ser obtido utilizando-se métodos quasiestáticos ou dinâmicos. Nos métodos quasi-estáticos, as medidas de pressão são obtidas após alguns segundos de fluxo zero. Já nos métodos dinâmicos, as pressões são obtidas durante um fluxo inspiratório constante. O ramo expiratório é melhor obtido com a utilização de um método quasi-estático, devido à dificuldade do controle do fluxo expiratório (Haas, 2000). 
Na prática clínica, uma das técnicas mais utilizadas para obtenção da curva $P V$ adota o método dos volumes aleatórios, que consiste na determinação da relação $P V$ inspiratória pela mudança intermitente do volume corrente. Pausas inspiratórias suficientemente longas são realizadas de forma a possibilitar a determinação da pressão de platô nos diferentes volumes correntes. Outro método empregado na prática clínica é o da PEEP versus complacência (Suter et al., 1978).

As pressões quasi-estáticas no sistema respiratório dependem dos volumes anteriores aos quais o sistema foi submetido, ou seja, o valor da pressão no ramo inspiratório para um determinado volume não é o mesmo que no ramo expiratório (Shardonofsky et al., 1990). Acredita-se que esta histerese seja devida à disfunções do surfactante e indique a presença de alvéolos recrutáveis colapsados (Haas, 2000). Um exemplo de curva $P V$ típica é apresentado na Figura 2.1.

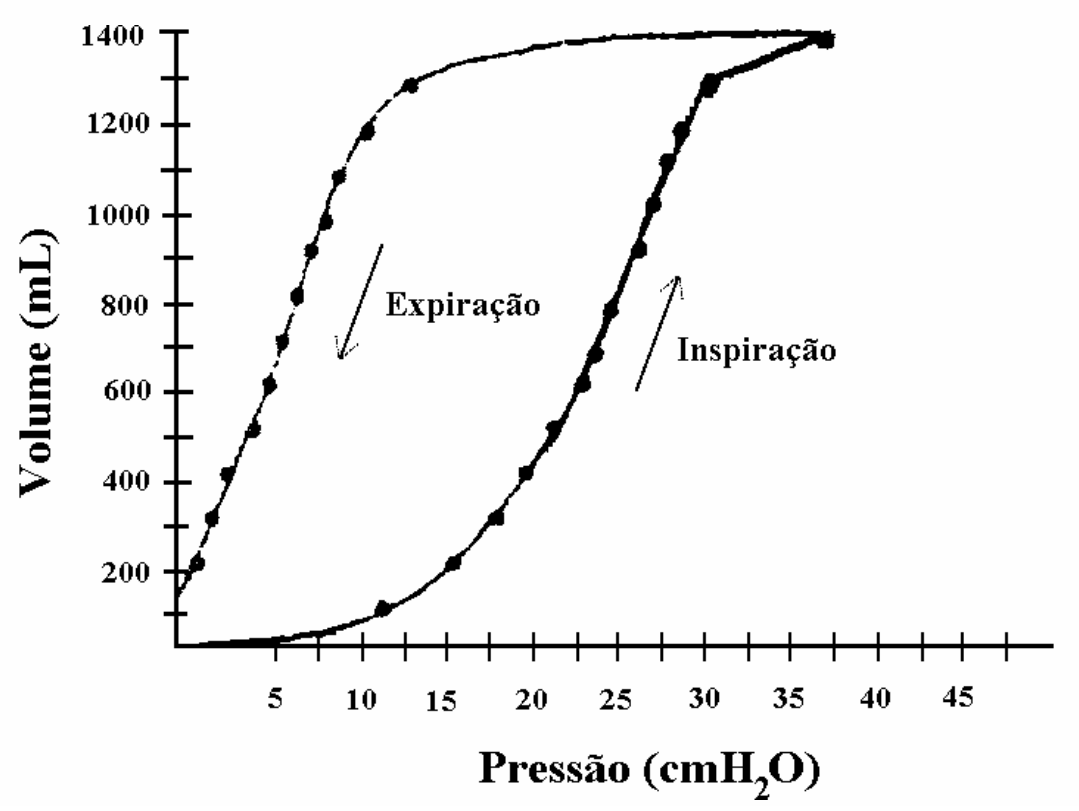

Figura 2.1. Exemplo de curva $P V$ típica (Haas, 2000). 
Grande parte dos estudos realizados através da análise das curvas $P V$ são destinados à obtenção de um valor da PEEP considerado ideal, ou seja, tenta-se obter o valor da $P E E P$ de forma que haja um bom recrutamento de unidades pulmonares sem a ocorrência de barotrauma e/ou volumotrauma (Dambrosio et al., 1997); (Hickling, 1998); (O'Keefe et al., 1998); (Jonson et al., 1999); (Lichtwarck-Aschoff et al., 2000); (Hickling, 2001); (Martin-Lefèvre et al., 2001).

Para fins de modelagem das características quasi-estáticas da curva $P V$, os pulmões são considerados como sendo um compartimento elástico único. Este compartimento se comporta de forma linear para pequenas excursões de volume acima da capacidade residual funcional $(C R F)$. Entretanto, em excursões próximas à capacidade pulmonar total $(C P T)$, a curva $P V$ se comporta de forma não-linear (Bates, 1998).

Algumas funções matemáticas são utilizadas para descrever, separadamente, os ramos inspiratório e expiratório da curva $P V$.

A função exponencial originalmente aplicada à curva $P V$ por Salazar e Knowles (1964) foi amplamente empregada em pesquisa (Eidelman et al.,1990) e, em um grau menor, na área clínica (Harris et al., 2000). Esta função é usualmente expressa na forma:

$$
V=A-B \cdot e^{-K \cdot P_{t p}}
$$

onde $V$ é o volume pulmonar e $P_{t p}$ é a pressão transpulmonar. 
De acordo com esta equação, $V$ inicia em um valor igual a $(A-B)$ quando $P$ é zero e tende para o valor de $A$ quando $P$ tende a infinito. A forma da curva é governada principalmente por $K$, que tem sido considerado um representante das propriedades mecânicas estáticas dos pulmões e um índice da elasticidade pulmonar independente do volume (Pare et al., 1982); (Eidelman et al., 1990).

Ultimamente, modelos com funções sigmoidais tem sido aperfeiçoados para melhor descrever as curvas $P V$ quasi-estáticas (Venegas et al., 1998); (Narusawa, 2001).

\subsection{MÉTODO DINÂMICO}

As propriedades dinâmicas do sistema respiratório são obtidas quando o fluxo respiratório varia com o tempo.

Em um primeiro nível de complexidade, pode-se adotar o modelo linear com apenas um compartimento. Trata-se de um modelo bastante empregado na área clínica, pois é simples e apresenta uma boa adequação à representação do sistema respiratório em muitas condições de interesse clínico (Bates, 1998); (Nucci et al., 2000); (Bates et al., 2002). Neste caso, modela-se o sistema respiratório por um sistema constituído por um tubo e um balão (Figura 2.2), sendo que há uma resistência $(R)$ associada ao tubo e uma elastância $(E)$ associada ao balão. $\mathrm{O}$ sistema está envolto em uma pressão $P_{e s}$, correspondente à da caixa torácica, a pressão dentro do balão é $P_{t p}$ e, na entrada do tubo, tem-se uma pressão $P_{a o}$. Um fluxo $\dot{V}$ é gerado através deste tubo devido ao desequilíbrio entre as pressões $P_{a o}$, $P_{e s}$ e $P_{t p}$. 


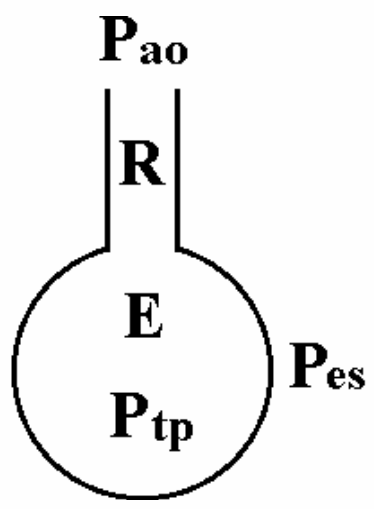

Figura 2.2. Modelo linear de um compartimento constituído por tubo (resistência) e balão (elastância).

A Teoria de Compartimentos é empregada nesta tese apenas com o intuito de mostrar a evolução dos modelos matemáticos, não sendo utilizado todo o rigor pertinente à esta Teoria.

A representação mecânica do modelo linear de um compartimento é apresentada na Figura 2.3. A resistência é modelada por um amortecedor e a elastância é modelada por uma mola. Este arranjo de uma resistência e uma elastância em paralelo é conhecido como corpo de Voigt.

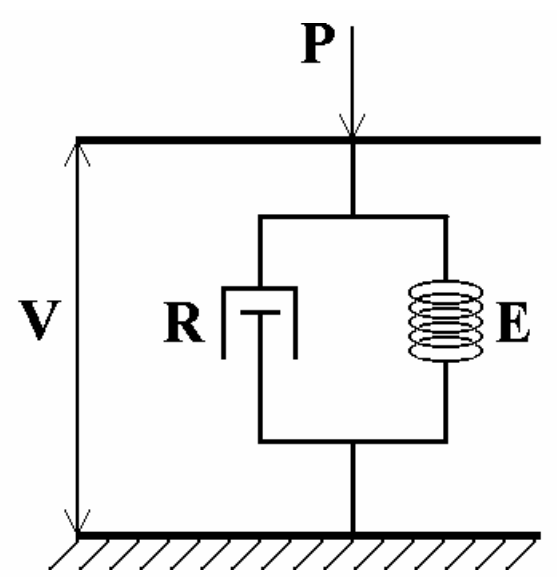

Figura 2.3. Representação mecânica do modelo linear de um compartimento. 
Aplicando-se uma força entre as barras (correspondente à pressão $P$ ), obtémse uma mudança na distância entre as barras (correspondente ao volume $V$ ), sendo que esta mudança é resultado do movimento do corpo de Voigt.

Segundo Similowski e Bates (1991), este modelo tornou-se tão popular que a equação que governa seu comportamento é geralmente (e erroneamente) referida como a "equação do movimento do sistema respiratório" ao invés de "equação do movimento de um modelo linear de um compartimento do sistema respiratório".

A equação do movimento deste modelo provém do fato da queda de pressão através do modelo $(P)$ ser igual à soma das quedas das pressões através das vias aéreas (tubo) e através dos tecidos respiratórios (balão) (Bates, 1998), sendo descrita pela Equação 2.2:

$$
P=R \cdot \dot{V}+E \cdot V+P_{0}
$$

onde a resistência do tubo $(R)$ é assumida como sendo independente do fluxo $(\dot{V})$ e a elastância do compartimento $(E)$ é independente do seu volume $(V)$. O parâmetro $P_{0}$ é o valor que $P$ assume quando $\dot{V}$ e $V$ são iguais a zero e sua utilidade prática é absorver qualquer erro que possa ser cometido na estimação da capacidade residual funcional $(C R F)$.

Observe-se que a Equação 2.2 não é linear devido ao termo $P_{0}$, porém por consistência com a literatura internacional e aplicações práticas de fisiologistas, essa equação será mencionada como linear nesta tese. É importante salientar que este problema é de fácil solução, simplesmente considerando a variável $P-P_{0}$ no lugar 
de $P$, como fazem usualmente os fisiologistas, resultando rigorosamente em um modelo incremental linear.

As interpretações fisiológicas de $R$ e $E$ dependem de qual queda de pressão $P$ através do modelo é utilizada.

Se $P$ é a pressão na abertura das vias aéreas $\left(P_{a o}\right)$, então $R$ é a soma das resistências do sistema respiratório e do tubo endotraqueal. Já $E$ é a soma das elastâncias dos pulmões e da caixa torácica.

Se $P$ é a pressão transpulmonar $\left(P_{t p}\right)$, a elastância $(E)$ e a resistência $(R)$ são referentes apenas aos pulmões.

No caso de $P$ ser a pressão esofagiana $\left(P_{e s}\right)$, tanto $E$ como $R$ são referentes apenas à caixa torácica.

Este modelo considera desprezíveis as forças inerciais. Esta consideração é válida para freqüências respiratórias até $2 \mathrm{~Hz}$ (Zin, 1999).

Apesar da resistência estar relacionada com o tubo no modelo linear de um compartimento, fisiologicamente a resistência total ao fluxo não é determinada apenas pela fricção dos gases fluindo através das vias aéreas. Existe também um componente da resistência relacionada ao movimento dos tecidos pulmonares e da caixa torácica (Bachofen, 1968). O modelo linear de um compartimento não é capaz de distinguir entre estes componentes da resistência total ao fluxo. Pacientes com doenças obstrutivas, edema ou inflamação das mucosas dos brônquios apresentam uma resistência total ao fluxo bastante alterada em relação a pessoas sadias.

A elastância é uma medida da rigidez do sistema respiratório (o inverso matemático da complacência). Diversas patologias podem alterar a elastância do sistema respiratório. Como exemplo podemos citar pacientes com Síndrome do 
Desconforto Respiratório Agudo (SDRA) que apresentam uma elastância aumentada devido aos fluídos inflamatórios que preenchem partes do espaço alveolar.

A estimação dos valores de $R, E$ e $P_{0}$ é atualmente realizada através de uma técnica facilmente implementada em computadores denominada regressão múltipla linear (Draper e Smith, 1998). A regressão múltipla linear foi utilizada pela primeira vez na avaliação da mecânica respiratória no final da década de 1960 (Bates, 1998). A técnica de regressão múltipla linear também pode ser aplicada de forma recursiva permitindo-se obter maiores informações sobre a maneira que os parâmetros da mecânica respiratória variam com o tempo (Lauzon e Bates, 1991); (Bates e Lauzon, 1992); (Avanzolini et al., 1997); (Nucci et al., 2000).

A regressão múltipla linear é a técnica mais utilizada na estimação de parâmetros na avaliação da mecânica respiratória, tanto para análises no domínio do tempo quanto para análises no domínio da freqüência (Nucci e Cobelli, 2001).

Antes do advento da aplicação de técnicas computacionais nos laboratórios de mecânica respiratória, $R$ e $E$ eram estimados utilizando-se técnicas como a de Mead-Whittenberger (também conhecida como método de subtração elétrica) e a isovolumétrica (Bergman e Waltemath, 1974).

Apesar da simplicidade matemática do modelo linear de um compartimento, trata-se do modelo mais utilizado na prática clínica e vários estudos foram e continuam sendo realizados com o auxílio deste modelo (Lauzon e Bates, 2000).

Segundo Similowski e Bates (1991), existem basicamente duas maneiras de aumentar a complexidade do modelo linear de um compartimento para melhorar a exatidão na descrição da mecânica respiratória. Uma das maneiras é aumentar o 
número de graus de liberdade mecânica, ou seja, adicionar mais compartimentos. A outra é tornar não-lineares os elementos do modelo.

Assim sendo, em seguida os modelos multicompartimentais serão apresentados e, posteriormente, os modelo não-lineares.

\subsubsection{MODELO MULTICOMPARTIMENTAIS}

A aproximação do sistema respiratório por um único compartimento uniformemente ventilado é considerada boa desde que o fluxo utilizado para excitar o sistema seja quasi-senoidal, o que significa que a maior parte da potência do sinal de excitação esteja confinada em uma única freqüência. Se o fluxo não é quasisenoidal, ou seja, se apresenta a potência distribuída em diversas freqüências, o sistema respiratório passa a responder como sendo composto por diversos componentes distintos, cujas contribuições relativas para o comportamento do sistema respiratório variam com a freqüência. A natureza desta variação reflete tanto a complexa natureza reológica dos tecidos respiratórios como qualquer nãohomogeneidade referente a variações temporais nas propriedades mecânicas através dos pulmões (Bates, 1998).

\subsubsection{EXCITAÇÃO PARA MODELOS MULTICOMPARTIMENTAIS}

Os ventiladores mecânicos convencionais geralmente não são capazes de prover um sinal de excitação com um conteúdo espectral suficientemente rico para possibilitar a identificação do caráter multicompartimental do sistema respiratório (Lutchen et al., 1993a). 
Inicialmente, a técnica empregada para prover o necessário conteúdo espectral para excitar o sistema respiratório consistia na aplicação separada de vários fluxos senoidais, cada um com uma freqüência distinta, com posterior análise de cada freqüência utilizada. Esta técnica também é conhecida como método de Du Bois (Michaelson et al., 1975). O paciente devia permanecer com a glote aberta e em apnéia durante a aplicação de cada fluxo. Esta técnica é ainda empregada em alguns casos para análise no domínio da freqüência, sendo sua aplicação bastante trabalhosa e demorada, praticamente inviabilizando seu uso clínico. Uma variante desta técnica consiste na aplicação de um fluxo pseudo-randômico contendo diversas freqüências, sendo que, posteriormente, somente as freqüências de interesse são utilizadas (Michaelson et al., 1975).

Desde que as oscilações aplicadas sejam diferentes da freqüência respiratória e se faça uma filtragem adequada, também é possível a aplicação de oscilações sobre as ventilações normal e/ou mecânica (Lándsér et al., 1976); (Farré et al., 2001).

Atualmente utiliza-se largamente como sinal de excitação um fluxo composto pela soma de várias senóides distintas, com freqüências escolhidas de forma a minimizar efeitos de cross-talk e de distorção harmônica (Daróczy e Hantos, 1990); (Suki e Lutchen, 1992); (Peslin et al., 1995). A análise desta técnica pode ser feita tanto no domínio do tempo (Peslin et al., 1995) como no da freqüência (Suki e Lutchen, 1992).

O fluxo composto pela soma de várias senóides é geralmente produzido por um pistão servocontrolado (Kaczka et al., 1997) ou por um alto-falante (Peslin et al., 1993) conectado ao paciente por conexões pneumáticas apropriadas. Quando a excitação é aplicada na caixa torácica, geralmente o paciente é colocado dentro de 
uma câmara com um gerador de pressão (Marchal et al., 1996); (Peslin e Duvivier, 1998).

Lutchen et al. (1993b) resolveram o problema de ventilar o paciente e ao mesmo tempo prover um fluxo rico em freqüências que possibilitasse a identificação multicompartimental desenvolvendo um tipo especial de forma de onda, denominada $O V W$, que minimiza o efeito da distorção causada por não-linearidades e, mesmo assim, provê energia suficiente para as freqüências desejadas. Esta forma de onda foi originalmente utilizada para análise no domínio da freqüência (Lutchen et al., 1993b); (Kaczka et al., 1997), mas pode também ser utilizada para análise no domínio do tempo (Peslin et al., 1995). Segundo Bates (1998), estas formas de fluxo necessitam de ventiladores servocontrolados especiais para serem aplicadas, mas elas maximizam a quantidade de informação mecânica que pode ser obtida do sistema respiratório.

Outra técnica utilizada para excitar o sistema respiratório de forma a tornar possível a análise multicompartimental é a de interrupção de fluxo. Esta técnica foi introduzida por von Neegard e Wirz em 1927 e tem sido empregada nos últimos anos devido a uma série de estudos que elucidaram os aspectos teóricos e fisiológicos nela envolvidos (Bates et al., 1988); (Romero et al., 1990); (Bates et al., 1992). A técnica de interrupção de fluxo consiste na medição da pressão nas vias aéreas após uma interrupção rápida do fluxo. A utilização de uma válvula de fechamento rápido é imprescindível para o sucesso desta técnica (Kessler et al., 1999). Esta técnica é bastante utilizada para análise no domínio do tempo (Bates et al., 1989); Antonaglia et al., 2000). Segundo Nucci e Cobelli (2001), demonstrou-se que na aplicação deste 
método deve-se prestar especial atenção aos efeitos do tempo de fechamento da válvula na complacência na vias aéreas superiores.

A técnica da expiração relaxada também é utilizada para identificação multicompartimental. Nesta técnica, é medido o fluxo no sistema após uma mudança em degrau na pressão das vias aéreas (Bates et al., 1986).

Recentemente, Bijaoui e colaboradores (2001) empregaram as oscilações cardiogênicas para realizar a análise multicompartimental do sistema respiratório.

\subsubsection{ANÁLISE NO DOMÍNIO DO TEMPO}

O modelo multicompartimental mais simples de ser implementado é o modelo linear de dois compartimentos.

Os modelos lineares de dois compartimentos podem ser divididos em 2 tipos fisiológicos distintos: os de redistribuição gasosa e os reológicos.

Os modelos de redistribuição gasosa descrevem a natureza multicompartimental do sistema respiratório devido à desigualdade da distribuição gasosa através dos pulmões.

Em 1956, Otis e colaboradores propuseram o chamado modelo paralelo de redistribuição gasosa (Hantos, 1999). Este modelo consiste de um arranjo paralelo de compartimentos alveolares (com elastâncias $E_{1}$ e $E_{2}$ ) conectados por vias aéreas separadas (com resistências $R_{1}$ e $R_{2}$ ) à traquéia (com resistência $R_{c}$ ) (Lutchen e Saidel, 1986). A Figura 2.4 apresenta as representações anatômica e mecânica do modelo paralelo de redistribuição gasosa. 


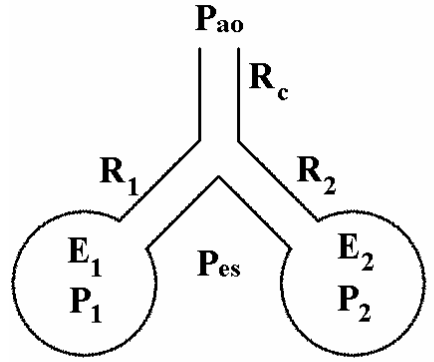

A

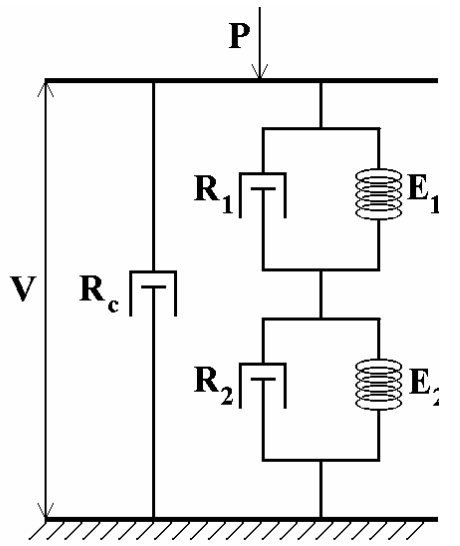

B

Figura 2.4. Modelo paralelo de redistribuição gasosa. (A) Representação anatômica. (B) Representação mecânica.

Segundo Bates e colaboradores (1988), a equação matemática do modelo paralelo de redistribuição gasosa é:

$$
\begin{aligned}
& \dot{P} \cdot\left(R_{1}+R_{2}\right)+P \cdot\left(E_{1}+E_{2}\right)=\ddot{V} \cdot\left(R_{1} \cdot R_{2}+R_{1} \cdot R_{c}+R_{2} \cdot R_{c}\right) \\
& +\dot{V} \cdot\left[E_{1} \cdot\left(R_{2}+R_{c}\right)+E_{2} \cdot\left(R_{1}+R_{c}\right)\right]+V \cdot\left(E_{1} \cdot E_{2}\right)
\end{aligned}
$$

$\mathrm{Na}$ representação mecânica do modelo paralelo de redistribuição gasosa (Figura 2.4.B) e na Equação 2.3, o valor de $P$ depende de qual é o objetivo do estudo (sistema respiratório, pulmões ou caixa torácica), conforme anteriormente explicitado para o modelo linear de um compartimento.

Alternativamente, Mead propôs o chamado modelo em série de redistribuição gasosa em 1969 (Zin e Gomes, 1999). Este modelo é composto por dois balões conectados em série. O balão distal representa um compartimento alveolar (com elastância $E_{2}$ ) conectado à traquéia (com resistência $R_{1}$ ) através de uma via aérea (com resistência $R_{2}$ ) e um balão proximal representando a árvore 
brônquica (com elastância $E_{1}$ ). As representações anatômica e mecânica do modelo em série de redistribuição gasosa são apresentadas na Figura 2.5.

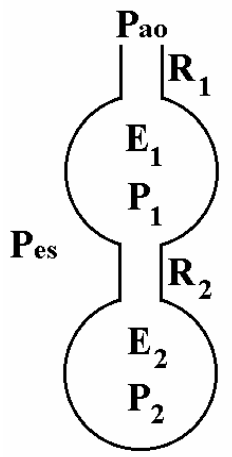

A

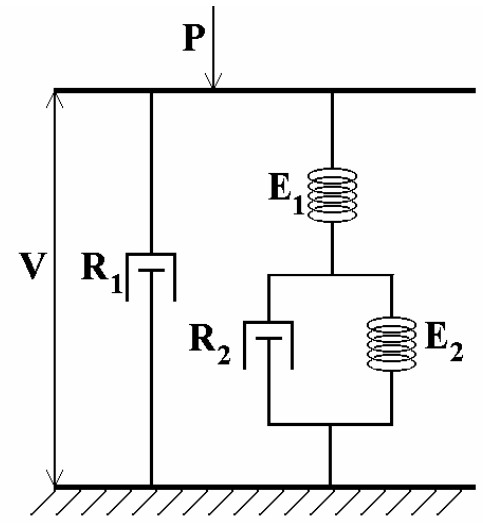

B

Figura 2.5. Modelo em série de redistribuição gasosa. (A) Representação anatômica. (B) Representação mecânica.

Segundo Similowski e Bates (1991), a equação matemática do modelo em série de redistribuição gasosa é:

$$
\dot{P} \cdot R_{2}+P \cdot E_{2}=\ddot{V} \cdot\left(R_{1} \cdot R_{2}\right)+\dot{V} \cdot\left[E_{2} \cdot R_{1}+E_{1} \cdot\left(R_{1}+R_{2}\right)\right]+V \cdot\left(E_{1} \cdot E_{2}\right)
$$

O valor de $P$ apresentado na representação mecânica do modelo em série de redistribuição gasosa (Figura 2.5.B) e na Equação 2.4, também, depende de qual é o objetivo do estudo (sistema respiratório, pulmões ou caixa torácica).

Os modelos reológicos não levam em consideração uma distribuição não uniforme da ventilação, mas descrevem as propriedades reológicas dos tecidos do sistema respiratório. Estes modelos estendem o modelo linear de um compartimento, 
incorporando uma estrutura viscoelástica ou plastoelástica de forma paralela ao corpo de Voigt.

O comportamento viscoelástico dos tecidos pulmonares foi inicialmente proposto por Bayliss e Robertson em 1939 (Suki et al., 1994a) e vem sendo estudado intensivamente desde então (Suki e Bates, 1991); (Navajas et al., 1992); (Navajas et al., 1995); (Zhang et al., 1998). A Figura 2.6 apresenta uma representação anatômica e uma implementação mecânica de um modelo linear de dois compartimentos com estrutura viscoelástica. Um corpo de Maxwell $\left(R_{2}\right.$ e $E_{2}$ em série) associado em paralelo com um corpo de Voigt ( $R_{1}$ e $E_{1}$ em paralelo) constituem o modelo mecânico viscoelástico. A viscoelasticidade é representada pelo corpo de Kelvin, constituído pelo corpo de Maxwell em paralelo com $E_{1}$ (Bates et al., 1989).

Segundo Bates e colaboradores (1989), a equação matemática do modelo viscoelástico é:

$$
\dot{P} \cdot R_{2}+P \cdot E_{2}=\ddot{V} \cdot\left(R_{1} \cdot R_{2}\right)+\dot{V} \cdot\left[E_{1} \cdot R_{2}+E_{2} \cdot\left(R_{1}+R_{2}\right)\right]+V \cdot\left(E_{1} \cdot E_{2}\right)
$$

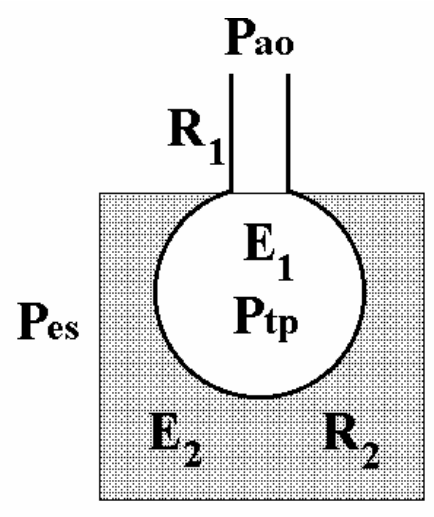

A

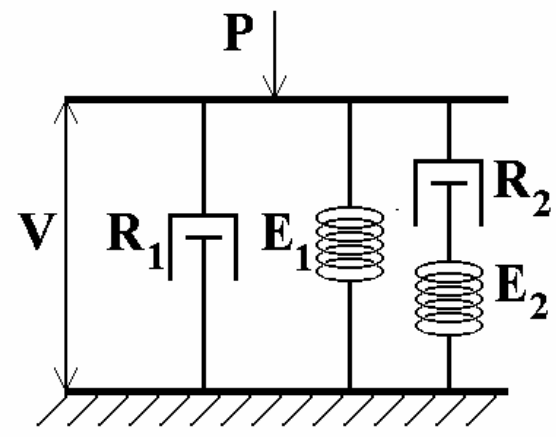

$\mathbf{B}$

Figura 2.6. Modelo viscoelástico. (A) Representação anatômica. (B) Uma das representações mecânicas. 
Conforme anteriormente explicitado para o modelo linear de um compartimento, o valor de $P$ apresentado na representação mecânica do modelo viscoelástico (Figura 2.6.B) e na Equação 2.5, também, depende de qual é o objetivo do estudo (sistema respiratório, pulmões ou caixa torácica).

O modelo linear viscoelástico tem sido bastante utilizado para descrever as diversas influências da freqüência e do tempo na resistência e na elastância do sistema respiratório (Lorino e Harf, 1993); (Pelosi et al., 1997); (Zin, 1999); (Antonaglia et al., 2000).

É importante notar que o corpo de Kelvin pode ser rearranjado de forma que o modelo viscoelástico apresente o mesmo comportamento dinâmico global, mas o valor da resistência associada aos tecidos irá ser modificada de acordo com o arranjo empregado (Bates et al., 1989). A Figura 2.7 apresenta dois modos equivalentes de arranjar três elementos de um corpo de Kelvin para representar um material viscoelástico.

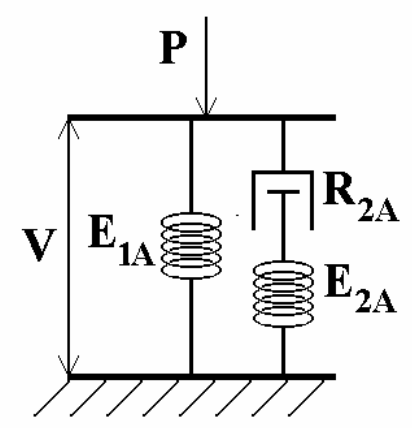

A

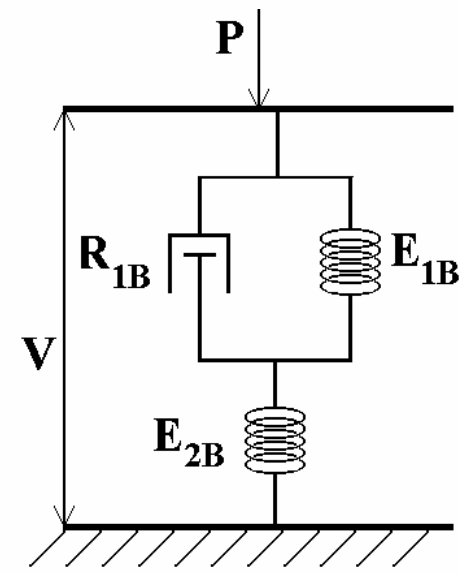

B

Figura 2.7. Dois modos equivalentes de arranjar três elementos de um corpo de Kelvin para representar um material viscoelástico. 
De acordo com Bates e colaboradores (1989), os parâmetros do modelo apresentado na Figura 2.7.B podem ser expressados pelos parâmetros do modelo apresentado na Figura 2.7.A através das seguintes relações:

$$
\begin{aligned}
& E_{1 B}=\frac{E_{1 A} \cdot\left(E_{1 A}+E_{2 A}\right)}{E_{2 A}} \\
& E_{2 B}=E_{1 A}+E_{2 A} \\
& R_{1 B}=R_{1 A} \cdot\left[\frac{\left(E_{1 A}+E_{2 A}\right)}{E_{2 A}}\right]^{2}
\end{aligned}
$$

O modelo plastoelástico (Figura 2.8) difere do modelo viscoelástico pela substituição do elemento viscoso $\left(R_{2}\right)$ no corpo de Maxwell por um elemento de fricção seca (também denominado elemento de Coulomb). Este novo corpo constituído pelo elemento de Coulomb e pela elastância $E_{2}$ é denominado corpo de Prandtl (Hildebrandt, 1969b).

O elemento de Coulomb não se move até que uma força maior que um determinado limite seja aplicada sobre ele. Caso a força aplicada sobre o elemento de fricção seca seja maior que a força limite, este elemento passa a exercer uma força constante de retardo. O modelo plastoelástico além de multicompartimental, também é não-linear.

Segundo Zin e Gomes (1999), este modelo pode descrever a histerese observada na curva de $P V$ quasi-estática em pulmões isolados. Entretanto, o modelo plastoelástico é raramente utilizado in vivo sob pequenas excursões de volume, pois os valores estimados de seus parâmetros são de difícil interpretação. 


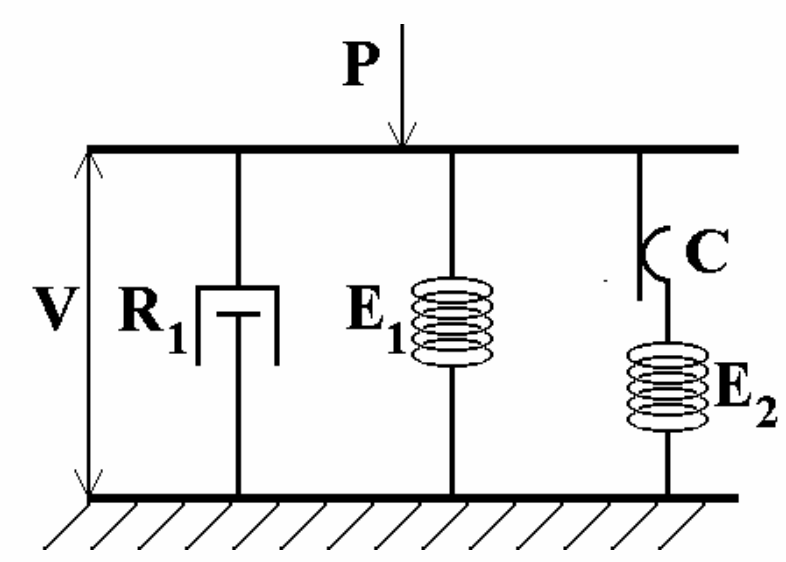

Figura 2.8. Representação mecânica do modelo plastoelástico.

A plastoelasticidade do sistema respiratório também pode ser estudada através do uso de outros modelos matemáticos (Peslin et al., 1990).

Apesar dos diferentes tipos de arranjo, evidentemente o modelo reológico viscoelástico e os modelos de redistribuição gasosa paralelo e em série apresentam a mesma função de transferência. Portanto, não é possível decidir qual destes modelos é o mais adequado para descrever o sistema respiratório estudado sem a realização de medições adicionais que forneçam informações fisiológicas importantes para a determinação estrutural (Similowski e Bates, 1991).

Diversos outros modelos multicompartimentais podem ser concebidos variando-se o número de corpos de Voigt, Kelvin ou Maxwell que são arranjados em paralelo (Bates et al., 1989); (Sato et al., 1991); (Zin e Gomes, 1999).

O problema com grande parte dos modelos multicompartimentais reside no fato de que à medida que é aumentada a quantidade de compartimentos, também 
aumenta-se o número de parâmetros do modelo e a interpretação fisiológica destes parâmetros passa a ser muito difícil.

Um outro modelo multicompartimental bastante conhecido foi proposto por Hildebrandt em meados de 1969 (Hildebrandt, 1969a); (Hildebrandt, 1969b); (Hildebrandt, 1970). Neste modelo, a pressão em um pulmão isolado de gato decresce linearmente como uma função do logaritmo neperiano do tempo após uma mudança em degrau do volume deste pulmão, conforme descrito na Equação 2.9.

$$
\frac{P_{D}(t)}{V_{D}(t)}=A-B \cdot \ln t
$$

onde: $\quad P_{D}(t)$ = pressão após uma mudança em degrau do volume;

$V_{D}(t)=$ mudança em degrau no volume;

$A, B=$ constantes;

$\ln t=$ logaritmo neperiano do tempo.

A multicompartimentabilidade deste modelo pode ser verificado pela existência de diversas constantes de tempo implícitas na Equação 2.9 (Zin e Gomes, 1999). Este modelo serviu de base para a elaboração de importantes modelos utilizados no domínio da freqüência (Hantos et al., 1990).

\subsubsection{ANÁLISE NO DOMÍNIO DA FREQÜÊNCIA}

As propriedades mecânicas do sistema respiratório estão convenientemente englobadas em termos de sua impedância mecânica $(Z)$, uma função complexa em 
relação à freqüência que leva em consideração tanto as propriedades conservativas como as dissipativas do sistema (Bijaoui et al., 2001).

Utiliza-se geralmente a técnica de oscilações forçadas para o cálculo da impedância mecânica do sistema respiratório. Esta técnica foi utilizada pela primeira vez por Du Bois e colaboradores em 1956 (Lucangelo, 1999).

O emprego correto da técnica de oscilações forçadas requer que o sistema respiratório apresente um comportamento linear (Michaelson et al., 1975). A condição de comportamento linear do sistema respiratório é alcançada sob determinadas condições. O sistema respiratório é excitado de tal forma a apresentar um fluxo de baixa amplitude e com um conteúdo espectral rico. A pressão necessária para produzir este fluxo é então relacionada com o fluxo no domínio da freqüência através de uma função complexa conhecida como impedância mecânica, sendo:

$$
Z(f)=\frac{P(f)}{\dot{V}(f)}
$$

onde $P(f)$ e $\dot{V}(f)$ são as transformadas de Fourier de $P(t)$ e $\dot{V}(t)$ (Bates, 1998).

Existem vários tipos diferentes de impedância mecânica. Se o fluxo é aplicado diretamente na abertura das vias aéreas (boca ou tubo endotraqueal) e a pressão é medida também na abertura das vias aéreas, a impedância calculada é chamada de impedância de entrada $\left(Z_{i n}\right)$. Se o fluxo é gerado através da aplicação de oscilações de pressão na superfície corporal e o fluxo é medido na entrada das vias aéreas ou vice versa, tem-se a impedância de transferência $\left(Z_{t r}\right)$ (Bijaoui et al., 2001). Também é possível se obter uma impedância pulmonar regional se as pressões 
aplicadas e os fluxos forem confinados em uma mesma região do pulmão. Como exemplos tem-se a técnica da cápsula alveolar (Davey e Bates, 1993); (Peták et al., 1993) e o uso de procedimentos broncoscópicos (Kaminsky et al., 2001); (Kaminsky et al., 2002).

A utilização da impedância de transferência $\left(Z_{t r}\right)$ em seres humanos tem demonstrado ser mais confiável do que a utilização da impedância de entrada $\left(Z_{\text {in }}\right)$ na avaliação da mecânica respiratória no intervalo de $4 \mathrm{~Hz}$ a $64 \mathrm{~Hz}$ (Lutchen e Jackson., 1992).

A impedância de entrada $\left(Z_{i n}\right)$ tem demonstrado ser bastante útil em dois intervalos de freqüência: em altas freqüências $(>100 \mathrm{~Hz})$, onde ela reflete a mecânica das vias aéreas e da caixa torácica (Suki et al., 1993), e em baixas freqüências $(<2 \mathrm{~Hz})$, onde a impedância de entrada reflete a mecânica do sistema respiratório durante o intervalo normal de respiração (Nucci e Cobelli, 2001).

De acordo com Bates (1998), a análise da impedância mecânica obtida através da técnica de oscilações forçadas pode ser realizada em diferentes níveis. No nível mais rudimentar, a impedância mecânica calculada utilizando-se a técnica de oscilações forçadas pode ser considerada apenas uma caracterização empírica do sistema, onde a parte real da impedância equivale à resistência e a parte imaginária é denominada reatância, equivalendo à elastância dividida por $-2 \cdot \pi \cdot f$ (Michaelson et al., 1975). Neste nível, a mecânica respiratória é representada por um modelo de primeira ordem, onde observa-se a dependência da resistência e da elastância em relação à freqüência.

Entretanto, para aprofundar o entendimento nas propriedades fisiológicas e patológicas do sistema respiratório, é necessário realizar a interpretação de $Z(f)$ 
através de modelos mais detalhados (Hantos et al., 1986); (Lutchen e Jackson, 1986); (Lutchen et al., 1988).

Nos últimos anos, o chamado modelo de fase constante tem se tornado muito popular para modelar a impedância do sistema respiratório a partir de dados obtidos em baixa freqüência, uma vez que tem provado ser superior aos modelos utilizados no domínio do tempo (Nucci e Cobelli, 2001).

O modelo de fase constante foi proposto por Hantos e colaboradores em 1987 (Hantos et al., 1992). A impedância do sistema respiratório é modelada como sendo composta por um componente devido às vias aéreas e outro devido aos tecidos, ou seja:

$$
Z_{r s}=Z_{a w}+Z_{t i}
$$

onde: $Z_{r s}=$ impedância do sistema respiratório;

$\mathrm{e}$

$$
Z_{a w}=R_{a w}+j \cdot 2 \cdot \pi \cdot f \cdot I_{a w}
$$

sendo que $Z_{a w}$ é a impedância devido às vias aéreas. $R_{a w}$ denota a resistência das vias aéreas. $I_{a w}$ representa a inertância das vias aéreas. $j$ é a unidade imaginária e $f$ é a freqüência cíclica em $\mathrm{Hz}$;

$$
Z_{t i}=\frac{G_{t}-j \cdot H_{t}}{(2 \cdot \pi \cdot f)^{\alpha}}
$$




$$
\alpha=\frac{2}{\pi} \cdot \operatorname{arctg}\left(\frac{H_{t}}{G_{t}}\right)
$$

sendo que $Z_{t i}$ é a impedância devido aos tecidos. $G_{t}$ é uma constante e caracteriza a dissipação de energia nos tecidos e $H_{t}$ também é uma constante e caracteriza a armazenagem de energia nos tecidos.

Apesar de a letra $G$ ser utilizada para representar a condutância na Teoria de Circuitos Elétricos (Engenharia de Eletricidade), nesta pesquisa foi mantida a notação amplamente empregada na literatura referente ao modelo de fase constante.

Observe-se que o modelo é denominado inadequadamente de fase constante, pois apenas a impedância devida aos tecidos $\left(Z_{t i}\right)$ apresenta uma fase que é independente da freqüência (Hantos et al., 1992). As partes real e imaginária de $Z_{t i}$ decrescem com a mesma potência $(\alpha)$ de $f$ fazendo com que a fase de $Z_{t i}$ seja constante, ou seja:

$$
\begin{aligned}
& \operatorname{Re}\left[Z_{t i}\right]=\frac{G_{t}}{(2 \cdot \pi \cdot f)^{\alpha}} \\
& \operatorname{Im}\left[Z_{t i}\right]=\frac{-H_{t}}{(2 \cdot \pi \cdot f)^{\alpha}} \\
& \text { Fase }\left[Z_{t i}\right]=\operatorname{arctg}\left\{\frac{\operatorname{Im}\left[Z_{t i}\right]}{\operatorname{Re}\left[Z_{t i}\right]}\right\}=\operatorname{arctg}\left\{\frac{-H_{t}}{G_{t}}\right\}=c t e
\end{aligned}
$$


O modelo de fase constante incluindo tanto as vias aéreas como os tecidos é descrito pela seguinte equação:

$$
Z_{r s}(f)=R_{a w}+j \cdot 2 \cdot \pi \cdot f \cdot I_{a w}+\frac{G_{t}-j \cdot H_{t}}{(2 \cdot \pi \cdot f)^{\alpha}}
$$

Um exemplo da aplicação do modelo de fase constante para modelar a impedância de entrada do sistema respiratório de um camundongo, calculada entre 0,5 Hz a 19,75 Hz e utilizando o software ANADAT versão 5.2 (RHT Info, Montreal, QC, Canadá), pode ser observado na Figura 2.9. Estes dados foram obtidos em um experimento com camundongo no laboratório de mecânica respiratória do Vermont Lung Center em Colchester, VT - EUA. Cada par de pontos (um vermelho e um azul) representa a impedância de entrada calculada para uma determinada freqüência. O ponto vermelho representa a parte real e o ponto azul representa a parte imaginária da impedância de entrada. As linhas que passam sobre os pontos constituem as componentes da impedância estimada pelo modelo de fase constante.Os parâmetros do modelo de fase constante são também apresentados na Figura 2.9.

Devido à uma questão de estilo, utilizou-se, nesta pesquisa, uma nomenclatura para os parâmetros do modelo de fase constante que difere um pouco da adotada pelo software ANADAT versão 5.2. Assim sendo, na Figura 2.9, o valor de $R_{a w}$ é de $0,31977 \pm 0,00205 \quad \mathrm{cmH}_{2} \mathrm{O} / \mathrm{mL} / \mathrm{s}$, o valor de $I_{a w}$ é de $-0,00013 \pm 0,00002 \quad \mathrm{cmH}_{2} \mathrm{O} / \mathrm{mL} / \mathrm{s}^{2}, \quad$ o valor de $G_{t}$ é de 
$2,95593 \pm 0,01789 \quad \mathrm{cmH}_{2} \mathrm{O} / \mathrm{mL} / \mathrm{s}^{(1-\alpha)}, \quad$ o valor de $H_{t}$ é de $27,8748 \pm 0,0089 \mathrm{cmH}_{2} \mathrm{O} / \mathrm{mL} / \mathrm{s}^{(1-\alpha)}$ e o valor de $\alpha$ é de 0,933 . Como será apresentado no final do Capítulo 3, o programa ANADAT versão 5.2 também fornece informação sobre a variância estimada do ruído no sinal medido, indicada por $E N V$. Neste caso, resultou o valor de 0,07555 para esta variância.

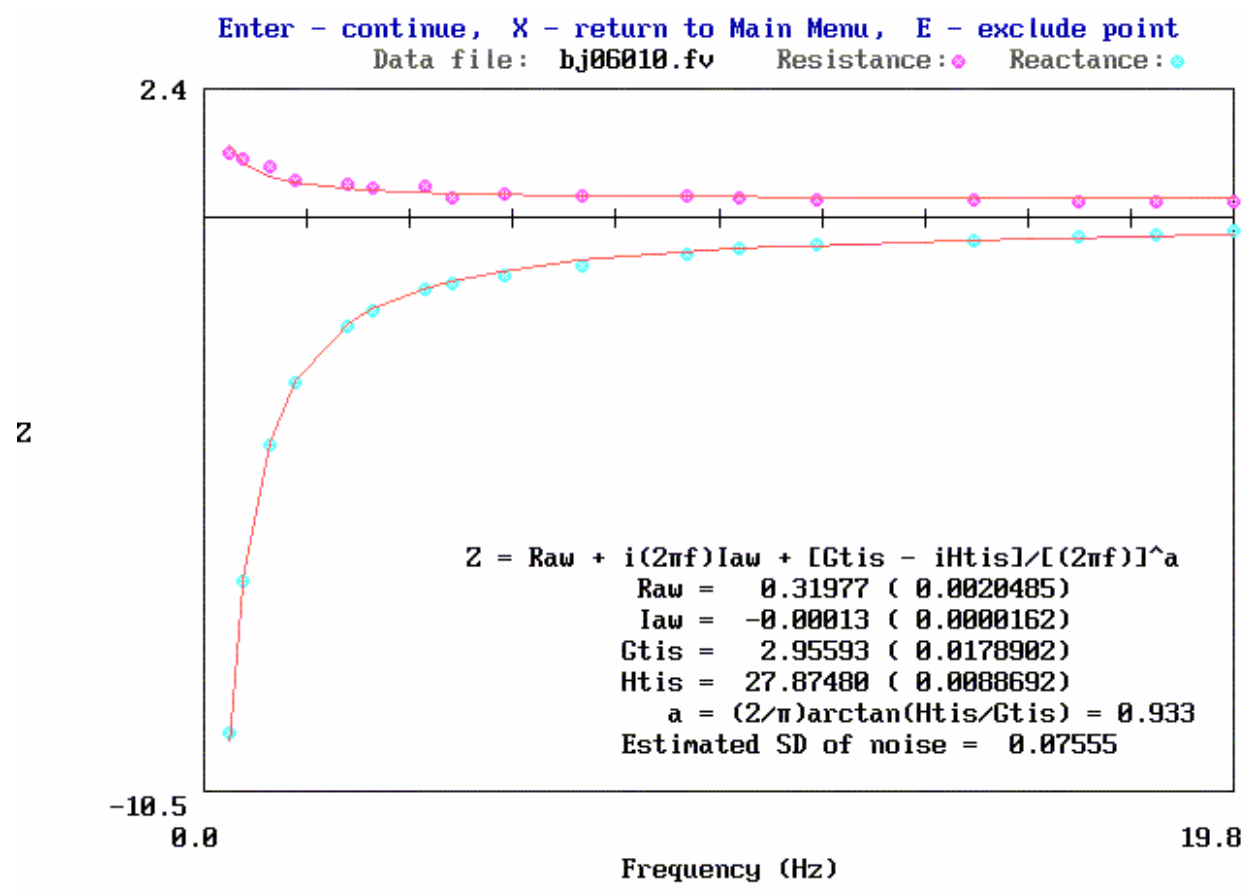

Figura 2.9. Exemplo de aplicação do modelo de fase constante para modelamento da impedância de entrada do sistema respiratório de um camundongo.

Vários estudos aplicam o modelo de fase constante para avaliar diversos aspectos da mecânica respiratória, sobressaindo-se: influências do volume pulmonar e da caixa torácica (Hirai et al., 1999), diferenças entre espécies (Gomes et al., 2000), efeitos das pressões vasculares pulmonares (Peták et al., 2002).

O modelo de fase constante tem sido modificado para levar em consideração vários outros efeitos, por exemplo, a broncoconstrição (Kaczka et al., 1997), a não- 
homogeneidade das vias aéreas (Suki et al., 1997) e as não-linearidades dos tecidos respiratórios (Suki et al., 1997).

A utilização da técnica de oscilações forçadas fornece uma maior quantidade de informações fisiológicas do que a análise convencional de modelos compartimentais no domínio do tempo. Em contrapartida, a técnica de oscilações forçadas requer uma maior complexidade instrumental e computacional (Lándsér et al., 1976); (Peslin et al., 1984); (Peslin et al., 1996); (Bates, 1998).

\subsubsection{MODELOS NÃO-LINEARES}

Pode-se geralmente modelar o sistema respiratório como sendo um sistema linear, mas diversos tipos de fenômenos não-lineares podem ser observados no comportamento mecânico das vias aéreas e dos tecidos respiratórios, principalmente durante patologias.

O fluxo de gás através de um conduto é não-linearmente relacionado com a diferença de pressão que o origina quando a geometria do conduto é complexa e/ou o fluxo turbulento. Em 1915, Rohrer sugeriu que a perda de pressão nas vias aéreas era uma função quadrática do fluxo. A equação proposta por Rohrer (1915) apud (Otis, 1986) para perda de pressão para fluxo unidirecional foi a seguinte :

$$
P_{a o}=K_{1} \cdot \dot{V}+K_{2} \cdot \dot{V}^{2}
$$

onde: $P_{a o}$ é a perda de pressão através das vias aéreas;

$K_{1}$ e $K_{2}$ são conhecidos como coeficientes de Rohrer; 
$K_{1}$ depende da viscosidade do gás;

$K_{2}$ depende da densidade do gás;

$\dot{V}$ é fluxo nas vias aéreas.

Para fluxos em dois sentidos, a forma apropriada da equação de Rohrer é:

$$
P_{a o}=K_{1} \cdot \dot{V}+K_{2} \cdot \dot{V} \cdot|\dot{V}|
$$

onde $|\dot{V}|=$ módulo do fluxo nas vias aéreas.

Estudos subseqüentes demonstraram que a equação de Rohrer contém termos que correspondem a fluxos em regime laminar (pressão linearmente dependente ao fluxo) e em regime turbulento (pressão dependente da multiplicação do fluxo com seu módulo). Verificou-se também que, em condutos irregulares e fluxos intermediários dentro do sistema respiratório, a relação pressão-fluxo é mais complicada (Hantos, 1999).

Horsfield e colaboradores (Horsfield et al., 1971); (Horsfield et al.,1982) propuseram modelos morfométricos que mostram a grande assimetria das vias aéreas, característica que facilita a ocorrência da não-linearidade observada por Rohrer. Os modelos morfométricos são muito utilizados para realização de simulações computacionais que visam melhor interpretar a mecânica respiratória (Thorpe e Bates, 1997); (Gillis e Lutchen, 1999).

Apesar de toda a complexidade morfológica do sistema respiratório, o modelo de Rohrer tem permanecido como sendo um modelo plausível e facilmente aplicado para representar a reologia das vias aéreas (Hantos, 1999). O uso de tubos 
endotraqueais e cânulas para intubação potencializa o comportamento não-linear observado por Rohrer (Wright et al., 1989).

De acordo com Suki e colaboradores (1991), enquanto vários resultados referentes ao fato da resistência das vias aéreas ser dependente do fluxo estarem em satisfatório acordo, a extensão da contribuição da não-linearidade dos tecidos pulmonares para as propriedades mecânicas do sistema respiratório ainda permanece um assunto bastante controverso.

Um passo significativo na modelagem da mecânica não-linear dos tecidos pulmonares foi realizado por Hildebrandt (1970), que associou as não-linearidades com o fenômeno da plastoelasticidade (Peslin et al., 1990).

De acordo com Hantos (1999), estudos recentes em modelagem tem confirmado que a plastoelasticidade é um fenômeno plausível, mas não único para explicar o comportamento não-linear dos tecidos pulmonares, sendo que vários modelos viscoelásticos não-lineares podem também simular o comportamento dos tecidos (Sato et al., 1991); (Suki e Bates, 1991).

O modo mais simples de considerar os efeitos da dependência dos tecidos pulmonares ao volume dos sistema respiratório é fazer com que a elastância seja uma função linear do volume (Bates, 1998), ou seja:

$$
E=E_{1}+E_{2} \cdot V
$$

onde: $\quad E_{1}$ e $E_{2}$ são constantes.

Estudos recentes relataram que uma elastância dependente do volume como a descrita pela Equação 2.21 é necessária para descrever adequadamente dados de 
ventilação mecânica obtidos durante a aplicação de valores elevados de volume corrente (Kano et al., 1994); (Bersten, 1998); (Wagers et al., 2002).

Outra causa de não-linearidade no comportamento do sistema respiratório é o fechamento e reabertura de unidades pulmonares. Esta não-linearidade é observada principalmente na histerese apresentada pelas curvas $P V$ (Kamm e Schroter, 1989).

Dechman e colaboradores (1994) verificaram que quando há baixos volumes pulmonares ocorre um progressivo aumento da elastância com o tempo, devido ao fechamento e reabertura de unidades pulmonares.

Diversos estudos foram realizados com o intuito de melhor entender o fenômeno de fechamento e reabertura de unidades pulmonares (Gaver III et al., 1990); (Halpern e Grotberg, 1993); (Perun e Gaver III, 1995); (Otis Jr. et al., 1996); (Hickling, 1998); (Suki et al., 2000); (Hickling, 2001). Um dos mais importantes dentre esses estudos (Suki et al., 1994b) demonstrou, através de simulações, que a abertura de uma via aérea facilita a abertura de uma via aérea vizinha. Com isso há um processo tipo avalanche na abertura das vias aéreas. Este fenômeno de avalanche demonstra a natureza estocástica do processo de reabertura das vias aéreas. Esta característica tem sido explorada em pesquisas que introduzem uma variabilidade nos parâmetros ventilatórios (Arold et al., 2002).

Devido à grande quantidade de não-linearidades existentes e a não compreensão de todas as suas causas e efeitos, existem atualmente diversos modelos matemáticos não-lineares sendo adotados e analisados (Hantos et al., 1982); (Suki, 1993); (Zhang et al., 1995); (Maksym e Bates, 1997). A adoção de um dentre eles é uma tarefa bastante complexa e controversa. 
O modelo mais simples utilizado para descrever o comportamento não-linear do sistema respiratório é o chamado modelo não-linear de um compartimento. Este modelo é obtido substituindo-se as Equações 2.20 e 2.21 no modelo linear de um compartimento, representado pela Equação 2.2, resultando:

$$
P=K_{1} \cdot \dot{V}+K_{2} \cdot|\dot{V}| \cdot \dot{V}+E_{1} \cdot V+E_{2} \cdot V^{2}+P_{0}
$$

A estimação dos valores de $K_{1}, K_{2}, E_{1}, E_{2}$ e $P_{0}$ é também realizada através da regressão múltipla linear. Mais uma vez, dependendo da pressão utilizada $(P)$, pode-se obter parâmetros tanto em relação a todo o sistema respiratório como apenas à caixa torácica e aos pulmões.

Alguns estudos utilizam o modelo não-linear de um compartimento conforme descrito acima, outros levam em consideração somente o efeito da resistência nãolinear (Vassiliou et al., 2000) e uma grande maioria considera apenas a elastância não-linear (Kano et al., 1994); (Bersten, 1998); (Wagers et al., 2002).

Modelos não-lineares contendo termos polinomiais de ordem mais elevada também foram propostos (Muramatsu et al., 2001), mas a interpretação fisiológica dos parâmetros adicionais vai se tornando cada vez mais difícil com o aumento dessa ordem e da conseqüente quantidade de parâmetros necessários ao modelo.

As não-linearidades observadas no comportamento do sistema respiratório também podem ser modeladas no domínio da freqüência (Suki et al., 1995); (Zhang et al., 1999). Entretanto, estes modelos geralmente utilizam séries infinitas, como as séries de Volterra (Korenberg e Hunter, 1996), de difícil relação com parâmetros fisiológicos e conseqüente pouca aplicabilidade. 


\subsection{MÉTODO DE ESCOLHA DO MODELO A SER UTILIZADO}

Um fator determinante na escolha do tipo de modelo a ser utilizado é a natureza das entradas aplicadas para identificação do sistema. Se as entradas utilizadas apresentarem banda-larga, então os modelos que podem ser utilizados apresentam um caráter multicompartimental e refletem as complexas propriedades reológicas dos tecidos respiratórios, bem como qualquer não-homogeneidade regional. Por outro lado, se as entradas forem quasi-senoidais, permitirão a identificação de simples modelos topológicos (Bates, 1998). A utilização de entradas com amplitudes muito baixas ou muito elevadas, independentemente da riqueza espectral, leva à utilização de modelos não-lineares. As amplitudes muito baixas levam ao fenômeno de abertura e fechamento de unidades pulmonares e as amplitudes muito elevadas levam ao fenômeno de hiperdistensão dos tecidos pulmonares.

Entretanto, a natureza das entradas empregadas não leva à escolha de apenas um determinado modelo. Para decidir qual dentre os modelos de um mesmo tipo é o mais adequado para aquele conjunto de dados, existem testes estatísticos que podem ser realizados (Wagers et al., 2002).

Diversos estudos foram realizados para verificar qual modelo é o mais adequado para avaliação da mecânica respiratória (Kaczka et al., 1995). Entretanto, levando-se em consideração fatores matemáticos e clínicos, pode-se dizer que atualmente não há um modelo ideal para realizar a estimação da mecânica respiratória. Cada modelo deve ser aplicado conforme a natureza da informação que se deseja obter. Segundo Zin e Gomes (1999), a escolha de um modelo irá depender 
das informações fisiológicas e patológicas que se pretende obter. Os modelos devem ser escolhidos de acordo com o questionamento científico, técnicas, métodos e condições experimentais empregadas.

Um modelo matemático que descreva perfeitamente os dados obtidos experimentalmente, mas que não possa ser interpretado fisiologicamente, tem muito pouca utilidade em estudos clínicos e laboratoriais, pois este modelo não irá fornecer informações relevantes quanto ao funcionamento do sistema respiratório.

\subsection{MODELOS COMPUTACIONAIS}

Diversos estudos tem sido realizados utilizando modelos para simulações computacionais visando um melhor entendimento da mecânica respiratória (Lutchen e Costa, 1990); (Schuessler et al., 1997); (Hickling, 1998); (Hickling, 2001). Estes modelos são geralmente baseados nos modelos descritos anteriormente e utilizam o grande potencial dos computadores para realizar simulações com altos graus de complexidade.

\subsection{ESTADO ATUAL DA AVALIAÇÃO DA MECÂNICA RESPIRATÓRIA}

A avaliação da mecânica respiratória em pacientes sob assistência ventilatória mecânica atualmente é realizada, na maioria das unidades de terapia intensiva, de maneira rudimentar, sendo limitada a um pouco mais do que um exame dos picos de pressão nas vias aéreas. Segundo Bates (1998), a consideração de que este tipo de 
avaliação é difícil de ser realizada não corresponde à realidade, pois com um equipamento portátil constituído basicamente de um microcomputador e transdutores de fluxo e pressão pode-se obter, de forma relativamente simples e barata, informações importantes sobre a mecânica respiratória de pacientes submetido à ventilação artificial.

Nessa minoria das unidades de terapia intensiva que realizam algum tipo de avaliação da mecânica respiratória, os procedimentos mais adotados são a construção de curvas $P V$ e a aplicação do modelo linear de um compartimento.

A avaliação por meio de imagens médicas vem sendo muito pesquisada para a realização de uma melhor avaliação do comportamento do sistema respiratório. A utilização de imagens de tomografia computadorizada é bastante comum em pesquisas (Gattinoni et al., 1993) e a tomografia por impedância elétrica apresenta-se como uma técnica promissora (Adler et al., 1997); (Adler et al., 1998); (Kunst et al., 1999). Entretanto, vale lembrar que a avaliação por meio de imagens não torna obsoleta a utilização de modelos matemáticos para avaliação da mecânica respiratória, pois os modelos matemáticos fornecem informações fisiológicas que as imagens muitas vezes não conseguem fornecer. A situação ideal é a utilização conjunta das duas técnicas, ou seja, a obtenção de imagens médicas e a avaliação da mecânica respiratória por meio de modelos matemáticos.

De acordo com Bates (1998), os modelos utilizados com a técnica de oscilações forçadas potencialmente fornecem uma maior quantidade de informações fisiológicas, mas isto é realizado às custas de maiores complexidades instrumental e computacional. Devido à esta grande relevância fisiológica, a pesquisa sobre os modelos multicompartimentais é bastante ativa no presente e possivelmente irá 
tornar-se rotina no futuro a utilização de métodos que utilizem excitações em banda larga, tanto em procedimentos clínicos como em desenvolvimentos de pesquisa. A utilização da $O V W$ proposta por Lutchen e colaboradores (1993b) é particularmente promissora, embora sua aplicação necessite da introdução de uma nova geração de ventiladores mecânicos que sejam capazes de aplicar fluxos com formas de onda muito mais complexas do que as atualmente disponíveis nessa classe de equipamentos médicos. 


\section{MATERIAIS E MÉTODOS}

Um método capaz de analisar o comportamento mecânico não-linear do sistema respiratório em camundongos submetidos a ventilação mecânica com fluxos tipo $O V W$ foi desenvolvido.

Para alcançar o objetivo desta pesquisa, alguns modelos matemáticos foram desenvolvidos e testados em camundongos normais, conforme detalhado a seguir.

\subsection{PROCEDIMENTOS EXPERIMENTAIS}

Quatro camundongos Balb/c pesando 22,4 $\pm 0,5 \mathrm{~g}$ (média \pm desvio padrão) foram utilizados. Cada camundongo foi anestesiado com $90 \mathrm{mg} / \mathrm{kg}$ de pentobarbital sódico e paralisado com $1 \mathrm{mg} / \mathrm{kg}$ de brometo de pancurônio, sendo que todas as doses foram injetadas de forma intraperitonial.

Estes camundongos foram traqueostomizados com uma cânula metálica de 18-gauge e ventilados mecanicamente com volume corrente de $0,25 \mathrm{~mL}$ e uma freqüência respiratória de 200 respirações/minuto utilizando um ventilador para pequenos animais denominado flexiVent (SCIREQ, Montreal, QC, Canadá).

Uma foto de um camundongo sendo ventilado é apresentada na Figura 3.1. O flexiVent consiste de um cilindro contendo um pistão controlado por computador que pode funcionar como um ventilador mecânico convencional e também como gerador de perturbações para procedimentos de identificação de sistemas quando seu pistão é programado para aplicar uma determinada perturbação em volume (Schuessler e 
Bates, 1995). Uma foto do flexiVent utilizado nesta pesquisa é apresentada na Figura 3.2.

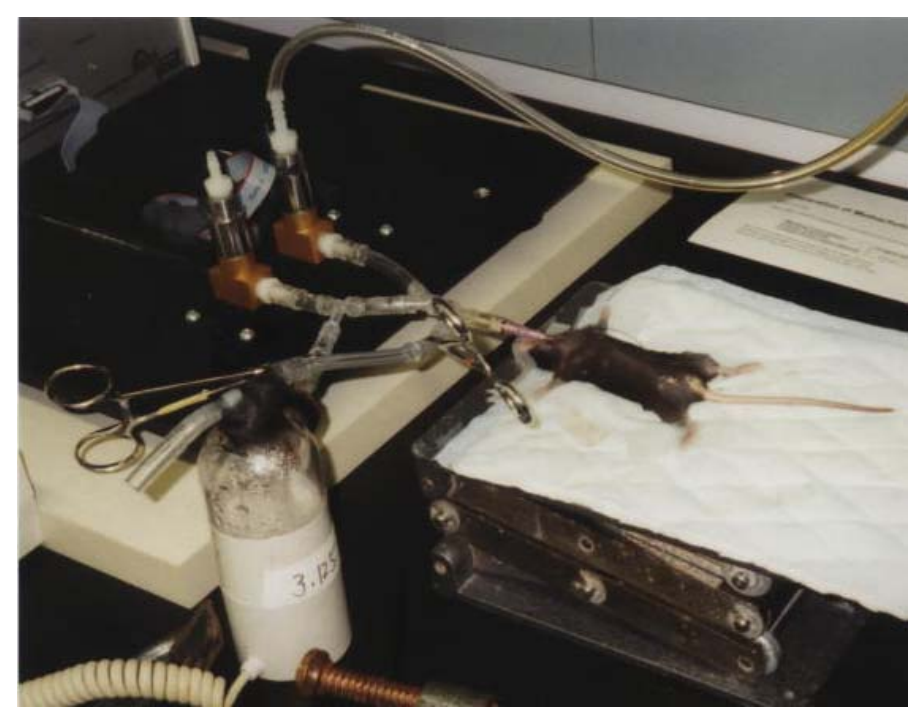

Figura 3.1. Camundongo sendo ventilado.

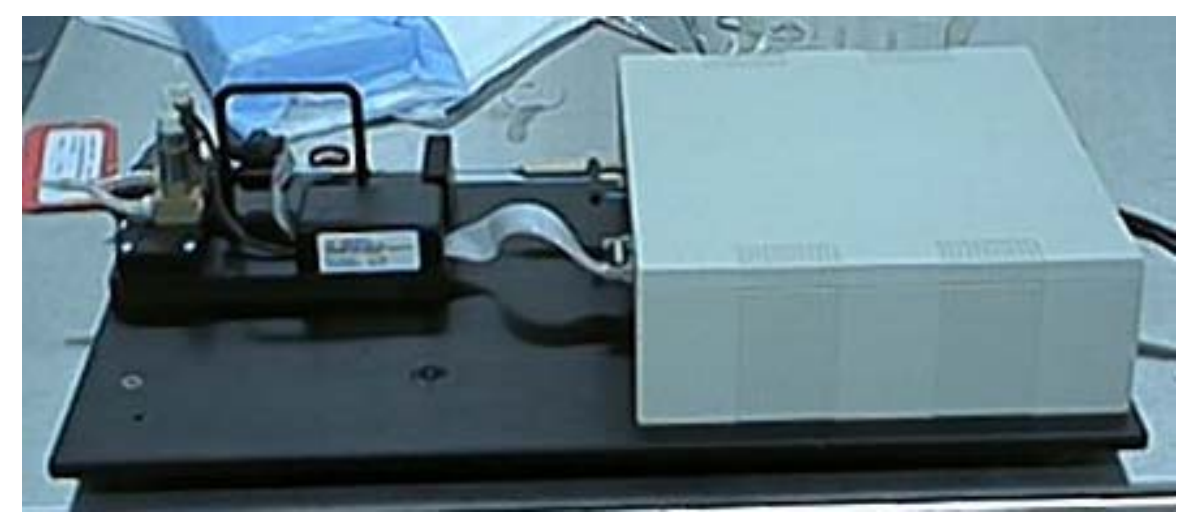

Figura 3.2. Foto do flexiVent utilizado nesta pesquisa.

Este ventilador para pequenos animais é capaz de ventilar desde camundongos com $10 \mathrm{~g}$ de massa até pequenos mamíferos com $10 \mathrm{~kg}$ de massa. Existem 5 módulos intercambiáveis, sendo que cada módulo é utilizado para um 
determinado tamanho/massa de animal. Cada módulo é composto por transdutores de pressão e um conjunto cilindro/pistão/válvulas, compatível com o tamanho do animal a ser estudado. Neste estudo foi utilizado o módulo número 1, que apresenta um volume total do cilindro de $1,8 \mathrm{~mL}$.

Um conjunto composto por um microcomputador tipo PC contendo uma placa de conversão analógico/digital (DT01-EZ, Data Translation, Marlboro, MA, EUA) e uma placa de conversão digital/analógico (DAC-02, Keithley Instruments, Tauton, MA, EUA) foi utilizado para controlar o ventilador para pequenos animais.

O pistão é movido por um motor linear e sua posição é determinada com o auxílio de um LVDT (do inglês Linear Variable Differential Transducer). Sabendose o tamanho do cilindro e a posição do pistão, é possível saber qual é o volume aplicado devido ao deslocamento do pistão $\left(V_{c y l}\right)$. Um transdutor de pressão piezelétrico é posicionado de forma a medir-se a pressão interna do cilindro $\left(P_{c y l}\right)$.

Um diagrama esquemático do flexiVent é apresentado na Figura 3.3. Conforme pode ser observado nessa figura, o flexiVent apresenta duas válvulas, uma inspiratória e outra expiratória, conectadas a uma tubulação plástica tipo Y onde a cânula utilizada no animal é encaixada.

A válvula inspiratória controla o fluxo que entra e sai do cilindro e apresenta três vias. Esta válvula permite ou que o cilindro seja conectado com a tubulação tipo Y ou que o cilindro seja conectado com o ar ambiente. Já a válvula expiratória apresenta somente duas vias e controla o fluxo entre a tubulação tipo Y e o ar ambiente. 


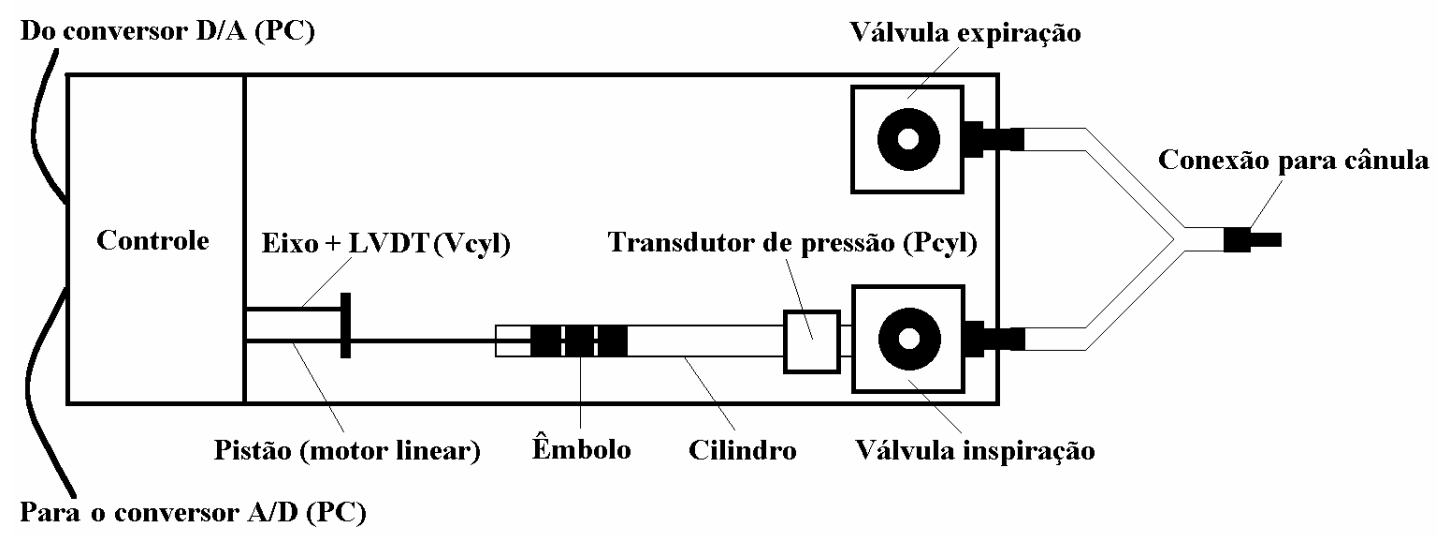

Figura 3.3. Diagrama esquemático do flexiVent.

A inspiração do animal acontece quando o pistão move-se para frente, deslocando uma quantidade de ar em direção à tubulação tipo Y. A válvula inspiratória está fechada para comunicação com o ar ambiente e permite a passagem do fluxo vindo do cilindro para o animal, enquanto que a válvula expiratória fecha a comunicação da tubulação tipo Y com o ar ambiente.

A expiração é passiva, a válvula expiratória se abre e a válvula inspiratória fecha a comunicação do animal com o cilindro, abrindo a comunicação do cilindro com o ar ambiente, permitindo que ar fresco entre no cilindro à medida que o êmbolo se movimenta para trás.

Durante a realização das perturbações em volume programadas, as válvulas se portam como se estivessem em uma etapa de inspiração, ou seja, a válvula inspiratória conecta o cilindro como a tubulação em Y e a válvula expiratória permanece fechada.

Nos experimentos realizados nesta pesquisa, a PEEP era medida e ajustada conectando-se a saída da válvula expiratória do ventilador em um recipiente graduado contendo água destilada. 
Os animais foram ventilados em intervalos de 6 minutos contra três diferentes níveis de $\operatorname{PEEP}\left(0,3\right.$ e $\left.6 \mathrm{cmH}_{2} \mathrm{O}\right)$ e em uma ordem aleatória para evitar tendências devido às seqüências de $P E E P$ utilizada. Para cada nível de $P E E P$, os pulmões eram inicialmente insuflados duas vezes até uma pressão de $25 \mathrm{cmH}_{2} \mathrm{O}$ para homogeneizar o histórico do volume pulmonar. Após 1 minuto de ventilação regular, quatro diferentes amplitudes $(0,1,0,2,0,3$ e $0,4 \mathrm{~mL})$ da perturbação em volume e com 8 segundos de duração cada foram aplicadas em seqüência. As diferentes amplitudes foram aplicadas em uma ordem aleatória com 1,5 minutos de ventilação regular entre cada perturbação. A ordem aleatória da aplicação das diferentes amplitudes também foi utilizada para evitar tendências devido às seqüências utilizadas. Após a aplicação dos três níveis de $P E E P$, o procedimento era repetido para uma PEEP final de $9 \mathrm{cmH}_{2} \mathrm{O}$. Esta PEEP de $9 \mathrm{cmH}_{2} \mathrm{O}$ foi aplicada só no final do experimento para evitar que qualquer dano resultante de hiperinsuflação nos pulmões pudesse afetar as medições realizadas em níveis menores de PEEP.

A ventilação mecânica era interrompida para que as perturbações em volume fossem aplicadas, sendo que havia um atraso de 1 segundo entre o fim da ventilação mecânica e o começo da aplicação da perturbação em volume. Este intervalo de 1 segundo foi utilizado para que o animal pudesse expirar contra o nível de PEEP aplicado, evitando-se assim a ocorrência de hiperinsuflação dinâmica.

Durante a aplicação de cada perturbação em volume, os sinais referentes ao posicionamento do pistão $\left(V_{c y l}\right)$ e a pressão dentro do cilindro $\left(P_{c y l}\right)$ foram filtrados por um filtro analógico passa-baixas (filtro de Bessel com 6 pólos) com freqüência de corte de $300 \mathrm{~Hz}$ e posteriormente amostrados em $1024 \mathrm{~Hz}$. Observe-se que este filtro analógico passa-baixas tem sua freqüência de corte pré-ajustada pelo fabricante 
do flexiVent. O mesmo acontece para o valor da taxa de amostragem. Os sinais amostrados foram então filtrados com um filtro digital passa-baixas (filtro de Bessel com 6 pólos) com freqüência de corte em $30 \mathrm{~Hz}$, amostrados em $128 \mathrm{~Hz}$ e armazenados em um microcomputador tipo PC para posterior análise. Esta taxa de amostragem e a freqüência de corte da filtragem digital são ajustadas pelo usuário do flexiVent. Estes valores para a segunda amostragem e para a filtragem digital foram escolhidos com o intuito de minimizar os efeitos de sub-amostragem e de recobrimento.

\subsection{GERAÇÃO DA PERTURBAÇÃO EM VOLUME}

Uma perturbação em volume foi gerada por software tomando-se como base as idéias originalmente desenvolvidas por Lutchen e colaboradores (1993b) com o intuito de se obter um fluxo tipo $O V W$.

A programação da perturbação em volume foi realizada utilizando-se os softwares MATLAB versão 5.3 (The Mathworks, Natick, MA, EUA) e ANADAT versão 5.2 .

Inicialmente foi gerado um conjunto de 50.000 sinais com 4 segundos de duração. Cada sinal apresentava o mesmo conteúdo espectral, sendo que as freqüências das componentes se espalhavam de $0,5 \mathrm{~Hz}$ a $10,25 \mathrm{~Hz}$ (13 componentes no total: $0,5 \mathrm{~Hz}, 0,75 \mathrm{~Hz}, 1,25 \mathrm{~Hz}, 1,75 \mathrm{~Hz}, 2,75 \mathrm{~Hz}, 3,25 \mathrm{~Hz}, 4,25 \mathrm{~Hz}, 4,75 \mathrm{~Hz}$, $5,75 \mathrm{~Hz}, 7,25 \mathrm{~Hz}, 7,75 \mathrm{~Hz}, 9,25 \mathrm{~Hz}$ e $10,25 \mathrm{~Hz}$ ) e eram primas mutuamente. As freqüências das componentes foram escolhidas dessa forma para evitar distorção harmônica (Daróczy e Hantos, 1990), sendo que o intervalo de freqüências utilizado 
é próprio para estudar o particionamento entre a resistência das vias aéreas e a resistência devido às propriedades viscoelásticas dos tecidos pulmonares em camundongos (Gomes et al., 2000). As amplitudes dos componentes senoidais decresciam hiperbolicamente com a freqüencia visando tentar otimizar a taxa de sinal/ruído nas medidas (Bijaoui et al., 2001). A fase de cada componente foi escolhida de forma aleatória, com o intuito de gerar diversas formas de onda.

A partir deste conjunto inicial de perturbações, foram selecionadas somente aquelas que cruzaram quatro vezes o valor médio do sinal, para corresponderem a dois ciclos respiratórios.

Utilizando este sub-conjunto, foi escolhido o sinal que apresentava as menores variações abruptas como sendo o sinal para a perturbação em volume. Para obter-se o sinal com menores variações abruptas foi escolhido aquele que apresentava o menor valor para a integral do valor absoluto da sua segunda derivada, calculada durante toda a extensão da perturbação.

Estes dois critérios foram utilizados objetivando-se simular uma perturbação que também ventilasse adequadamente o animal.

Finalmente, as amostras do sinal escolhido foram ciclicamente permutadas de modo que o sinal começasse com o seu menor valor. Esta escolha garantiu que o sinal fosse aplicado nos pulmões dos animais em instantes nos quais as mudanças resultantes no volume dos pulmões sempre ocorressem acima do volume pulmonar definido pelo valor do nível de PEEP escolhido.

A perturbação em volume utilizada foi constituída pelo sinal obtido pelo procedimento anteriormente descrito e repetido duas vezes. Desta forma, o sinal de 
perturbação apresentava duração de 8 segundos, garantindo-se redundância no sinal de perturbação.

O sinal de perturbação em volume escolhido foi dimensionado para apresentar excursões de pico a pico de $0,1,0,2,0,3$ e $0,4 \mathrm{~mL}$.

A Figura 3.4 apresenta uma das perturbações em volume utilizadas, aquela dimensionada para ter $0,3 \mathrm{~mL}$ pico-a-pico.

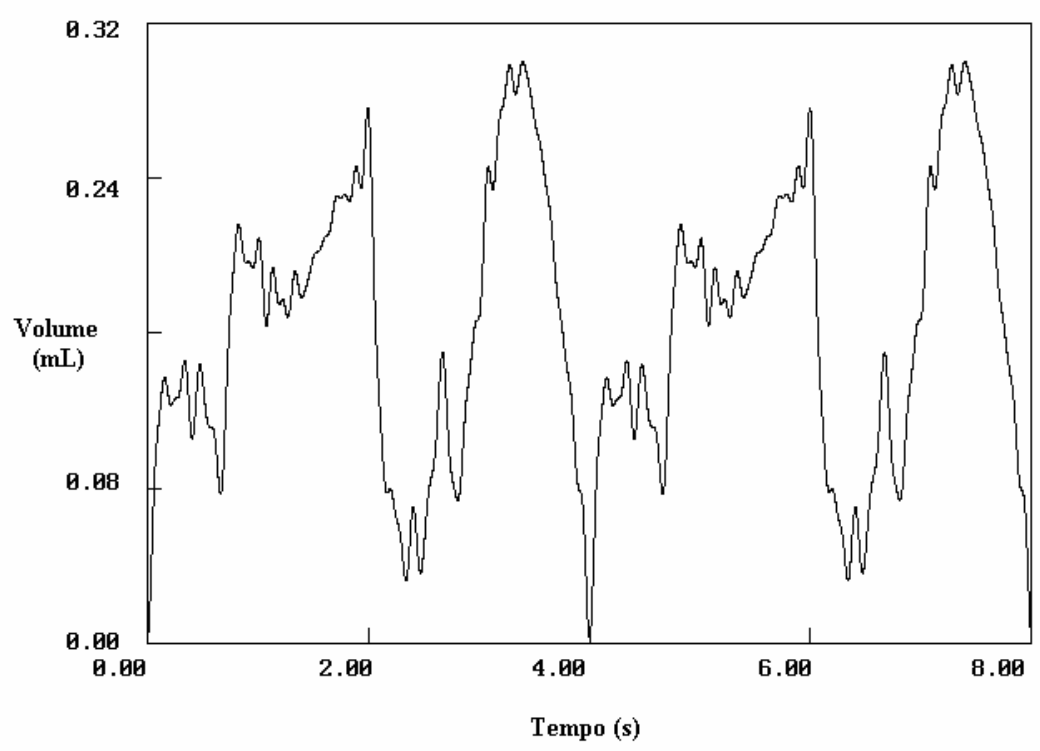

Figura 3.4. Perturbação em volume utilizada, dimensionada para ter $0,3 \mathrm{~mL}$ pico-a-pico.

Para utilização no flexiVent, a perturbação em volume gerada deve possuir uma freqüência de amostragem de $1024 \mathrm{~Hz}$.

\subsection{ANÁLISE DOS DADOS EXPERIMENTAIS}

A análise dos dados experimentais foi realizada utilizando-se os softwares MATLAB versão 5.3 e ANADAT versão 5.2. 
Os valores medidos de $V_{c y l}$ e $P_{c y l}$ não podem ser utilizados diretamente como os valores submetidos aos animais, pois há tanto perdas devido à compressibilidade dos gases dentro do cilindro do ventilador como perdas resistivas e acelerativas nos tubos de conexão e na cânula. As correções necessárias já foram descritas na literatura (Bates et al., 1997) e foram realizadas nesta pesquisa.

A Figura 3.5 apresenta o equivalente elétrico para o modelo flexiVentcamundongo.

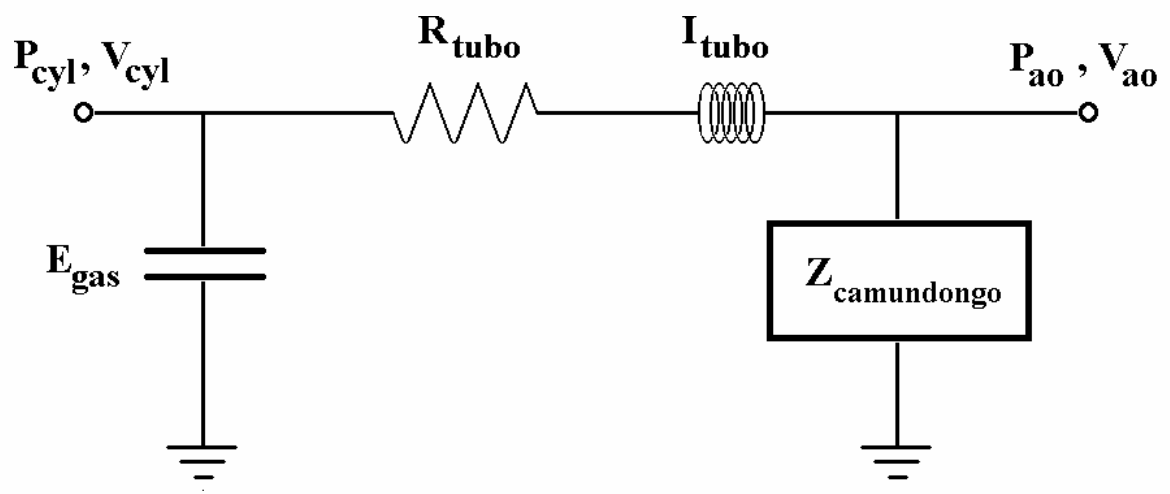

Figura 3.5. Equivalente elétrico do modelo flexiVent-camundongo (Bates et al., 1997).

Segundo Bates e colaboradores (1997), o flexiVent é modelado como sendo uma elastância que representa a compressibilidade do gás contido dentro do conjunto formado pelo cilindro e tubos de conexão $\left(E_{g a s}\right)$ em paralelo com uma resistência $\left(R_{\text {tubo }}\right)$ e uma inertância $\left(I_{\text {tubo }}\right)$ que representam a impedância devido às tubulações e à cânula. Esta impedância está em série com a impedância do animal. A pressão dentro do cilindro $\left(P_{c y l}\right)$ e o volume devido ao movimento do pistão $\left(V_{c y l}\right)$ são medidos. A pressão $\left(P_{a o}\right)$ e o fluxo $\left(\dot{V}_{a o}\right)$ nas vias aéreas do animal são obtidos levando-se em consideração os efeitos causados por $E_{g a s}, R_{t u b o}$ e $I_{t u b o}$. 
Resumidamente, pode-se decompor $V_{c y l}$ em duas partes: um volume entrando no animal pela cânula $\left(V_{a o}\right)$ e um volume comprimido dentro do cilindro. Da mesma forma, $P_{c y l}$ é a soma da pressão aplicada no animal pela cânula $\left(P_{a o}\right)$ com a queda de pressão devido aos tubos que conectam o cilindro ao animal.

Para calcular $P_{a o}$ e $V_{a o}$ a partir dos valores medidos de $P_{c y l}$ e $V_{c y l}$, dois procedimentos foram realizados.

No primeiro procedimento, o pistão do ventilador oscilou conforme a forma de onda utilizada como perturbação em volume, enquanto que a cânula estava completamente obstruída. Neste caso, os valores de pressão $\left(P_{\text {ocluido }}\right)$ e volume $\left(V_{\text {ocluido }}\right)$ medidos foram relacionados pela seguinte equação:

$$
P_{\text {ocluido }}=E_{\text {gas }} \cdot V_{\text {ocluido }}
$$

O valor de $E_{g a s}$ foi obtido através da técnica de regressão múltipla linear (Draper e Smith, 1998) e utilizado no segundo procedimento descrito a seguir e nas correções realizadas em $P_{c y l}$ e $V_{c y l}$, apresentadas posteriormente.

No segundo procedimento, o pistão foi mais uma vez oscilado com a perturbação em volume previamente descrita, sendo que a cânula encontrava-se aberta para o ar ambiente. Neste caso, parte do volume medido indiretamente através da posição do pistão $\left(V_{\text {aberto }}\right)$ é comprimida enquanto que o restante sai pela cânula $\left(V_{a o_{a b e r o}}\right)$ e pode ser calculado através da seguinte equação: 


$$
V_{\text {ao } a \text { aberto }}=V_{\text {aberto }}-\frac{P_{\text {aberto }}}{E_{\text {gas }}}
$$

onde $P_{\text {aberto }}$ é a queda de pressão ao longo do caminho do fluxo de ar e é medida durante o procedimento.

Assume-se que $P_{\text {aberto }}$ é determinada por uma resistência à passagem do fluxo $\left(R_{t u b o}\right)$ e uma inertância do gás contido no conjunto formado por cilindro e tubos de conexão $\left(I_{\text {tubo }}\right)$. Desta forma, $R_{\text {tubo }}$ e $I_{\text {tubo }}$ podem ser calculadas através de regressão linear múltipla utilizando-se a seguinte relação:

$$
P_{\text {aberto }}=\dot{V}_{\text {ao aberto }} \cdot R_{\text {tubo }}+\ddot{V}_{\text {ao aberto }} \cdot I_{\text {tubo }}
$$

onde $\dot{V}_{a a_{\text {aberto }}}$ é a derivada no tempo de $V_{a a_{a b e r t o}}$ e $\ddot{V}_{a a_{\text {aberto }}}$ é a derivada no tempo de $\dot{V}_{a o_{a b e r t o}}$.

A diferenciação numérica de um sinal, utilizada nesta pesquisa, foi realizada através do ajuste de um segmento de reta para cada três pontos consecutivos no sinal e do cálculo do coeficiente angular deste segmento de reta. Este coeficiente foi considerado como sendo o valor da derivada do sinal no segundo ponto. Apesar deste método de diferenciação numérica ser simples, ele apresenta bons resultados para os casos estudados e é empregado com uma certa freqüência na avaliação da mecânica respiratória, pois está implementado no software ANADAT versão 5.2. 
Estes dois procedimentos foram realizados para cada uma das diferentes amplitudes de perturbação em volume utilizadas $(0,1,0,2,0,3$ e $0,4 \mathrm{~mL})$, obtendo-se diferentes valores de $E_{g a s}, R_{t u b o}$ e $I_{t u b o}$.

Quando um animal é conectado ao flexiVent, obtém-se o volume que realmente chega até o animal $\left(V_{a o}\right)$ utilizando-se o valor de $E_{g a s}$ previamente obtido para a amplitude de perturbação em volume utilizada e a seguinte equação:

$$
V_{a o}=V_{c y l}-\frac{P_{c y l}}{E_{g a s}}
$$

O fluxo que realmente chega até o animal $\left(\dot{V}_{a o}\right)$ é obtido diferenciando-se $V_{a o}$ numericamente.

A pressão na saída da cânula $\left(P_{a o}\right)$, obtida quando o animal está conectado ao ventilador, é obtida utilizando-se os valores de $R_{\text {tubo }}$ e $I_{t u b o}$, previamente obtidos para a amplitude de perturbação em volume utilizada, e a seguinte equação:

$$
P_{a o}=P_{c y l}-\dot{V}_{a o} \cdot R_{t u b o}-\ddot{V}_{a o} \cdot I_{\text {tubo }}
$$

Os valores de $P_{a o}, V_{a o}$ e $\dot{V}_{a o}$ obtidos com cada animal foram utilizados na aplicação de cinco modelos distintos:

Modelo de fase constante no domínio da freqüência: 


$$
Z_{r s}(f)=R_{a w}+j \cdot 2 \cdot \pi \cdot f \cdot I_{a w}+\frac{G_{t}-j \cdot H_{t}}{(2 \cdot \pi \cdot f)^{\alpha}}
$$

Aproximação no domínio do tempo do modelo de fase constante:

$$
P_{a o}(t)=R_{a w} \cdot \dot{V}(t)+A \cdot V(t)-A \cdot k \cdot\{\dot{V}(t) \otimes[\ln (t) \cdot d(t)]\}+P_{0}
$$

Aproximação no domínio do tempo do modelo de fase constante com a adição do termo relativo à inertância:

$$
P_{a o}(t)=R_{a w} \cdot \dot{V}(t)+I_{a w} \cdot \ddot{V}(t)+A \cdot V(t)-A \cdot k \cdot\{\dot{V}(t) \otimes[\ln (t) \cdot d(t)]\}+P_{0}
$$

Aproximação no domínio do tempo do modelo de fase constante com resistência dependente do fluxo:

$$
P_{a o}(t)=R_{1} \cdot \dot{V}(t)+R_{2} \cdot \dot{V}(t) \cdot|\dot{V}(t)|+A \cdot V(t)-A \cdot k \cdot\{\dot{V}(t) \otimes[\ln (t) \cdot d(t)]\}+P_{0}
$$

Aproximação no domínio do tempo do modelo de fase constante com elastância dependente do volume:

$$
P_{a o}(t)=R_{a w} \cdot \dot{V}(t)+E \cdot V^{2}(t)+A \cdot V(t)-A \cdot k \cdot\{\dot{V}(t) \otimes[\ln (t) \cdot d(t)]\}+P_{0}
$$

As Equações 4.17, 4.18, 4.19 e 4.20 são contribuições do autor nesta pesquisa e por isso são desenvolvidas no Capítulo 4 referente aos resultados. 
Para a aplicação dos modelos no domínio do tempo foi utilizada a técnica de regressão múltipla linear.

O cálculo de impedância mecânica de entrada do sistema respiratório $\left(Z_{r s}\right)$ foi realizado seguindo os procedimentos descritos por Michaelson e colaboradores (1975). Em linhas gerais, os arquivos referentes aos sinais com 8 segundos de duração $\left(P_{a o}\right.$ e $\left.\dot{V}_{a o}\right)$ foram divididos cada um em três blocos de 4 segundos de duração, sendo que estes blocos apresentavam uma superposição de 50\% com o bloco anterior e 50\% com o bloco posterior. O primeiro bloco de cada arquivo foi descartado para evitar transientes devido ao início do movimento do pistão do flexiVent (Gomes et al., 2000); (Bijaoui et al., 2001).

Supondo que $P_{a o_{2}}$ e $P_{a o_{3}}$ sejam o segundo e o terceiro blocos do sinal de saída $P_{a o}$, e que $\dot{V}_{a o_{2}}$ e $\dot{V}_{a o_{3}}$ sejam o segundo e o terceiro blocos do sinal de entrada $\dot{V}_{a o}$, as transformadas discretas de Fourier de $P_{a o_{2}}, P_{a o_{3}}, \dot{V}_{a o_{2}}$ e $\dot{V}_{a o_{3}}$ foram calculadas utilizando o software ANADAT versão 5.2, obtendo-se $D F T_{P_{\mathrm{ao}_{2}}}, D F T_{P_{\mathrm{ao}_{3}}}, D F T_{\dot{\mathrm{aOO}}_{2}}$ e $D F T_{\dot{V}_{a 0_{3}}}$

A partir das transformadas discretas de Fourier $D F T_{P_{a_{2}}}, D F T_{P_{a o_{3}}}, D F T_{\dot{V}_{a o_{2}}}$ e $D F T_{\dot{V}_{\text {a }}}$, as densidades espectrais de potência dos blocos referentes ao sinal de entrada $\dot{V}_{a o}$ foram calculadas, utilizando o software ANADAT versão 5.2, obtendose $G_{\dot{V}_{a o_{2}} \dot{V}_{a o_{2}}}$ e $G_{\dot{V}_{a 0_{3}} \dot{V}_{a o_{3}}}$. Analogamente, obteve-se $G_{P_{a 0_{2}} P_{a o_{2}}}$ e $G_{P_{a 0_{3}} P_{a 0_{3}}}$ em relação ao sinal de saída $P_{a o}$, e $G_{P_{a o_{2}} \dot{V}_{a o_{2}}}$ e $G_{P_{a o_{3}} \dot{V}_{a o_{3}}}$ em relação às densidades espectrais de potência cruzada. 
Para evitar os efeitos do ruído na medição, as densidades espectrais de potência do sinal de entrada $\left(G_{\dot{V}_{a o} \dot{V}_{a o}}\right)$ e do sinal de saída $\left(G_{P_{a o} P_{a o}}\right)$ foram calculadas como sendo as médias das densidade espectrais de potência dos blocos referentes aos sinais de entrada $\dot{V}_{a o}$ e saída $P_{a o}$. Também, pelo mesmo motivo, a densidade espectral de potência cruzada $\left(G_{P_{a o} \dot{V_{a o}}}\right)$ foi considerada como sendo a média de $G_{P_{a_{2} a_{a o_{2}}} \dot{V}_{P_{a_{3}} \dot{V}_{a_{3}}}}$, ou seja,

$$
\begin{aligned}
& G_{\dot{V}_{a 0} \dot{V}_{a o}}=\frac{G_{\dot{V}_{a 02} \dot{V}_{a o_{2}}}+G_{\dot{V}_{a 03} \dot{V}_{a 03}}}{2} \\
& G_{P_{a o} P_{a o}}=\frac{G_{P_{a o_{2}} P_{a o_{2}}}+G_{P_{a 0_{3}} P_{a 0_{3}}}}{2} \\
& G_{P_{a o} \dot{V}_{a o}}=\frac{G_{P_{a 0_{2}} \dot{V}_{a 0_{2}}}+G_{P_{a a_{3}} \dot{V}_{a o_{3}}}}{2}
\end{aligned}
$$

Desta forma, a impedância $Z_{r s}$ foi calculada utilizando a seguinte equação:

$$
Z_{r s}=\frac{G_{P_{a o} \dot{V}_{a o}}}{G_{\dot{V}_{a o} \dot{V}_{a o}}}
$$

Foram calculadas também as funções de coerência entre o sinal de entrada e de saída para cada freqüência em estudo (Michaelson et al., 1975), de acordo com a expressão: 


$$
\gamma^{2}=\frac{\left|G_{P_{a o} \dot{V}_{a o}}\right|^{2}}{G_{P_{a o} P_{a o}} \cdot G_{\dot{V}_{a o} \dot{V}_{a o}}} \quad, 0 \leq \gamma^{2} \leq 1
$$

A aplicação do modelo de fase constante aos dados relativos à impedância calculada foi realizada utilizando-se uma das rotinas existentes no software ANADAT versão 5.2. Esta rotina utiliza o seguinte esquema iterativo: inicialmente, assume-se o valor 1,0 para o parâmetro $\alpha$ e os demais parâmetros $\left(R_{a w}, I_{a w}, G_{t} \mathrm{e}\right.$ $H_{t}$ ) são estimados através do uso da técnica de regressão múltipla linear e pela utilização da Equação 2.18. Os valores obtidos de $G_{t}$ e $H_{t}$ são então utilizados na Equação 2.14 para obter-se um novo valor de $\alpha$. Este novo valor de $\alpha$ é utilizado para obter-se novos parâmetros $R_{a w}, I_{a w}, G_{t}$ e $H_{t}$ que são novamente estimados utilizando-se a regressão múltipla linear e a Equação 2.18, o que permite uma segunda estimativa de $\alpha$ e assim por diante. Este procedimento é repetido por dez vezes. Verificou-se que os valores dos parâmetros tipicamente convergem para um erro na quarta casa decimal dentro de cinco iterações.

O grau de não-linearidade do sistema respiratório modelado foi estimado através do índice de não-linearidade proposto por Zhang e colaboradores (1995) e calculado através da seguinte equação:

$$
k_{d}=\sqrt{\frac{P_{N I}}{P_{T O T}}} \cdot 100(\%)
$$


onde $P_{T O T}$ é a potência total de $P_{a o}$ e $P_{N I}$ é a potência de $P_{a o}$ nas freqüências que não estão presentes no sinal de entrada $\dot{V}_{a o}$.

Quanto maior o valor de $k_{d}$, mais relevante é o comportamento não-linear do sistema excitado.

O software SigmaStat (SPSS Science, Chicago, IL, EUA) foi utilizado para verificar a dependência estatística de $k_{d}$ com as amplitudes de perturbação e os diferentes valores de PEEP.

\subsection{COMPARAÇÃO ENTRE OS MODELOS}

Os desempenhos do modelo correspondente à aproximação no domínio do tempo do modelo de fase constante (Equação 4.17) e do modelo de fase constante (Equação 2.18) foram comparados em termos das diferenças percentuais entre os parâmetros $R, G_{t}$ e $H_{t}$ estimados pelos dois modelos.

A variância estimada do ruído $(E N V)$ foi utilizada como um índice da qualidade da adequação do modelo aos dados experimentais (Wagers et al., 2002):

$$
E N V=\frac{1}{n-m} \sum_{i=1}^{n}\left(P_{i}-\hat{P}_{i}\right)^{2}
$$

onde $P_{i}$ é a pressão medida, $\hat{P}_{i}$ é a pressão estimada pelo modelo, $n$ é o número de amostras e $m$ é o número de parâmetros do modelo. Nesta pesquisa a pressão medida foi $P_{a o}$. 
Quanto menor o valor de $E N V$, melhor será a predição realizada pelo modelo.

Quando dois modelos diferentes são utilizados para estimar o mesmo conjunto de dados, um dos modelos produz um valor menor ou igual de $E N V$. Para decidir se a redução na $E N V$ foi estatisticamente significante, calcula-se o percentual de melhora da $E N V$ pela equação:

$$
\Delta E N V=\left(\frac{E N V_{1}-E N V_{2}}{E N V_{1}}\right) \cdot 100(\%)
$$

onde $E N V_{1}$ é o maior entre os dois valores de $E N V$.

Supondo que o ruído nos dados experimentais apresente uma distribuição normal, a taxa entre $E N V_{1}$ e $E N V_{2}$ segue uma distribuição tipo $F$ cujo número de graus de liberdade é determinado pelo tamanho da amostra e o número de parâmetros dos dois modelos.

Utilizando a distribuição tipo $F$ adequada, observou-se que se $\Delta E N V$ é maior que $30 \%$, então a hipótese de $E N V_{1}$ e $E N V_{2}$ serem estimativas da mesma variância populacional é menor que 5\% (Wagers et al., 2002).

Conseqüentemente, quando $\triangle E N V$ é maior que $30 \%$, conclui-se que o modelo 2 apresenta uma melhor estimativa dos dados do que o modelo 1 . Se o contrário acontecer, o modelo 2 não é melhor que o modelo 1 .

Entretanto, deve-se notar que o critério de $\triangle E N V$ maior que $30 \%$ só é válido se as diferenças entre os dados experimentais e os dados obtidos com o modelo forem distribuídas de forma gaussiana. 
Foi utilizado o cálculo do $\triangle E N V$ para comparar os desempenhos da aproximação no domínio do tempo do modelo de fase constante sem e com a adição do termo relativo à inertância (Equações 4.17 e 4.18). Além disso, o cálculo do $\triangle E N V$ também foi utilizado para comparar a aproximação no domínio do tempo do modelo de fase constante (Equação 4.17) e suas variações não-lineares com elastância dependente de volume (Equação 4.20) e com resistência dependente de fluxo (Equação 4.19).

No caso das comparações realizadas nesta pesquisa, as diferenças entre os dados experimentais e os dados obtidos com os modelos não apresentaram uma distribuição normal. Portanto, do ponto de vista prático, considerou-se apenas os valores de $\triangle E N V$ que foram muito maiores ou muito menores que $30 \%$. 


\section{RESULTADOS}

Inicialmente será apresentada a maneira pela qual a equação da aproximação no domínio do tempo do modelo de fase constante foi desenvolvida pelo autor.

Em seguida, serão apresentados os resultados referentes à comparação entre o modelo de fase constante no domínio da freqüência e sua aproximação no domínio do tempo.

O índice de não-linearidade do sistema respiratório modelado será então apresentado para cada valor de PEEP e amplitude de perturbação utilizados.

Posteriormente, serão apresentadas as variações não-lineares da aproximação no domínio do tempo do modelo de fase constante, tanto com elastância dependente do volume como com resistência dependente do fluxo.

Finalmente, os resultados das comparações entre o modelo de fase constante no domínio da freqüência e suas extensões não-lineares no domínio do tempo serão apresentados.

A análise dos resultados obtidos e a correspondente discussão serão apresentadas no capítulo seguinte.

\subsection{DESENVOLVIMENTO DO MODELO MATEMÁTICO}

Inicialmente, foi desenvolvido um modelo matemático que é uma aproximação no domínio do tempo do modelo de fase constante.

O modelo de fase constante foi calculado inicialmente por Hantos e colaboradores em 1987 no domínio da freqüência e modela a impedância mecânica do sistema respiratório $\left(Z_{r s}\right)$, sendo descrito pela Equação 2.18 (Hantos et al., 1992): 


$$
Z_{r s}(f)=R_{a w}+j \cdot 2 \cdot \pi \cdot f \cdot I_{a w}+\frac{G_{t}-j \cdot H_{t}}{(2 \cdot \pi \cdot f)^{\alpha}}
$$

A componente do modelo de fase constante que está relacionada com a impedância mecânica dos tecidos $\left(Z_{t i}\right)$ foi descrita pela Equação 2.13:

$$
Z_{t i}(f)=\frac{G_{t}-j \cdot H_{t}}{(2 \cdot \pi \cdot f)^{\alpha}}
$$

No domínio do tempo, a Equação 2.13 corresponde à seguinte equação (Hildebrandt, 1969a); (Hantos et al., 1992):

$$
z_{t i}(t)=A \cdot t^{-k} \cdot d(t)
$$

na qual $d(t)$ é a função de Heaviside, definida como:

$$
\begin{cases}d(t)=1 & , t \geq 0 \\ d(t)=0 & , t<0\end{cases}
$$

$A$ e $k$ são constantes e $t$ é o tempo.

Os parâmetros $G_{t}$ e $H_{t}$ estão relacionados com $A$ e $k$ através das seguintes equações: 


$$
\begin{aligned}
& G_{t}=A \cdot \Gamma(\alpha) \cdot \cos \left(\frac{\alpha \cdot \pi}{2}\right) \\
& H_{t}=A \cdot \Gamma(\alpha) \cdot \operatorname{sen}\left(\frac{\alpha \cdot \pi}{2}\right) \\
& k=1-\alpha
\end{aligned}
$$

onde $\Gamma(\alpha)$ é a função gama de $\alpha$, descrita pela equação:

$$
\Gamma(\alpha)=\int_{0}^{\infty} t^{\alpha-1} \cdot e^{-t} d t
$$

O ANEXO A apresenta o detalhamento matemático da obtenção da Equação 4.1 a partir da Equação 2.13.

Manipulando matematicamente $z_{t i}(t)$, obtém-se:

$$
z_{t i}(t)=A \cdot t^{-k} \cdot d(t)=A \cdot e^{-k \cdot \ln (t)} \cdot d(t)
$$

onde $\ln (t)$ é o logaritmo neperiano de $t$.

Observando-se que $t^{-k}$ pode ser reescrito na seguinte forma de uma série infinita:

$$
t^{-k}=e^{-k \cdot \ln t}=1+\frac{(-k \cdot \ln t)}{1 !}+\frac{(-k \cdot \ln t)^{2}}{2 !}+\frac{(-k \cdot \ln t)^{3}}{3 !}+\ldots, t \geq 0
$$


e aproximando o valor de $t^{-k}$ pelos dois primeiros termos da série infinita, obtém-se:

$$
t^{-k}=e^{-k \cdot \ln t} \cong 1-k \cdot \ln (t) \quad, t \geq 0
$$

A aproximação da Equação 4.9 foi realizada para que fosse possível a utilização da técnica de regressão múltipla linear na estimação dos parâmetros do modelo.

Desta forma, pode-se reescrever $z_{t i}(t)$ pela expressão:

$$
z_{t i}(t)=A \cdot t^{-k} \cdot d(t)=A \cdot e^{-k \cdot \ln (t)} \cdot d(t) \cong A \cdot[1-k \cdot \ln (t)] \cdot d(t)
$$

Por outro lado, no domínio da freqüência, a pressão nos tecidos devido ao fluxo aplicado é descrita pela seguinte equação:

$$
P_{t i}(f)=\dot{V}(f) \cdot Z_{t i}(f)
$$

onde $P_{t i}$ é a pressão nos tecidos e $\dot{V}$ é o fluxo aplicado.

Desta forma, no domínio do tempo, tem-se:

$$
P_{t i}(t)=\dot{V}(t) \otimes z_{t i}(t)
$$

onde $\otimes$ denota a operação de convolução no tempo.

Substituindo a Equação 4.10 na Equação 4.12, obtém-se: 


$$
P_{t i}(t)=\dot{V}(t) \otimes\{A \cdot[1-k \cdot \ln (t)] \cdot d(t)\}
$$

Entretanto, lembrando que $d(t)$ é a função degrau unitário, resulta:

$$
\dot{V}(t) \otimes[A \cdot d(t)]=A \cdot V(t)
$$

onde $V$ é o volume aplicado,

e

$$
\dot{V}(t) \otimes[A \cdot k \cdot \ln (t) \cdot d(t)]=A \cdot k \cdot\{\dot{V}(t) \otimes[\ln (t) \cdot d(t)]\}
$$

obtendo-se finalmente:

$$
P_{t i}(t)=A \cdot V(t)-A \cdot k \cdot\{\dot{V}(t) \otimes[\ln (t) \cdot d(t)]\}
$$

Se $I_{a w}$ for considerado desprezível e adicionar-se os termos $R_{a w} \cdot \dot{V}(t)$ e $P_{0}$ na Equação 4.16, obtém-se uma aproximação no domínio do tempo do modelo de fase constante e objetivo deste desenvolvimento:

$$
P_{a o}(t)=R_{a w} \cdot \dot{V}(t)+A \cdot V(t)-A \cdot k \cdot\{\dot{V}(t) \otimes[\ln (t) \cdot d(t)]\}+P_{0}
$$


O termo $P_{0}$ é uma constante cuja finalidade é absorver quaisquer erros na estimação da capacidade residual funcional (Lauzon e Bates, 1991).

Quando aplicada aos dados experimentais, a convolução $\dot{V}(t) \otimes[\ln (t) \cdot d(t)]$ foi calculada utilizando-se o método de Euler de integração implementado no software ANADAT versão 5.2. Este método foi utilizado devido ao fato de já se encontrar implementado e, apesar de sua simplicidade, mostrar-se bastante eficiente.

Para utilizar esta aproximação no domínio do tempo do modelo de fase constante, os sinais de pressão, volume e fluxo não podem iniciar em $t=0$, pois $\ln (0) \rightarrow-\infty$. Para evitar esta situação, todos os sinais utilizados iniciaram em $t=0,01 \mathrm{~s}$, sendo este valor escolhido de forma arbitrária.

Outra consideração a ser feita sobre a Equação 4.17 é que ela só é válida quando a magnitude de $k \cdot \ln (t)$ for menor que a unidade, pois somente assim é válida a aproximação realizada na Equação 4.10. Esta condição não é válida em geral, pois $k \cdot \ln (t)$ tende a mais infinito à medida que $t$ tende a infinito e a menos infinito conforme $t$ tende a zero. Entretanto, para o caso estudado nesta pesquisa, basta a aproximação realizada na Equação 4.10 ser válida durante a existência nãonula dos sinais utilizados, ou seja de $t=0,01 \mathrm{~s}$ até $8,01 \mathrm{~s}$. Esta condição foi testada calculando-se $z_{t i}(t)$ no referido intervalo de tempo utilizando a Equação 4.7 e a aproximação realizada na Equação 4.10 com o valor de $k$ igual a 0,1 , sendo este valor de $k$ bastante representativo, conforme já demonstrado por outros estudos (Bates et al., 1994). Observou-se que as duas estimativas concordavam nesse intervalo de 8 segundos dentro de um erro médio de 1,2\% com um desvio-padrão de $0,9 \%$. 


\subsection{ESTUDO DA IMPORTÂNCIA DA INERTÂNCIA}

Para analisar a importância da inertância, utilizando-se a técnica de regressão múltipla linear, os dados obtidos experimentalmente foram aplicados ao modelo apresentado na Equação 4.17 e ao modelo representado pela seguinte equação:

$$
P_{a o}(t)=R_{a w} \cdot \dot{V}(t)+I_{a w} \cdot \ddot{V}(t)+A \cdot V(t)-A \cdot k \cdot\{\dot{V}(t) \otimes[\ln (t) \cdot d(t)]\}+P_{0}
$$

onde $\ddot{V}(t)$ é a aceleração do volume aplicado.

A Figura 4.1 apresenta um exemplo da aplicação da aproximação no domínio do tempo do modelo de fase constante (Equação 4.17) aos dados experimentais utilizando o software ANADAT versão 5.2.

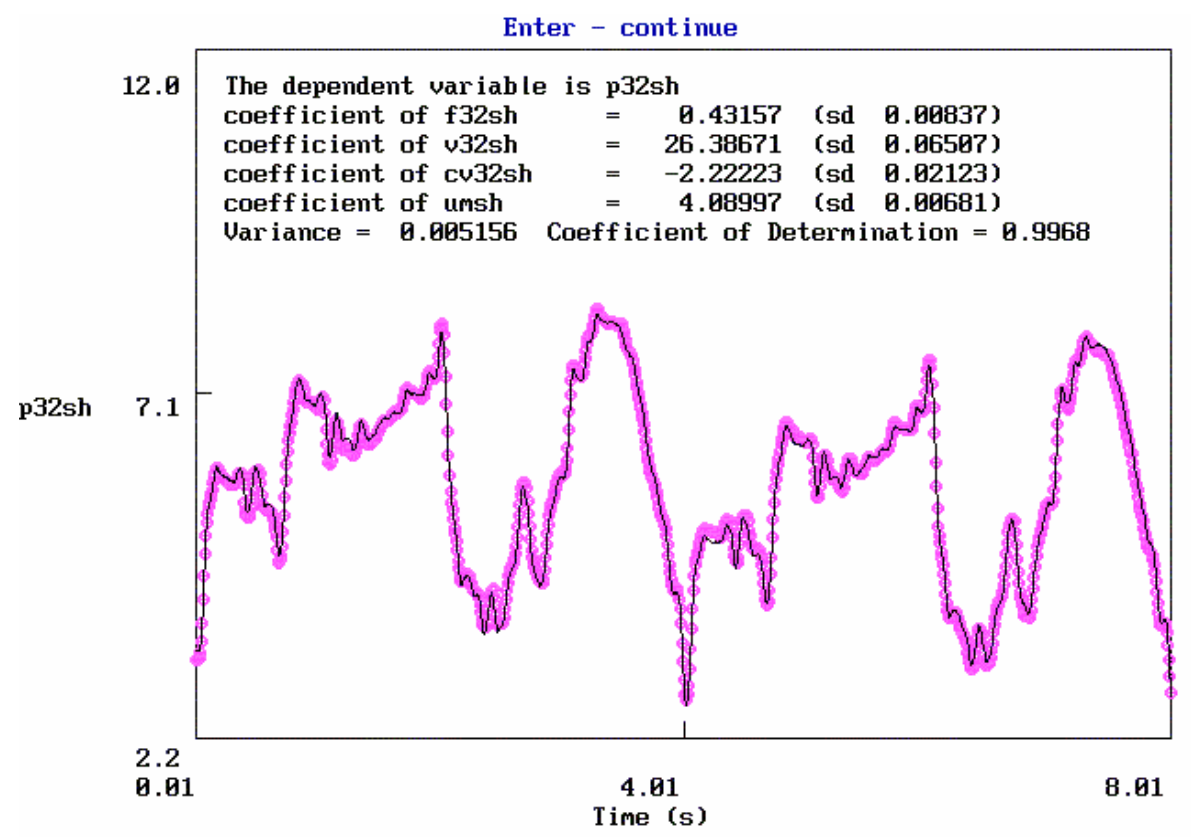

Figura 4.1. Exemplo de aplicação da aproximação no domínio do tempo do modelo de fase constante (Equação 4.17) aos dados experimentais obtidos (camundongo número 2, PEEP de $3 \mathrm{cmH}_{2} \mathrm{O}$ e amplitude de $0,2 \mathrm{~mL}$ ). 
Na Figura 4.1, foram utilizados termos mnemônicos para a pressão $(p 32 s h)$, o fluxo (f32sh), o volume (v32sh), a convolução (cv32sh) e $P_{0}$ (umsh). Estes termos estão presentes nos diversos exemplos deste capítulo, foram utilizados para facilitar o tratamento dos dados e variaram conforme o animal, as condições de ventilação e o modelo matemático empregados. Assim sendo, o valor de $R_{a w}$ é de $0,43157 \pm 0,00837 \mathrm{cmH}_{2} \mathrm{O} / \mathrm{mL} / \mathrm{s}$, o valor de $A$ é de $26,38671 \pm 0,06507 \mathrm{cmH}_{2} \mathrm{O} / \mathrm{mL}$, o valor de $A \cdot k$ é de 2,22223 $\pm 0,02123 \mathrm{cmH}_{2} \mathrm{O} / \mathrm{mL}$, o valor de $P_{0}$ é de $4,08997 \pm 0,00681 \mathrm{cmH}_{2} \mathrm{O}$ e o valor de $E N V$ é de 0,005156 .

A Figura 4.2 apresenta um exemplo da aplicação da aproximação no domínio do tempo do modelo de fase constante com a adição do termo referente à inertância (Equação 4.18) aos dados experimentais utilizando o software ANADAT versão 5.2.

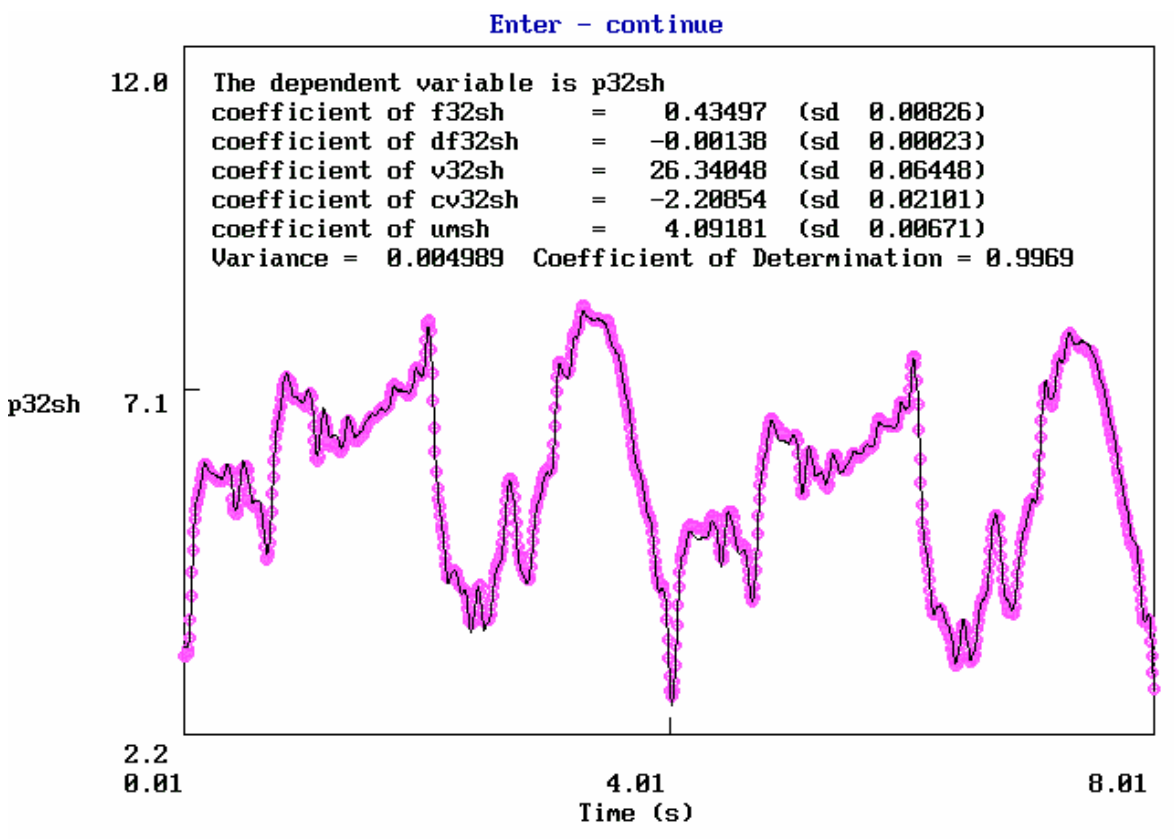

Figura 4.2. Exemplo de aplicação da aproximação no domínio do tempo do modelo de fase constante com a adição do termo relativo à inertância (Equação 4.18) aos dados experimentais obtidos (camundongo número 2, PEEP de $3 \mathrm{cmH}_{2} \mathrm{O}$ e amplitude de $0,2 \mathrm{~mL}$ ). 
Na Figura 4.2, o valor de $R_{a w}$ é de $0,43497 \pm 0,00826 \mathrm{cmH}_{2} \mathrm{O} / \mathrm{mL} / \mathrm{s}$, o valor de $I_{a w}$ é de $-0,00138 \pm 0,00023 \quad \mathrm{cmH}_{2} \mathrm{O} / \mathrm{mL} / \mathrm{s}^{2}$, o valor de $A$ é de $26,34048 \pm 0,06448 \quad \mathrm{cmH}_{2} \mathrm{O} / \mathrm{mL}, \quad$ o valor de $A \cdot k$ é de 2,20854 $\pm 0,02101 \mathrm{cmH}_{2} \mathrm{O} / \mathrm{mL}$, o valor de $P_{0}$ é de $4,09181 \pm 0,00671 \mathrm{cmH}_{2} \mathrm{O}$ e o valor de $E N V$ é de 0,004989 .

Os valores de inertância $\left(I_{a w}\right)$ obtidos com as várias amplitudes de perturbação e valores de PEEP são apresentados na Tabela 4.1.

Tabela 4.1. Valores de $I_{a w}\left(\mathrm{cmH}_{2} \mathrm{O} / \mathrm{mL} / \mathrm{s}^{2}\right)$ (média \pm desvio-padrão)

\begin{tabular}{|c|c|c|c|c|}
\hline $\begin{array}{c}\text { Amplitude } \\
\text { perturbação } \\
\downarrow\end{array}$ & $P E E P O \mathrm{cmH}_{2} \mathrm{O}$ & $P E E P 3 \mathrm{cmH}_{2} \mathrm{O}$ & $P E E P 6 \mathrm{cmH}_{2} \mathrm{O}$ & $P E E P 9 \mathrm{cmH}_{2} \mathrm{O}$ \\
\hline $0,1 \mathrm{~mL}$ & $0,00049 \pm 0,00117$ & $0,00048 \pm 0,00144$ & $-0,00058 \pm 0,00142$ & $-0,00068 \pm 0,00260$ \\
\hline $0,2 \mathrm{~mL}$ & $-0,00094 \pm 0,00071$ & $-0,00060 \pm 0,00083$ & $-0,00004 \pm 0,00080$ & $0,00169 \pm 0,00146$ \\
\hline $0,3 \mathrm{~mL}$ & $-0,00058 \pm 0,00087$ & $-0,00038 \pm 0,00052$ & $0,00145 \pm 0,00087$ & $0,00392 \pm 0,00191$ \\
\hline $0,4 \mathrm{~mL}$ & $-0,00058 \pm 0,00091$ & $0,00052 \pm 0,00031$ & $0,00491 \pm 0,00136$ & $0,01317 \pm 0,00390$ \\
\hline
\end{tabular}

A Figura 4.3 mostra quanto a adição da inertância à aproximação no domínio do tempo do modelo de fase constante melhora o ajuste aos dados experimentais.

Note-se que a adição do termo referente à inertância produz valores de $\triangle E N V$ que chega ao máximo de 5,5\% no caso de melhor ajuste (PEEP de $3 \mathrm{cmH}_{2} \mathrm{O}$ e amplitude de perturbação de $0,1 \mathrm{~mL}$ ). 


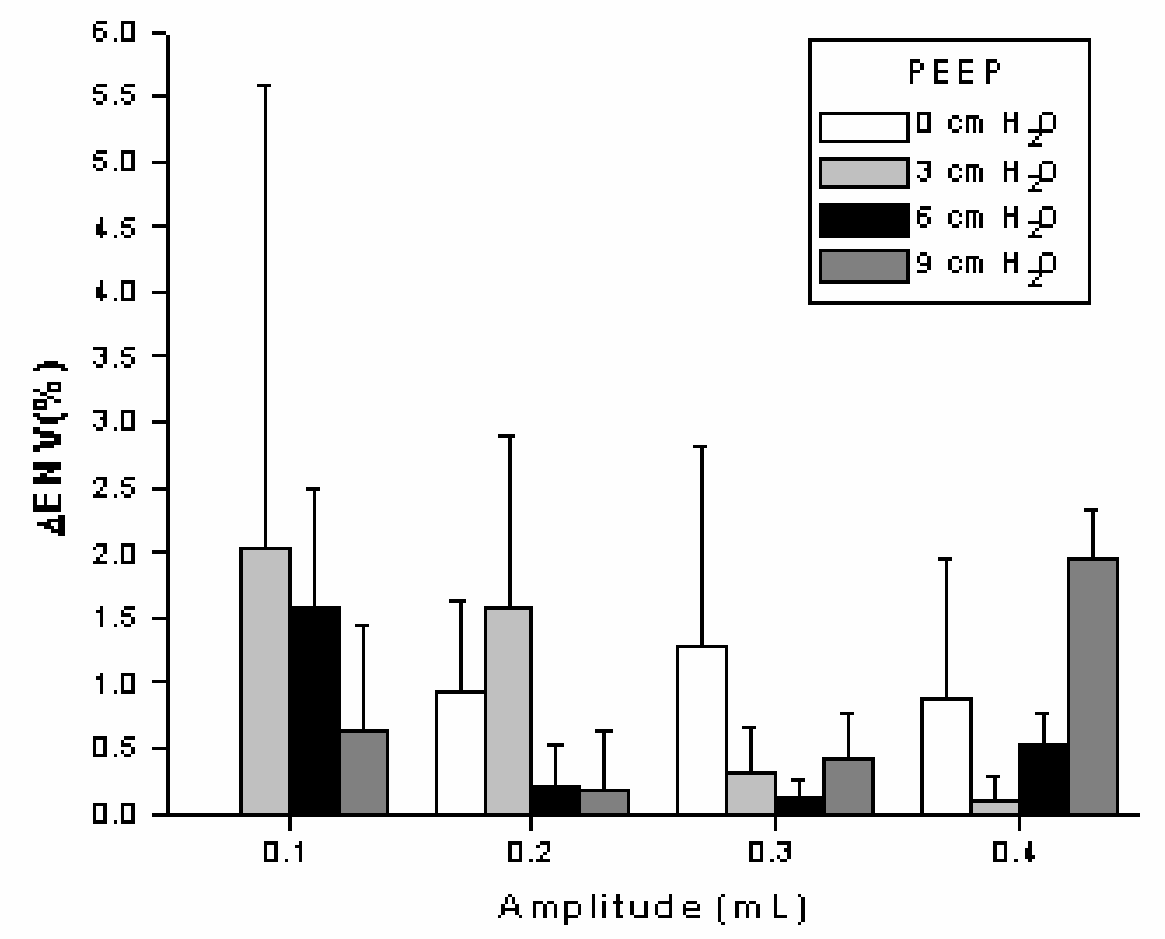

Figura 4.3. Comportamento de $\triangle E N V$ com a adição do termo referente à inertância $\left(I_{a w}\right)$ em relação à aproximação no domínio do tempo do modelo de fase constante.

\subsection{COMPARAÇÃO ENTRE O MODELO DE FASE}

\section{CONSTANTE E SUA APROXIMAÇÃO NO DOMÍNIO DO}

\section{TEMPO}

A Figura 4.4 apresenta um exemplo da aplicação do modelo de fase constante (Equação 2.18) aos valores calculados da impedância utilizando o software ANADAT versão 5.2 e a mesma base de dados dos resultados anteriormente apresentados (camundongo número 2, PEEP de $3 \mathrm{cmH}_{2} \mathrm{O}$ e amplitude de 0,2 $\mathrm{mL}$ ). 


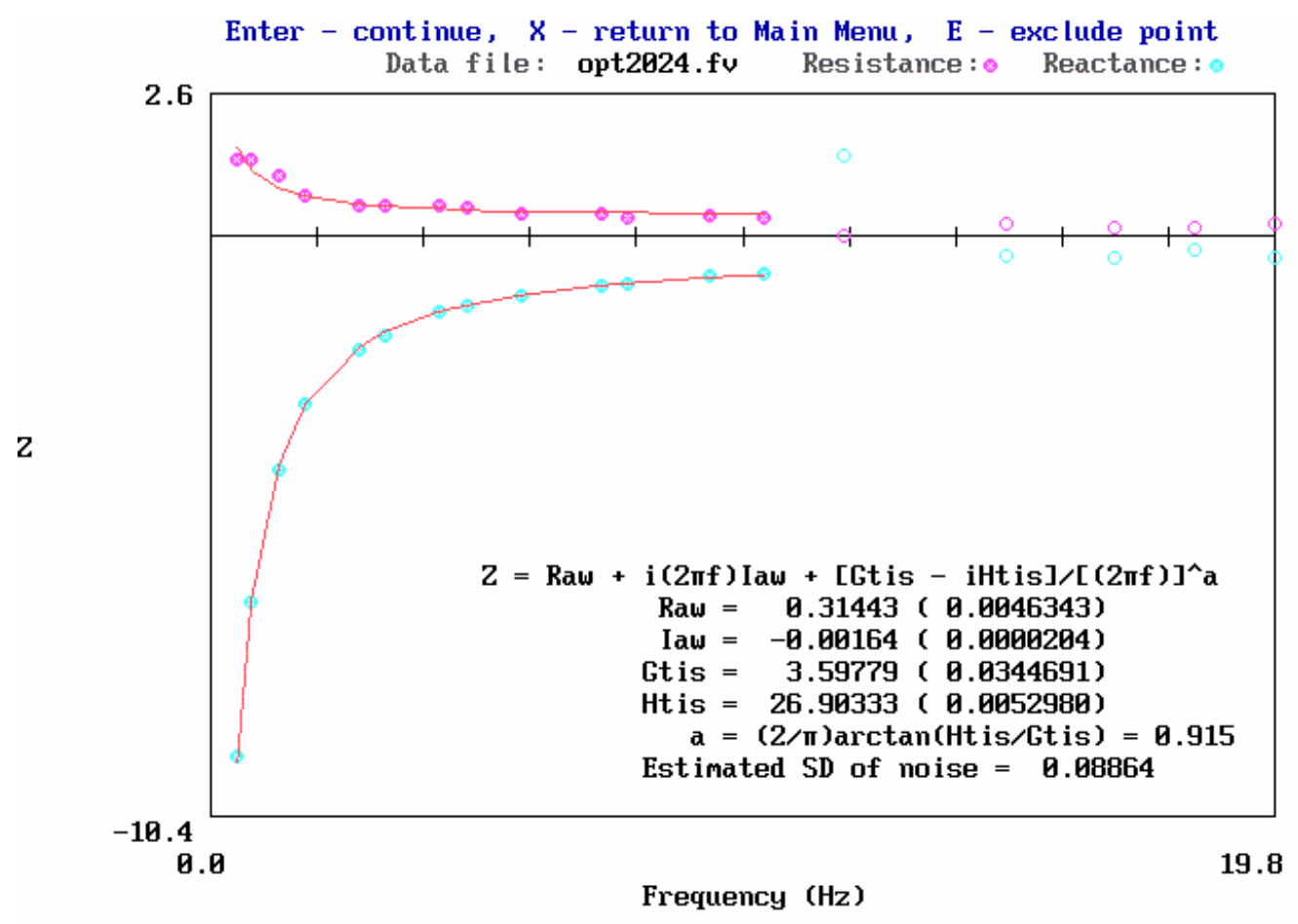

Figura 4.4. Exemplo de aplicação do modelo de fase constante (Equação 2.18) no domínio da freqüência aos valores calculados da impedância (camundongo número 2, PEEP de $3 \mathbf{c m H}_{2} \mathrm{O}$ e amplitude de $0,2 \mathrm{~mL}$ ).

Na Figura 4.4, o valor de $R_{a w}$ é de $0,31443 \pm 0,00463 \mathrm{cmH}_{2} \mathrm{O} / \mathrm{mL} / \mathrm{s}$, o valor de $I_{a w}$ é de $-0,00164 \pm 0,00002 \quad \mathrm{cmH}_{2} \mathrm{O} / \mathrm{mL} / \mathrm{s}^{2}$, o valor de $G_{t}$ é de $3,59779 \pm 0,03447 \quad \mathrm{cmH}_{2} \mathrm{O} / \mathrm{mL} / \mathrm{s}^{(1-\alpha)}, \quad$ o valor de $H_{t}$ é de $26,90333 \pm 0,00530 \mathrm{cmH}_{2} \mathrm{O} / \mathrm{mL} / \mathrm{s}^{(1-\alpha)}$, o valor de $\alpha$ é de 0,915 e o valor de $E N V$ é de 0,08864 .

Os valores dos parâmetros $R_{a w}, G_{t}$ e $H_{t}$ estimados pelo modelo de fase constante (Equação 2.18) em cada combinação de amplitude de perturbação e nível de PEEP são apresentados nas Tabelas 4.2 a 4.4 . 
Tabela 4.2. Valores de $\boldsymbol{R}_{a w}\left(\mathrm{cmH}_{2} \mathrm{O} / \mathrm{mL} / \mathrm{s}\right)$ (média \pm desvio padrão) para o modelo de fase constante.

\begin{tabular}{|c|c|c|c|c|}
\hline $\begin{array}{c}\text { Amplitude } \\
\text { perturbação } \\
\downarrow\end{array}$ & PEEP $0 \mathrm{cmH}_{2} \mathrm{O}$ & PEEP $3 \mathrm{cmH}_{2} \mathrm{O}$ & PEEP $6 \mathrm{cmH}_{2} \mathrm{O}$ & PEEP $9 \mathrm{cmH}_{2} \mathrm{O}$ \\
\hline $0,1 \mathrm{~mL}$ & $0,296 \pm 0,116$ & $0,388 \pm 0,066$ & $0,349 \pm 0,053$ & $0,464 \pm 0,038$ \\
\hline $0,2 \mathrm{~mL}$ & $0,383 \pm 0,113$ & $0,377 \pm 0,132$ & $0,429 \pm 0,098$ & $0,606 \pm 0,052$ \\
\hline $0,3 \mathrm{~mL}$ & $0,498 \pm 0,248$ & $0,415 \pm 0,128$ & $0,509 \pm 0,144$ & $0,676 \pm 0,080$ \\
\hline $0,4 \mathrm{~mL}$ & $0,535 \pm 0,250$ & $0,499 \pm 0,181$ & $0,705 \pm 0,135$ & $0,603 \pm 0,119$ \\
\hline
\end{tabular}

Tabela 4.3. Valores de $G_{t}\left(\mathrm{cmH}_{2} \mathrm{O} / \mathrm{mL} / \mathbf{s}^{(1-a)}\right)$ (média \pm desvio padrão) para o modelo de fase constante.

\begin{tabular}{|c|c|c|c|c|}
\hline $\begin{array}{c}\text { Amplitude } \\
\text { perturbação }\end{array}$ & $P E E P\left(0 \mathrm{CmH}_{2} \mathrm{O}\right.$ & PEEP $3 \mathrm{cmH}_{2} \mathrm{O}$ & PEEP $6 \mathrm{cmH}_{2} \mathrm{O}$ & $P E E P 9 \mathrm{cmH}_{2} \mathrm{O}$ \\
\hline $0,1 \mathrm{~mL}$ & $5,174 \pm 1,211$ & $3,711 \pm 0,678$ & $3,326 \pm 0,199$ & $4,807 \pm 0,111$ \\
\hline $0,2 \mathrm{~mL}$ & $4,331 \pm 0,878$ & $3,030 \pm 0,678$ & $2,731 \pm 0,370$ & $4,324 \pm 0,361$ \\
\hline $0,3 \mathrm{~mL}$ & $3,630 \pm 0,632$ & $2,689 \pm 0,669$ & $2,022 \pm 0,489$ & $3,883 \pm 0,228$ \\
\hline $0,4 \mathrm{~mL}$ & $3,433 \pm 0,844$ & $2,391 \pm 0,601$ & $1,019 \pm 0,590$ & $6,027 \pm 0,959$ \\
\hline
\end{tabular}

Tabela 4.4. Valores de $H_{t}\left(\mathrm{cmH}_{2} \mathrm{O} / \mathrm{mL} / \mathrm{s}^{(1-a)}\right)$ (média \pm desvio padrão) para o modelo de fase constante.

\begin{tabular}{|c|c|c|c|c|}
\hline $\begin{array}{c}\text { Amplitude } \\
\text { perturbação } \\
\downarrow\end{array}$ & $P E E P\left(0 \mathrm{cmH}_{2} \mathrm{O}\right.$ & PEEP $3 \mathrm{cmH}_{2} \mathrm{O}$ & PEEP $6 \mathrm{cmH}_{2} \mathrm{O}$ & PEEP $9 \mathrm{cmH}_{2} \mathrm{O}$ \\
\hline $0,1 \mathrm{~mL}$ & $32,136 \pm 9,088$ & $22,678 \pm 6,882$ & $20,293 \pm 2,406$ & $45,737 \pm 4,858$ \\
\hline $0,2 \mathrm{~mL}$ & $26,043 \pm 4,947$ & $21,735 \pm 6,312$ & $23,208 \pm 1,979$ & $64,085 \pm 7,783$ \\
\hline $0,3 \mathrm{~mL}$ & $24,673 \pm 3,999$ & $21,548 \pm 6,419$ & $31,956 \pm 6,787$ & $77,762 \pm 9,179$ \\
\hline $0,4 \mathrm{~mL}$ & $25,012 \pm 8,181$ & $25,144 \pm 9,541$ & $47,461 \pm 7,825$ & $78,864 \pm 7,107$ \\
\hline
\end{tabular}


Os valores dos parâmetros $R_{a w}, G_{t}$ e $H_{t}$ estimados pela aproximação no domínio do tempo do modelo de fase constante (Equação 4.17) em cada combinação de amplitude de perturbação e nível de PEEP são apresentados nas Tabelas 4.5 a 4.7.

Tabela 4.5. Valores de $\boldsymbol{R}_{a w}\left(\mathrm{cmH}_{2} \mathrm{O} / \mathrm{mL} / \mathrm{s}\right)$ (média \pm desvio padrão) para a aproximação no domínio do tempo do modelo de fase constante.

\begin{tabular}{|c|c|c|c|c|}
\hline $\begin{array}{c}\text { Amplitude } \\
\text { perturbação } \\
\downarrow\end{array}$ & $P E E P O \mathrm{cmH}_{2} \mathrm{O}$ & $P E E P 3 \mathrm{cmH}_{2} \mathrm{O}$ & $P E E P\left(6 \mathrm{cmH}_{2} \mathrm{O}\right.$ & $P E E P 9 \mathrm{cmH}_{2} \mathrm{O}$ \\
\hline $0,1 \mathrm{~mL}$ & $0,320 \pm 0,142$ & $0,468 \pm 0,137$ & $0,551 \pm 0,105$ & $0,763 \pm 0,073$ \\
\hline $0,2 \mathrm{~mL}$ & $0,540 \pm 0,119$ & $0,490 \pm 0,139$ & $0,573 \pm 0,106$ & $0,958 \pm 0,084$ \\
\hline $0,3 \mathrm{~mL}$ & $0,610 \pm 0,225$ & $0,550 \pm 0,151$ & $0,697 \pm 0,156$ & $1,043 \pm 0,063$ \\
\hline $0,4 \mathrm{~mL}$ & $0,683 \pm 0,241$ & $0,654 \pm 0,179$ & $0,886 \pm 0,171$ & $0,367 \pm 0,429$ \\
\hline
\end{tabular}

Tabela 4.6. Valores de $G_{t}\left(\mathrm{cmH}_{2} \mathrm{O} / \mathrm{mL} / \mathrm{s}^{(1-\alpha)}\right)$ (média \pm desvio padrão) para a aproximação no domínio do tempo do modelo de fase constante.

\begin{tabular}{|c|c|c|c|c|}
\hline $\begin{array}{c}\text { Amplitude } \\
\text { perturbação } \\
\downarrow\end{array}$ & PEEP $\mathbf{0} \mathbf{c m H}_{2} \mathbf{O}$ & PEEP $\mathbf{3} \mathbf{~ m H}_{2} \mathbf{O}$ & PEEP $\mathbf{6} \mathbf{c m H}_{2} \mathbf{O}$ & PEEP 9 $\mathbf{~ m H}_{2} \mathbf{O}$ \\
\hline $\mathbf{0 , 1} \mathbf{~ m L}$ & $7,692 \pm 2,829$ & $4,552 \pm 1,714$ & $2,567 \pm 1,041$ & $3,679 \pm 0,999$ \\
\hline $\mathbf{0 , 2} \mathbf{~ m L}$ & $4,630 \pm 1,089$ & $2,949 \pm 1,045$ & $2,058 \pm 0,640$ & $2,633 \pm 0,728$ \\
\hline $\mathbf{0 , 3} \mathbf{~ m L}$ & $3,804 \pm 0,628$ & $2,369 \pm 0,799$ & $1,423 \pm 0,654$ & $2,663 \pm 0,350$ \\
\hline $\mathbf{0 , 4} \mathbf{~ m L}$ & $3,156 \pm 0,725$ & $1,958 \pm 0,612$ & $0,712 \pm 0,697$ & $12,760 \pm 5,807$ \\
\hline
\end{tabular}


Tabela 4.7. Valores de $H_{t}\left(\mathrm{cmH}_{2} \mathrm{O} / \mathrm{mL} / \mathbf{s}^{(1-\alpha)}\right)$ (média \pm desvio padrão) para a aproximação no domínio do tempo do modelo de fase constante.

\begin{tabular}{|c|c|c|c|c|}
\hline $\begin{array}{c}\text { Amplitude } \\
\text { perturbação } \\
\downarrow\end{array}$ & $P E E P\left(0 \mathrm{cmH}_{2} \mathrm{O}\right.$ & PEEP $3 \mathrm{cmH}_{2} \mathrm{O}$ & PEEP $6 \mathrm{cmH}_{2} \mathrm{O}$ & PEEP $9 \mathrm{cmH}_{2} \mathrm{O}$ \\
\hline $0,1 \mathrm{~mL}$ & $31,696 \pm 8,321$ & $23,094 \pm 6,723$ & $21,624 \pm 2,666$ & $47,287 \pm 4,898$ \\
\hline $0,2 \mathrm{~mL}$ & $26,883 \pm 5,074$ & $22,473 \pm 6,325$ & $24,196 \pm 2,267$ & $65,338 \pm 7,833$ \\
\hline $0,3 \mathrm{~mL}$ & $25,343 \pm 4,008$ & $22,315 \pm 6,573$ & $32,301 \pm 6,754$ & $78,319 \pm 9,172$ \\
\hline $0,4 \mathrm{~mL}$ & $25,933 \pm 8,399$ & $25,745 \pm 9,614$ & $46,615 \pm 7,560$ & $72,992 \pm 7,909$ \\
\hline
\end{tabular}

As diferenças percentuais entre os parâmetros $R_{a w}, G_{t}$ e $H_{t}$ estimados pelo modelo de fase constante (Equação 2.18) e pela sua aproximação no domínio do tempo (Equação 4.17) foram calculadas para cada combinação de amplitude de perturbação e nível de PEEP. Os resultados são apresentados nas Figura 4.5 a 4.7.

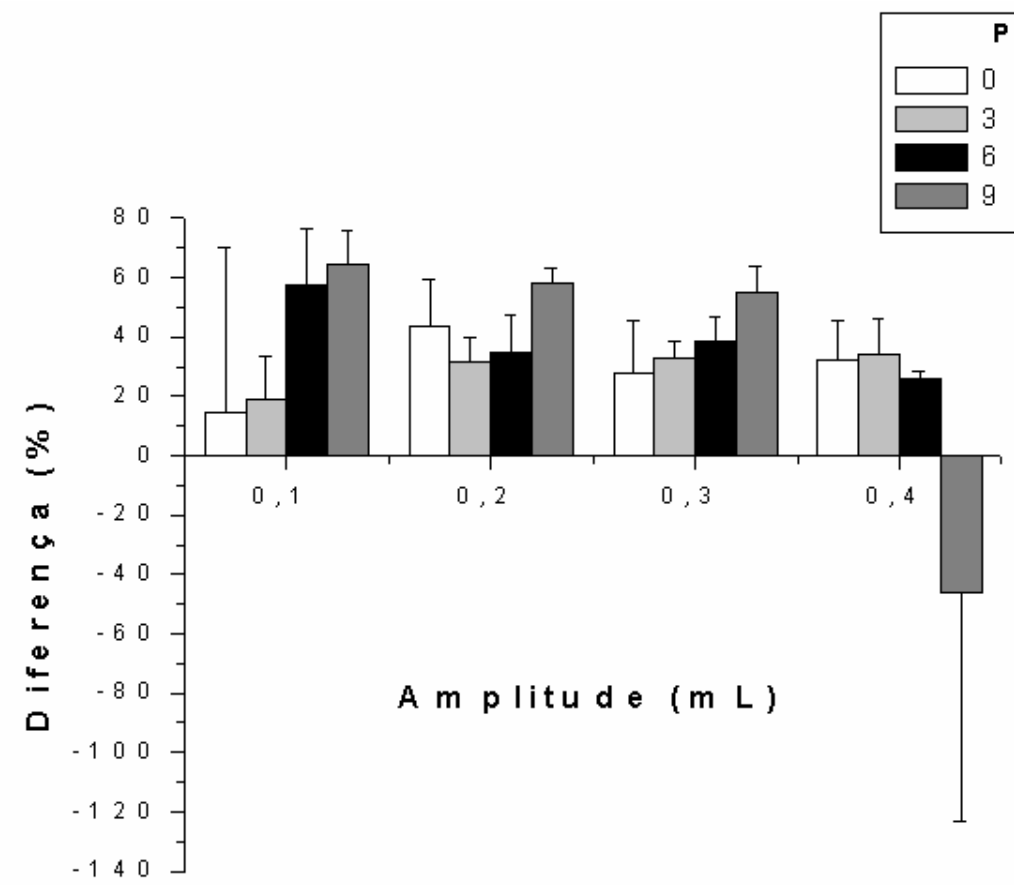

Figura 4.5. Diferenças percentuais entre os valores de resistência $\left(\boldsymbol{R}_{a w}\right)$ estimados pelo modelo de fase constante no domínio da freqüência (Equação 2.18) e a aproximação do modelo de fase constante no domínio do tempo (Equação 4.17). 


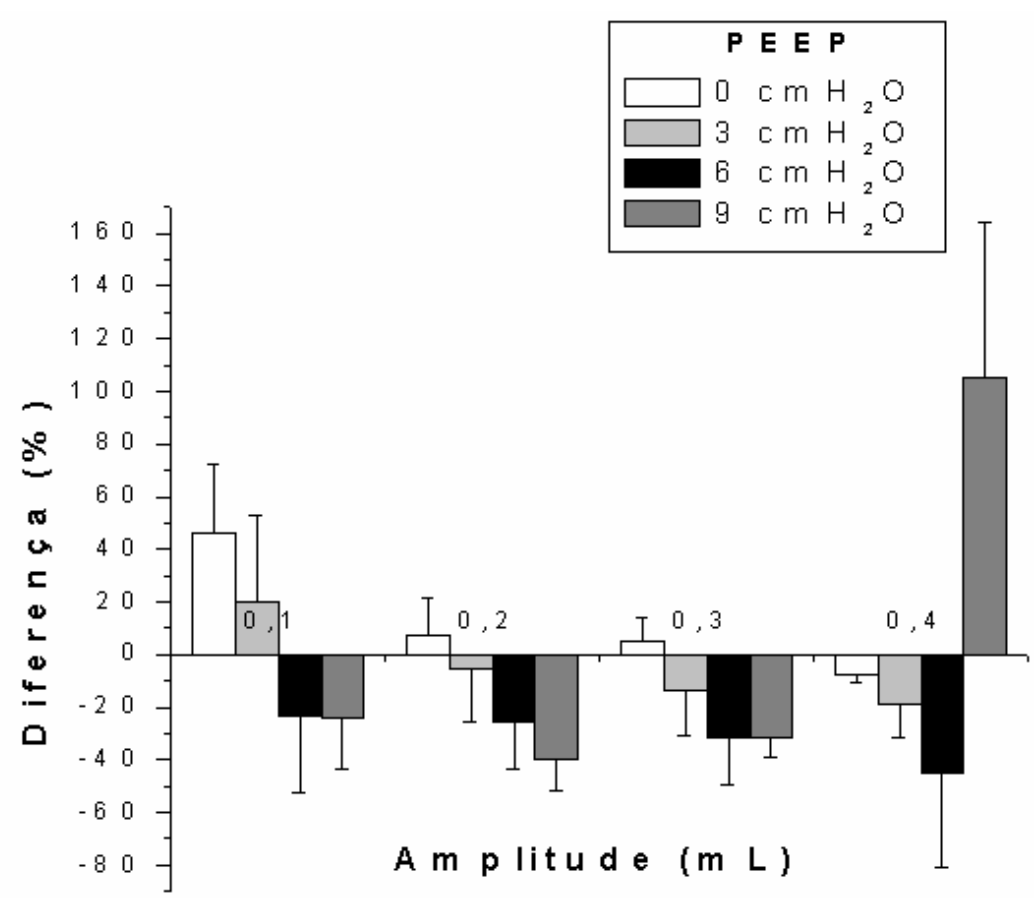

Figura 4.6. Diferenças percentuais entre os valores de $G_{t}$ estimados pelo modelo de fase constante no domínio da freqüência (Equação 2.18) e a aproximação do modelo de fase constante no domínio do tempo (Equação 4.17).

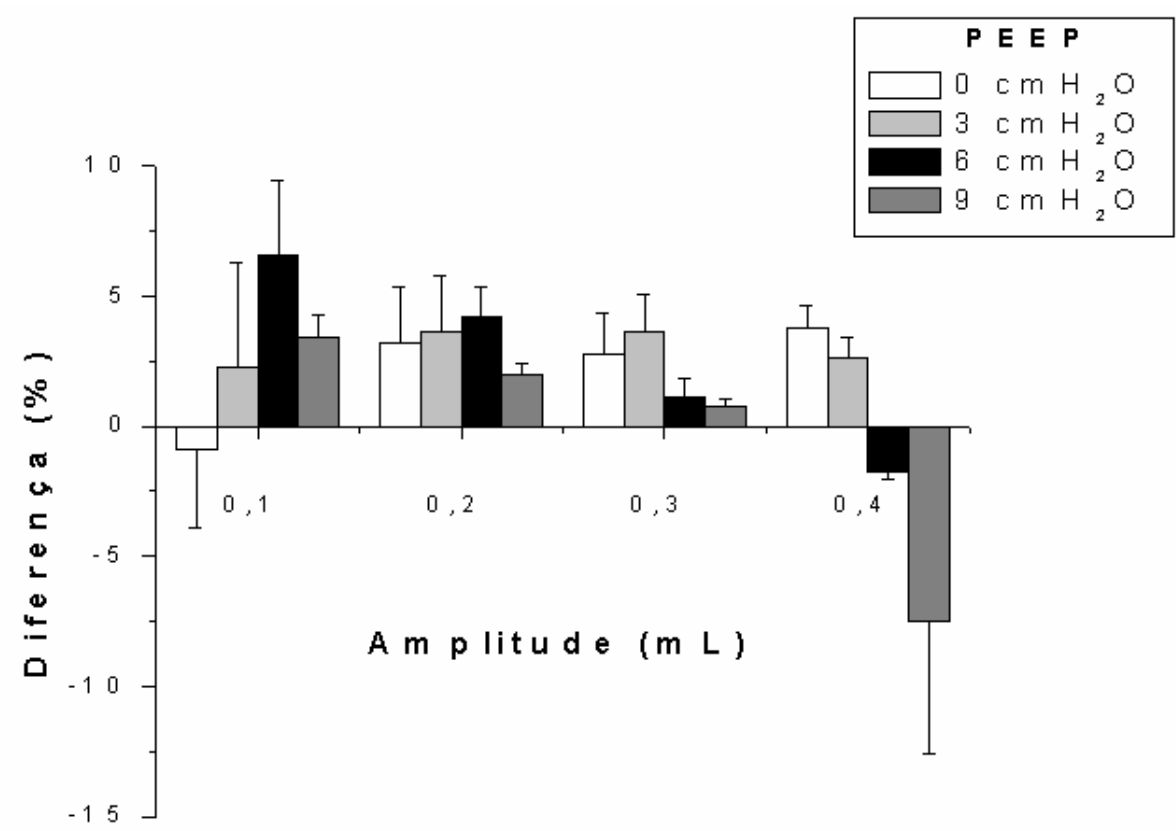

Figura 4.7. Diferenças percentuais entre os valores de $H_{t}$ estimados pelo modelo de fase constante no domínio da freqüência (Equação 2.18) e a aproximação do modelo de fase constante no domínio do tempo (Equação 4.17). 
Com uma amplitude de perturbação de $0,4 \mathrm{~mL}$ e uma $P E E P$ de $9 \mathrm{cmH}_{2} \mathrm{O}$, obteve-se uma mudança muito significativa e repentina nas diferenças entre os parâmetros relacionados aos tecidos $G_{t}$ e $H_{t}$. Suspeita-se que isto possa refletir o começo de um dano pulmonar devido à hiperinflação. Desta forma, os dados coletados sob estas condições não foram considerados para os cálculos e análises. Para os dados restantes, as diferenças percentuais em $H_{t}$ vão desde $0,73 \%$ em uma amplitude de $0,3 \mathrm{~mL}$ e uma PEEP de $9 \mathrm{cmH}_{2} \mathrm{O}$ até $6,56 \%$ em $0,1 \mathrm{~mL}$ e $6 \mathrm{cmH}_{2} \mathrm{O}$. As diferenças percentuais em $G_{t}$ vão de $5,13 \%$ em $0,2 \mathrm{~mL}$ e $3 \mathrm{cmH}_{2} \mathrm{O}$ a $45,81 \%$ em 0,1 $\mathrm{mL}$ e PEEP de $0 \mathrm{cmH}_{2} \mathrm{O}$. A menor diferença percentual de $R_{a w}$ é de $14,25 \%$ em $0 \mathrm{cmH}_{2} \mathrm{O}$ e $0,1 \mathrm{~mL}$, enquanto a maior diferença percentual é de $64,43 \%$ em $9 \mathrm{cmH}_{2} \mathrm{O}$ e $0,1 \mathrm{~mL}$.

\section{4. ÍNDICE DE NÃO-LINEARIDADE DO SISTEMA RESPIRATÓRIO MODELADO}

A Figura 4.8 apresenta o índice de não-linearidade $k_{d}$ (Equação 3.11) para as diversas amplitudes de perturbação e níveis de PEEP estudados.

$\mathrm{O}$ índice $k_{d}$ não depende, de uma forma estatisticamente significativa (ANOVA, comparação post-hoc Tukey), das amplitudes de perturbação ou das PEEP. O APÊNDICE I apresentado após a LISTA DE REFERÊNCIAS fornece os resultados gerados pelo software SigmaStat neste teste. 


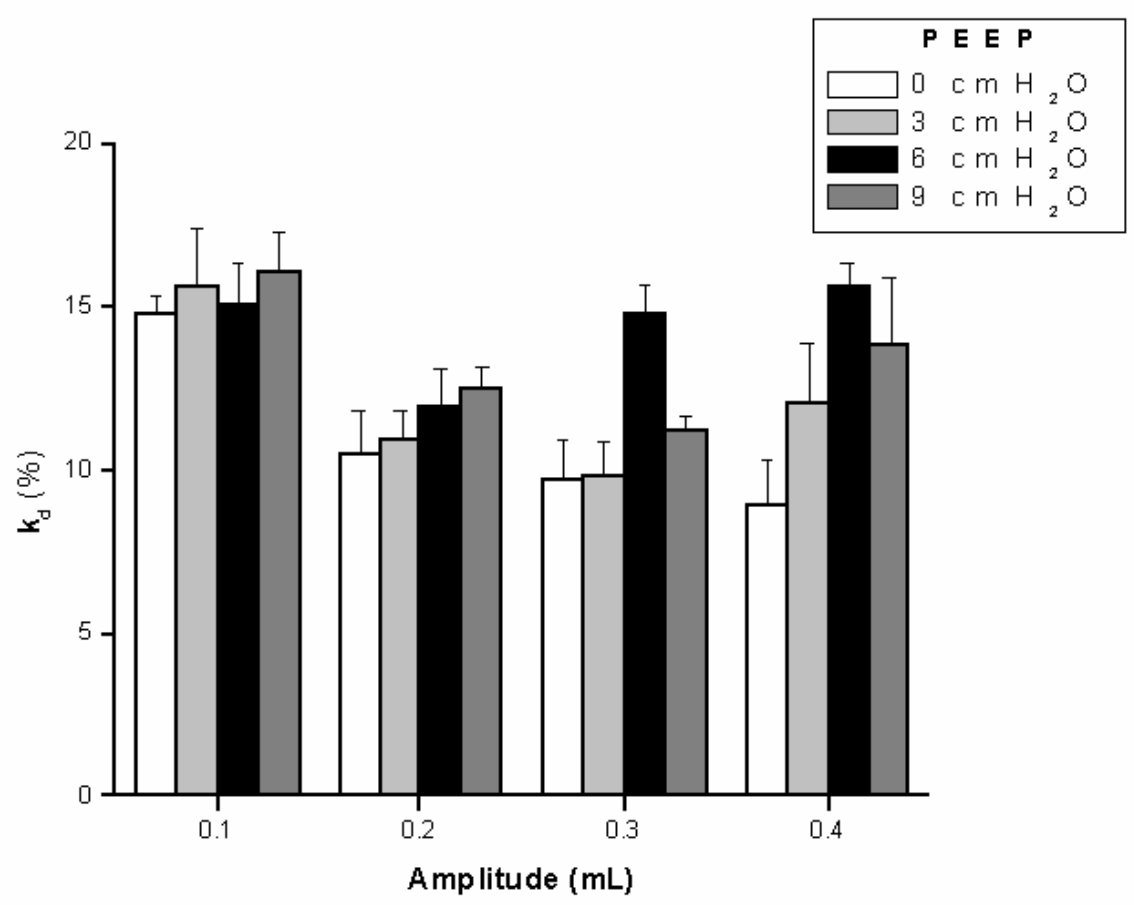

Figura 4.8. Índice de não-linearidade $k_{d}$ (Equação 3.11) para as diversas amplitudes de perturbação e níveis de $P E E P$ estudados.

\subsection{EXTENSÕES NÃO-LINEARES DA APROXIMAÇÃO NO DOMÍNIO DO TEMPO DO MODELO DE FASE CONSTANTE}

Dois outros modelos matemáticos não-lineares foram gerados a partir da aproximação no domínio do tempo do modelo de fase constante.

Adicionando-se a não-linearidade proposta por Rohrer à Equação 4.17, obtém-se um modelo com resistência não-linear:

$$
P_{a o}(t)=R_{1} \cdot \dot{V}(t)+R_{2} \cdot \dot{V}(t) \cdot|\dot{V}(t)|+A \cdot V(t)-A \cdot k \cdot\{\dot{V}(t) \otimes[\ln (t) \cdot d(t)]\}+P_{0}
$$


Um termo não-linear ad hoc na forma de uma elastância dependente do volume $\left[E \cdot V^{2}(t)\right]$ foi adicionado à Equação 4.17, gerando um modelo com elastância não-linear:

$$
P_{a o}(t)=R_{a w} \cdot \dot{V}(t)+E \cdot V^{2}(t)+A \cdot V(t)-A \cdot k \cdot\{\dot{V}(t) \otimes[\ln (t) \cdot d(t)]\}+P_{0}
$$

\subsection{COMPARAÇÃO ENTRE A APROXIMAÇÃO NO DOMÍNIO DO TEMPO DO MODELO DE FASE CONSTANTE E SUAS VARIAÇÕES NÃO-LINEARES}

Os dados experimentais foram ajustados à aproximação no domínio do tempo do modelo de fase constante (Equação 4.17) e as suas variações não-lineares com resistência dependente do fluxo (Equação 4.19) e com elastância dependente do volume (Equação 4.20).

$\triangle E N V$ foi calculada para comparar a aproximação do modelo de fase constante com cada variação não-linear.

A Figura 4.9 apresenta um exemplo da aplicação da variação não-linear da aproximação no domínio do tempo do modelo de fase constante com resistência dependente do fluxo (Equação 4.19) aos dados experimentais utilizando o software ANADAT versão 5.2. 


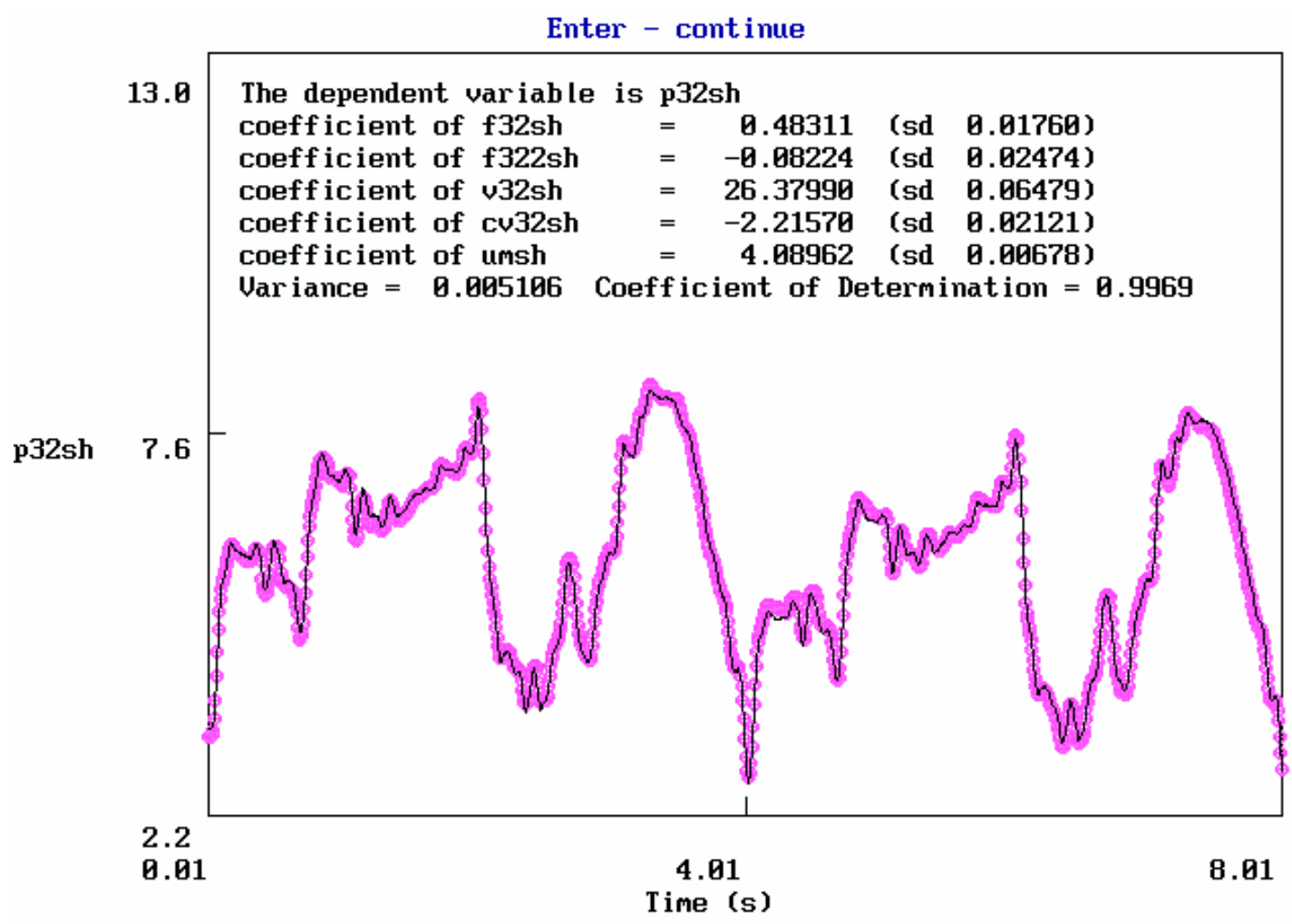

Figura 4.9. Exemplo de aplicação da variação não-linear da aproximação no domínio do tempo do modelo de fase constante com a resistência dependente do fluxo (Equação 4.19) aos dados experimentais obtidos (camundongo número 2, PEEP $3 \mathrm{cmH}_{2} \mathrm{O}$ e amplitude de $0,2 \mathrm{~mL}$ ).

Na Figura 4.9, o valor de $R_{1}$ é de $0,48311 \pm 0,01760 \mathrm{cmH}_{2} \mathrm{O} / \mathrm{mL} / \mathrm{s}$, o valor de $R_{2}$ é de $-0,08224 \pm 0,02474 \quad \mathrm{cmH}_{2} \mathrm{O} / \mathrm{mL}^{2} / \mathrm{s}^{2}$, o valor de $A$ é de $26,37990 \pm 0,06479 \quad \mathrm{cmH}_{2} \mathrm{O} / \mathrm{mL}, \quad$ o valor de $A \cdot k$ é de $2,21570 \pm 0,02121 \mathrm{cmH}_{2} \mathrm{O} / \mathrm{mL}$, o valor de $P_{0}$ é de $4,08962 \pm 0,00678 \mathrm{cmH}_{2} \mathrm{O}$ e o valor de $E N V$ é de 0,005106 .

Os valores de $\triangle E N V$ para a comparação entre a aproximação do modelo de fase constante e a aproximação não-linear com resistência dependente do fluxo são apresentados na Figura 4.10 para cada amplitude de perturbação e nível de $P E E P$ investigado. 


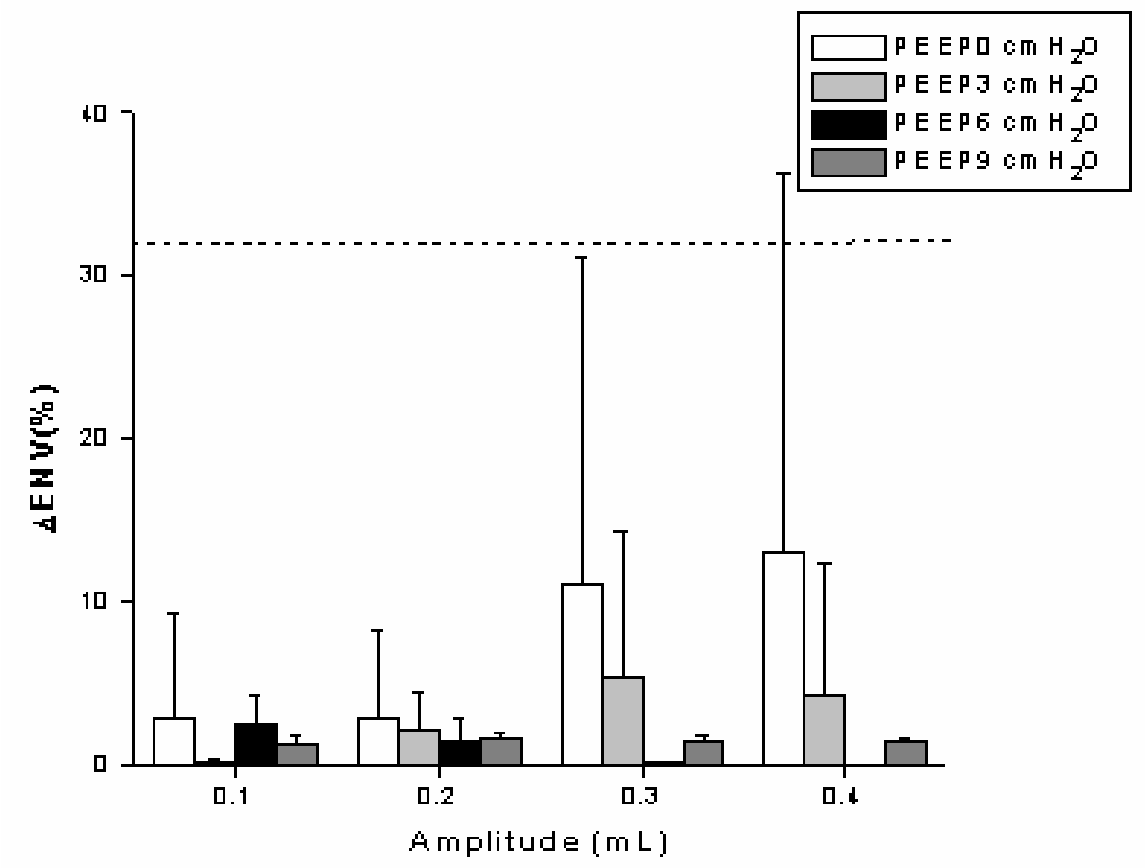

Figura 4.10. Comportamento de $\triangle E N V$ com a adição do termo referente à resistência dependente do fluxo em relação à aproximação no domínio do tempo do modelo de fase constante.

No caso da adição do termo referente à resistência dependente do fluxo, a maioria dos casos produz um valor de $\triangle E N V$ bem abaixo do nível de $30 \%$. Somente os dados referentes ao menor valor de PEEP nas duas maiores amplitudes de perturbação se aproximam do valor de $30 \%$.

A Figura 4.11 apresenta um exemplo da aplicação da variação não-linear da aproximação no domínio do tempo do modelo de fase constante com elastância dependente do volume (Equação 4.20) aos dados experimentais utilizando o software ANADAT versão 5.2. 


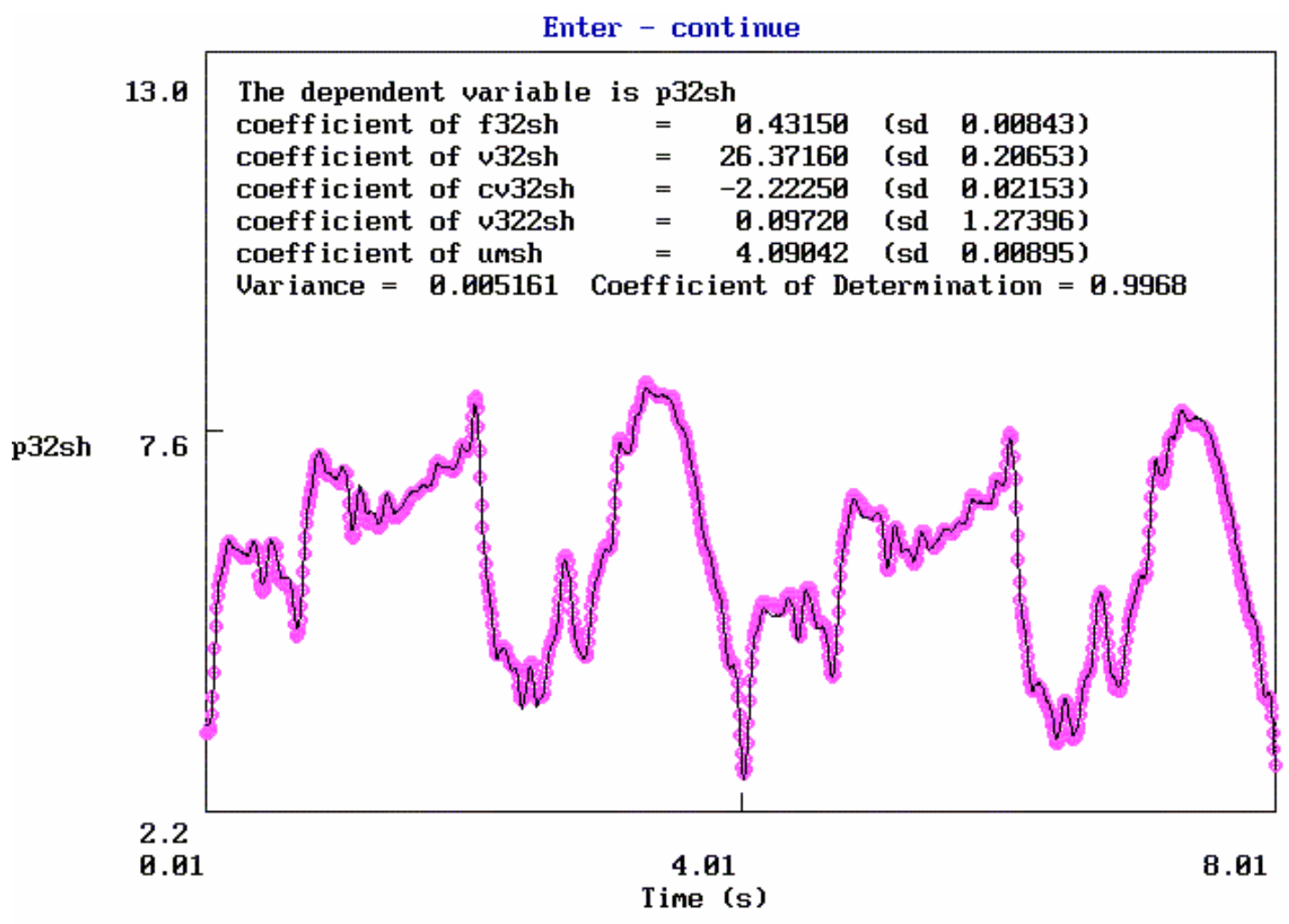

Figura 4.11. Exemplo de aplicação da variação não-linear da aproximação no domínio do tempo do modelo de fase constante com a elastância dependente do volume (Equação 4.20) aos dados experimentais obtidos (camundongo número 2, PEEP $3 \mathrm{cmH}_{2} \mathrm{O}$ e amplitude de $0,2 \mathrm{~mL}$ ).

Na Figura 4.11, o valor de $R_{a w}$ é de $0,43150 \pm 0,00843 \mathrm{cmH}_{2} \mathrm{O} / \mathrm{mL} / \mathrm{s}$, o valor de $A$ é de 26,37160 $\pm 0,20653 \mathrm{cmH}_{2} \mathrm{O} / \mathrm{mL}$, o valor de $A \cdot k$ é de $2,22250 \pm 0,02153 \mathrm{cmH}_{2} \mathrm{O} / \mathrm{mL}$, o valor de $E$ é de $0,09720 \pm 1,27396 \mathrm{cmH}_{2} \mathrm{O} / \mathrm{mL}^{2}$, o valor de $P_{0}$ é de 4,09042 $\pm 0,00895 \mathrm{cmH}_{2} \mathrm{O}$ e o valor de $E N V$ é de 0,005161 .

A Figura 4.12 mostra como se comporta o $\triangle E N V$ quando da adição da elastância não-linear à aproximação no domínio do tempo do modelo de fase constante (Equação 4.20). 


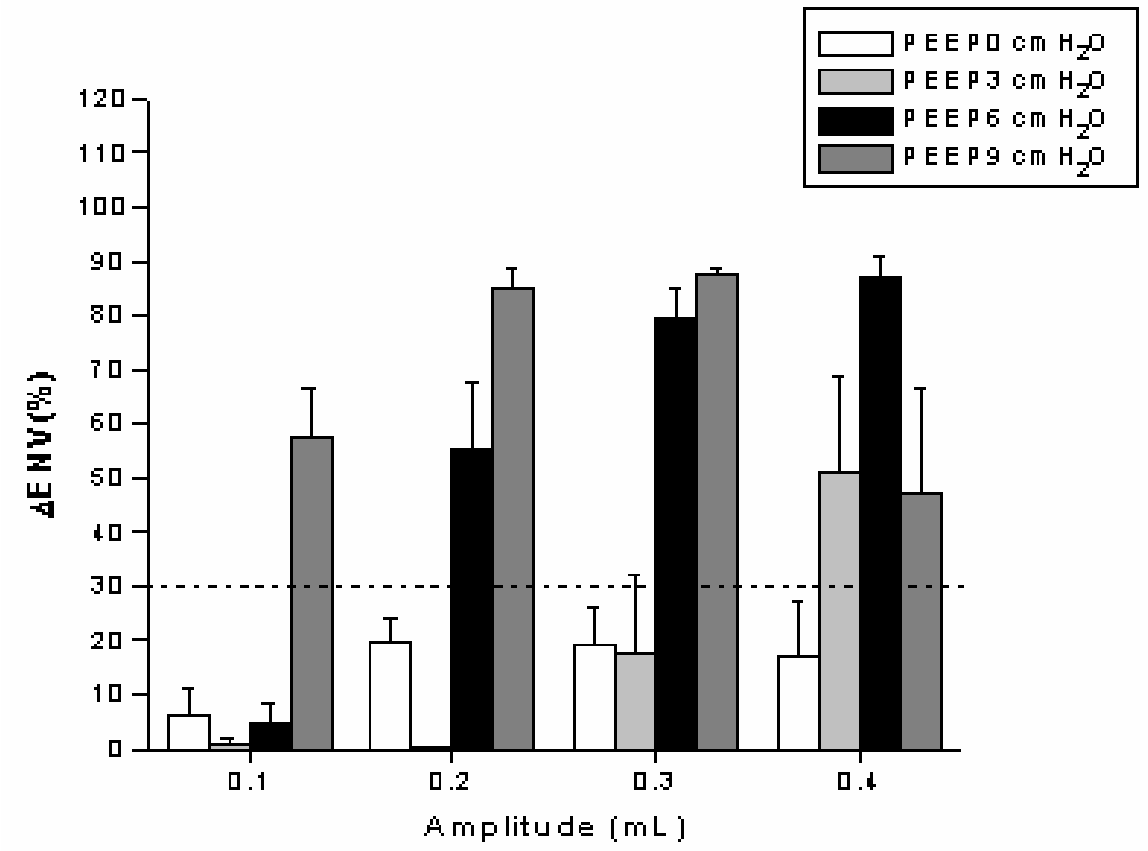

Figura 4.12. Comportamento de $\triangle E N V$ com a adição do termo referente à elastância dependente do volume em relação à aproximação no domínio do tempo do modelo de fase constante.

No caso da adição da elastância dependente do volume, verifica-se que várias situações levaram a valores de $\triangle E N V$ que excederam substancialmente o valor de $30 \%$.

\subsection{ARTIGOS PUBLICADOS E ACEITOS PARA PUBLICAÇÃO INTERNACIONAL}

Um resumo de um trabalho parcialmente relacionado com esta pesquisa (Kaminsky et al., 2001) foi apresentado sob a forma de pôster e publicado nos anais da American Thoracic Society (ATS) - 97 International Conference realizada entre os dias 18 e 23 de maio de 2001 em San Francisco, CA - EUA. 
$\mathrm{Na} A T S-98^{\text {th }}$ International Conference realizada entre os dias 17 e 22 de maio de 2002 em Atlanta, GA - EUA, foram apresentados sob a forma de pôsteres e publicados nos anais, dois resumos de trabalhos parcialmente relacionados com esta pesquisa (Kaminsky et al., 2002) e (Bates et al., 2002).

Um resumo relacionado diretamente à esta pesquisa (Moriya et al., 2001) foi apresentado e publicado nos anais do Annual Fall Meeting da Biomedical Engineering Society (BMES) realizado entre os dias 4 e 7 de outubro de $2001 \mathrm{em}$ Durham, NC - EUA.

Um artigo parcialmente relacionado com esta pesquisa (Wagers et al., 2002) foi publicado no Journal of Applied Physiology.

Esta pesquisa resultou, ainda, na produção de um artigo (Moriya et al., no prelo) que foi submetido à revista Annals of Biomedical Engineering da BMES e, posteriormente, aceito para publicação. O texto deste artigo encontra-se no APÊNDICE II. 


\section{DISCUSSÃO}

O uso do modelo de fase constante (Equação 2.18) para interpretar medidas de impedância respiratória tem conseguido uma grande repercussão recentemente (Hantos et al., 1992); (Gomes et al., 2000); (Bijaoui et al., 2001) e (Peták et al., 2002). Entretanto, a aplicação deste modelo supõe um comportamento dinâmico linear por parte do sistema respiratório (Michaelson et al., 1975); (Peslin e Fredberg, 1986). De fato, quando as oscilações impostas são de pequena amplitude, pode-se assumir o comportamento do sistema respiratório como sendo linear. Entretanto, um comportamento não-linear da mecânica respiratória pode se tornar aparente em valores normais de volumes correntes, especialmente quando o valor da PEEP é elevado (Hantos et al., 1992) ; (Kano et al., 1994); (Bersten, 1998); (Vassiliou et al., 2000) e (Wagers et al., 2002). Conseqüentemente, para que a condição de comportamento linear seja respeitada, geralmente utilizam-se amplitudes de oscilações que são consideravelmente menores que os valores normais do volume corrente.

Esta prática não pode evidentemente ser aplicada para fluxos tipo $O V W$ que, por definição, utilizam amplitudes comparáveis aos volumes correntes normais. Lutchen e colaboradores (1993b) empregaram uma técnica interessante para tratar com as não-linearidades quando utilizando fluxos tipo $O V W$. Esta técnica consiste em fazer com que os fluxos tipo $O V W$ apresentem somente componentes que satisfaçam o critério NSND (Suki e Lutchen, 1992) e calcular a impedância respiratória utilizando somente as freqüências presentes no sinal de fluxo excitatório. 
Isto significa que são descartadas todas as harmônicas do sinal de resposta (pressão) produzidas passando o sinal excitatório de fluxo por um sistema não-linear.

O problema com esta técnica é que uma quantidade significativa de informações sobre o sistema pode não estar sendo avaliada se as não-linearidades forem relevantes.

O objetivo desta pesquisa foi desenvolver um método capaz de encapsular o comportamento mecânico do sistema respiratório de um modo a reter pelo menos alguma parte desta informação sobre as não-linearidades presentes. Esta análise poderia ter sido realizada no domínio da freqüência utilizando séries de Volterra (Suki e Bates, 1991); (Korenberg e Hunter, 1996) e (Zhang et al., 1999). Entretanto, estas séries tornam-se rapidamente intratáveis e a interpretação fisiológica de seus vários termos é geralmente impossível. Suki e colaboradores (1995) investigaram uma abordagem alternativa no domínio do tempo, na qual modelos não-lineares estruturados em blocos foram ajustados a dados experimentais obtidos com cachorros. Maksym e Bates (1997) aplicaram uma abordagem similar para dados obtidos com pulmões de ratos. Entretanto, mais uma vez, não é óbvio como interpretar os elementos desses modelos em termos fisiológicos. Outro problema é que o processo de ajuste dos dados aos modelos possui uma certa complexidade computacional, necessitando a realização de iterações entre os domínios do tempo e da freqüência. Logo, decidiu-se desenvolver um modelo paramétrico não-linear dependente em freqüência no domínio do tempo e que utilizasse uma técnica simples de estimação de parâmetros.

Os modelos desenvolvidos neste trabalho foram deduzidos de um modelo linear no domínio da freqüência cuja utilização e interpretação são bastante 
reconhecidas (Hantos et al., 1992); (Gomes et al., 2000) e (Peták et al., 2002). Embora este modelo tenha sido proposto especificamente para a descrição dos pulmões (Hantos et al., 1992), mostrou-se que este modelo também fornece uma boa descrição do sistema respiratório como um todo, incluindo a caixa torácica (Gomes et al., 2000). Outra vantagem desses modelos desenvolvidos é que, com a utilização de uma expansão exponencial truncada (Equação 4.10), foi possível a utilização da técnica de regressão múltipla linear para ajustar os dados experimentais aos modelos utilizados. Esta abordagem tornou a tarefa computacional bastante simples.

O primeiro passo no processo de desenvolvimento dos novos modelos matemáticos foi refazer o modelo linear de fase constante no domínio do tempo. Não tratou-se de um processo trivial, pois o modelo de fase constante apresenta uma resposta impulsiva infinita em $t=0$. Logo, desenvolveu-se uma aproximação do modelo de fase constante no domínio do tempo que utiliza a operação de convolução com os dois primeiros termos de um expansão em série de potências. Para evitar valores infinitos, iniciou-se a resposta impulsiva em $t=0,01 \mathrm{~s}$.

Para verificar se a aproximação adotada (Equação 4.10) era válida para os propósitos desta pesquisa, $z_{t i}(t)$ foi calculada no intervalo de tempo dos sinais utilizados $(t=0,01 \mathrm{~s}$ até $8,01 \mathrm{~s})$ utilizando a Equação 4.7 e a aproximação realizada na Equação 4.10 com o valor de $k$ igual a 0,1 . Como as duas estimativas concordaram neste intervalo de 8 segundos dentro de um erro médio de 1,2\% com um desvio-padrão de $0,9 \%$, concluiu-se que a aproximação realizada para o cálculo de $z_{t i}(t)$ é suficientemente precisa para a finalidade desejada nesta pesquisa.

A inertância $\left(I_{a w}\right)$ presente no modelo de fase constante reflete principalmente a massa de gás nas vias aérea centrais (Peslin; Fredberg, 1986). Já 
havia sido demonstrado anteriormente que o termo $I_{a w}$ é desprezível em dados experimentais coletados junto a camundongos com freqüência abaixo de $10 \mathrm{~Hz}$ (Gomes et al., 2000). Estes resultados foram confirmados nesta pesquisa, pois observa-se na Tabela 4.1 que os valores obtidos de $I_{a w}$ são bastante baixos. Além disso, a Figura 4.3 mostra que a adição do termo relativo à inertância não representa uma melhora significativa à aproximação do modelo de fase constante no domínio do tempo (Equação 4.17), pois os valores de $\triangle E N V$ encontrados são muito inferiores à $30 \%$.

Os parâmetros do modelo de fase constante (Equação 2.18) variaram com a amplitude de perturbação e com o nível de PEEP de modo característico, como pode ser observado nas Tabelas 4.2 a 4.4. Por exemplo, o valor de $H_{t}$ foi mínimo em um valor intermediário de PEEP $\left(3 \mathrm{cmH}_{2} \mathrm{O}\right.$ em três amplitudes de perturbação investigadas e $6 \mathrm{cmH}_{2} \mathrm{O}$ na amplitude de perturbação remanescente). Este comportamento havia sido descrito anteriormente (Gomes et al., 2000) e acredita-se que seja devido ao endurecimento dos tecidos em valores elevados de $P E E P$ e, em um certo grau, ao fechamento alveolar para PEEP de $0 \mathrm{cmH}_{2} \mathrm{O}$. O parâmetro $G_{t}$ apresenta um padrão similar ao apresentado por $H_{t}$, devido aos mesmos motivos apresentados para o comportamento de $H_{t}$. A resistência $R_{a w}$ apresenta um comportamento instigador aumentando tanto com a PEEP como com a amplitude de perturbação. Se $R_{a w}$ fosse somente uma medida da resistência das vias aéreas, deveria se esperar que o comportamento de $R_{a w}$ fosse o oposto, já que as vias aéreas aumentam de tamanho com o aumento do volume pulmonar. Entretanto, é possível que os valores de $R_{a w}$ obtidos incluam alguma contribuição da caixa torácica. Este 
fato pode ser mais relevante em camundongos do que em outras espécies, pois camundongos apresentam vias aéreas relativamente grandes quando comparadas ao tamanho dos seus pulmões (Gomes et al., 2000), o que pode fazer com que os efeitos de seus tecidos em $R_{a w}$ sejam relativamente mais importantes do que em outras espécies.

A seguir tratou-se de comparar o modelo de fase constante no domínio da freqüência (Equação 2.18) com sua aproximação no domínio do tempo (Equação 4.17), com o intuito de verificar a equivalência entre os mesmos.

As versões do modelo de fase constante no domínio da freqüência (Equação 2.18) e no domínio do tempo (Equação 4.17) tratam os dados de forma diferente, pois minimizar os quadrados dos resíduos entre os valores preditos e calculados de $Z_{r s}$ não é equivalente a minimizar os resíduos entre os valores medidos e estimados de $P_{a o}$. Conseqüentemente, esperava-se que qualquer erro nos dados ou nos modelos afetasse os parâmetros de forma diferente no dois domínios. Então, deveria-se também esperar que as diferenças entre os parâmetros dos modelos obtidos em domínios diferentes aumentassem com grau de não-linearidade dos dados.

Entretanto, o que ocorreu no maior valor de PEEP e amplitude de perturbação, foi que as diferenças entre os parâmetros apresentaram um sinal oposto ao encontrado nos outros casos. Suspeita-se que este resultado seja devido à mudança no estado dos pulmões induzida pela hiperdistensão. A impressão que se teve durante os experimentos foi a de que os camundongos não estavam sendo ventilados de maneira eficiente nestas condições, por isso aplicou-se o maior valor de PEEP somente após os outros dados terem sido coletados. Para as outras situações apresentadas nas Figuras 4.5 a 4.7, existe uma sugestão que as diferenças entre os 
parâmetros aumente com a $P E E P$. Entretanto, os efeitos não são marcantes e por isso não pode-se concluir nada sobre este comportamento.

O parâmetro $H_{t}$ que caracteriza a energia armazenada nos tecidos apresenta as menores diferenças percentuais entre os modelos no domínio da freqüência e do tempo (Figura 4.7). Este resultado pode ser explicado pelo fato de que a maior parte do sinal $P_{a o}$ produzido pelas perturbações reflete a energia elástica armazenada, pois a maior parte da potência do sinal $V$ contém componentes de baixas freqüências. Conseqüentemente, $H_{t}$ é o melhor termo determinado pelos dados experimentais e apresenta a maior taxa sinal/ruído. Por outro lado, as maiores diferenças percentuais ocorrem em $R_{a w}$, que é o valor assintótico da parte real quando a freqüência tende ao infinito. $R_{a w}$ é então o parâmetro mais difícil de ser determinado pelos dados experimentais e portanto tende a ter a menor taxa sinal/ruído. Apesar disso, os dois modelos produzem valores de parâmetros pelo menos comparáveis nas condições investigadas.

O passo seguinte na metodologia consistiu em adicionar a capacidade para a aproximação no domínio do tempo do modelo de fase constante levar em consideração efeitos não-lineares.

Estudos prévios (Kano et al., 1994); (Bersten, 1998); (Muramatsu et al. 2001) e (Wagers et al., 2002) mostraram que a mais importante não-linearidade presente durante a ventilação mecânica é invariavelmente uma elastância dependente do volume. Logo, foi adicionado um termo ad hoc em $V^{2}$ ao modelo. Avaliou-se então a necessidade deste termo extra, em cada caso particular de PEEP e amplitude empregados, examinando-se quanto foi a melhora no ajuste dos dados ( $\triangle E N V)$. 
Verificou-se que o ajuste aos dados experimentais melhorava significativamente quando tanto a amplitude da perturbação como a PEEP aumentavam (Figura 4.12). Isto é explicável com base no fato dos tecidos respiratórios assumirem progressivamente um enrijecimento, fazendo com que suas propriedades pressãovolume se tornem cada vez mais não-lineares (Dechman et al., 1994); (Kano et al., 1994); (Bersten, 1998); (Muramatsu et al., 2001) e (Wagers et al., 2002).

Também examinou-se os efeitos da adição de um termo com resistência dependente do fluxo à aproximação do modelo de fase constante no domínio do tempo. Na maioria dos casos, essa adição teve um efeito mínimo em $\triangle E N V$ (Figura 4.10). Cabe observar que os $\triangle E N V$ obtidos com a resistência dependente do fluxo foram maiores nos dois maiores valores de amplitude da perturbação e nos menores níveis de PEEP. Esse resultado é consistente com a hipótese de que o fluxo turbulento nas vias aéreas tem maior probabilidade de ocorrer em valores altos de fluxo (produzidos pelas altas amplitudes de perturbação) passando através de vias aéreas estreitas (em baixos valores de volume pulmonar). 


\section{CONCLUSÕES}

A aproximação no domínio do tempo do modelo de fase constante (Equação 4.17) e suas variações não-lineares (Equações 4.19 e 4.20) são modelos paramétricos no domínio do tempo que não apresentam precedentes na literatura e permitiram a avaliação da mecânica respiratória com o emprego de oscilações forçadas em camundongos de forma inovadora.

Esta pesquisa originou diversos resumos e dois artigos que foram aceitos para publicação internacional. Parte desta pesquisa foi apresentada no 2001 Annual Fall Meeting da BMES realizado em Durham, NC - EUA de 4 a 7 de outubro de 2001 (Moriya et al., 2001). Um artigo que resume a pesquisa apresentada (Moriya et al., no prelo) foi aceito para publicação na revista Annals of Biomedical Engineering da $B M E S$, este artigo encontra-se no APÊNDICE II. Vários resumos de trabalhos parcialmente relacionados com esta pesquisa foram publicados em congressos internacionais (Kaminsky et al., 2001); (Kaminsky et al., 2002) e (Bates et al., 2002) e um artigo também parcialmente relacionado com esta pesquisa foi publicado (Wagers et al., 2002).

A aplicação dos modelos desenvolvidos mostrou que, em camundongos normais, a ventilação com fluxos tipo $O V W$ produz um comportamento mecânico no sistema respiratório que vai se tornando cada vez mais não-linear à medida que os valores de $P E E P$ e amplitude de perturbação são aumentados. Embora estas nãolinearidades possam ser negligenciadas utilizando-se uma forma de onda criada para evitar as distorções harmônicas, uma parte significativa e interessante dos dados pode ser descartada. Em particular, monitorando-se a não-linearidade dependente em 
volume, pode-se detectar a hiperinsuflação dos pulmões, conforme também mostrado por Bersten (1998), ou o começo de patologias que fazem com que os tecidos pulmonares adquiram um comportamento elástico não-linear em valores de volumes menores que os normais.

Deve-se ressaltar que a utilização de uma análise no domínio do tempo levou à possibilidade de incorporação de parâmetros com certo significado fisiológico, o que usualmente não é possível quando se utiliza topologias tipo Hammerstein e Wiener na análise no domínio da freqüência como as utilizadas por Suki e colaboradores (1995).

Embora os dados analisados neste estudo tenham sido coletados sob condições estacionárias, os modelos propostos (Equações 4.17, 4.19 e 4.20) podem ser aplicados com a técnica de mínimos quadrados recursiva proposta por Lauzon e Bates (1991), permitindo, conseqüentemente, aplicações com dados nãoestacionários visando seguir as mudanças nos valores dos parâmetros dos modelos e permitindo uma melhor compreensão de comportamentos transitórios do sistema respiratório. 


\section{ANEXO A}

\section{OBTENÇÃO DA EQUAÇÃO 4.1}

Partindo-se da Equação 2.13:

$$
Z_{t i}(f)=\frac{G_{t}-j \cdot H_{t}}{(2 \cdot \pi \cdot f)^{\alpha}}
$$

e assumindo-se que:

$$
\omega=2 \cdot \pi \cdot f
$$

obtém-se:

$$
Z_{t i}(\omega)=\frac{G_{t}-j \cdot H_{t}}{\omega^{\alpha}}
$$

Como:

$$
G_{t}=A \cdot \Gamma(\alpha) \cdot \cos \left(\frac{\alpha \cdot \pi}{2}\right)
$$

$$
\text { e }
$$




$$
H_{t}=A \cdot \Gamma(\alpha) \cdot \operatorname{sen}\left(\frac{\alpha \cdot \pi}{2}\right)
$$

obtém-se:

$$
Z_{t i}(\omega)=\frac{A \cdot \Gamma(\alpha) \cdot \cos \left(\frac{\alpha \cdot \pi}{2}\right)-j \cdot A \cdot \Gamma(\alpha) \cdot \operatorname{sen}\left(\frac{\alpha \cdot \pi}{2}\right)}{\omega^{\alpha}}
$$

Rearranjando-se os termos, resulta:

$$
Z_{t i}(\omega)=\frac{A \cdot \Gamma(\alpha) \cdot\left[\cos \left(\frac{\alpha \cdot \pi}{2}\right)-j \cdot \operatorname{sen}\left(\frac{\alpha \cdot \pi}{2}\right)\right]}{\omega^{\alpha}}
$$

Utilizando a relação de Euler:

$$
Z_{t i}(\omega)=\frac{A \cdot \Gamma(\alpha) \cdot e^{-j \cdot \frac{\alpha \cdot \pi}{2}}}{\omega^{\alpha}}
$$

e, como:

$$
e^{-j \cdot \frac{\alpha \cdot \pi}{2}}=\left(e^{j \cdot \frac{\pi}{2}}\right)^{-\alpha}=j^{-\alpha}
$$


obtém-se:

$$
Z_{t i}(\omega)=\frac{A \cdot \Gamma(\alpha) \cdot j^{-\alpha}}{\omega^{\alpha}}
$$

Rearranjando-se os termos:

$$
Z_{t i}(\omega)=A \cdot \Gamma(\alpha) \cdot(j \cdot \omega)^{-\alpha}
$$

e utilizando-se o operador da transformada de Laplace:

$$
s=j \cdot \omega
$$

obtém-se:

$$
Z_{t i}(s)=A \cdot \Gamma(\alpha) \cdot(s)^{-\alpha}
$$

Assumindo-se que:

$$
\alpha=1-k
$$


obtém-se:

$$
Z_{t i}(s)=A \cdot \Gamma(1-k) \cdot(s)^{-(1-k)}
$$

Rearranjando-se os termos, resulta:

$$
Z_{t i}(s)=\frac{A \cdot \Gamma(1-k)}{s^{1-k}}
$$

Finalmente, observa-se que, segundo Hildebrandt (1969a), a anti-transformada de Laplace da Equação A.8b é dada pela seguinte expressão, alvo desta demonstração:

$$
z_{t i}(t)=A \cdot t^{-k} \cdot d(t)
$$




\section{LISTA DE REFERÊNCIAS}

ADLER, A.; AMYOT, R.; GUARDO, R.; BATES, J. H. T.; BERTHIAUME, Y. Monitoring changes in lung air and liquid volumes with electrical impedance tomography. Journal of Applied Physiology, v. 83, n. 5, p. 1762-237, 1997.

ADLER, A.; SHINOZUKA, N.; BERTHIAUME, Y.; GUARDO, R.; BATES, J. H. T. Electrical impedance tomography can monitor dynamic hyperinflation in dogs. Journal of Applied Physiology, v. 84, n. 2, p. 726-237, 1998.

AGOSTONI E.; RAHN, H. Abdominal and thoracic pressures at different lung volumes. Journal of Applied Physiology, v. 15, n. 6, p. 1087-1092, 1960.

ANTONAGLIA, V.; PERATONER, A.; SIMONI, L.; GULLO, A.; MILIC-EMILI, J.; ZIN, W. A. Bedside assessment of respiratory viscoelastic properties in ventilated patients. European Respiratory Journal, v. 16, p. 302-308, 2000.

AROLD, S. P.; MORA, R.; LUTCHEN, K. R.; INGENITO, E. P.; SUKI, B. Variable tidal volume ventilation improves lung mechanics and gas exchange in a rodent model of acute lung injury. American Journal of Respiratory and Critical Care Medicine, v. 165, n. 3, p. 366-371, 2002.

AVANZOLINI, G.; BARBINI, P.; CAPPELLO, A.; CEVENINI, G.; CHIARI, L. A new approach for tracking respiratory mechanical parameters in real-time. Annals of Biomedical Engineering, v. 25, p. 154-163, 1997.

BACHOFEN, H. Lung tissue resistance and pulmonary hysteresis. Journal of Applied Physiology, v. 24, p. 296-301, 1968.

BATES, J. H. T.; DECRAMER, M.; ZIN, W. A.; HARF, A.; MILIC-EMILI, J.; CHANG, H. K. Respiratory resistance with histamine challenge by single-breath and forced oscillation methods. Journal of Applied Physiology, v. 61, n. 3, p. 873$880,1986$.

BATES, J. H. T.; BACONNIER, P.; MILIC-EMILI, J. A theoretical analysis of interrupter technique for measuring respiratory mechanics. Journal of Applied Physiology, v. 64, n. 5, p. 2204-2214, 1988.

BATES, J. H. T.; BROWN, K. A.; KOCHI, T. Respiratory mechanics in the normal dog determined by expiratory flow interruption. Journal of Applied Physiology, v. 67, n. 6, p. 2276-2285, 1989.

BATES, J. H. T.; LAUZON, A.-M. A nonstatistical approach to estimating confidence intervals about model parameters: application to respiratory mechanics. IEEE Transactions on Biomedical Engineering, v. 39, n. 1, p. 94-100, 1992. 
BATES, J. H. T.; DARÓCZY, B.; HANTOS, Z. A comparison of interrupter and forced oscillation measurements of respiratory resistance in the dog. Journal of Applied Physiology, v. 72, n. 1, p. 46-52, 1992.

BATES, J. H. T.; MAKSYM, G. N.; NAVAJAS, D.; SUKI, B. Lung tissue rheology and 1/f noise. Annals of Biomedical Engineering, v. 22, p. 674-681, 1994.

BATES, J. H. T.; SCHUESSLER, T. F.; DOLMAN, C.; EIDELMAN, D. H. Temporal dynamics of acute isovolume bronchoconstriction in the rat. Journal of Applied Physiology, v. 82, n. 1, p. 55-62, 1997.

BATES, J. H. T. Assessment of mechanics. In: MARINI, J. J.; SLUTSKY, A. S.(Ed.) Physiological basis of ventilatory support. New York: Marcel Dekker, 1998. p. 231-259.

BATES, J. H. T.; WAGERS, S.; MORIYA, H. T.; YOUNG, M. Continuous monitoring of lung mechanics in mechanically ventilated patients: variability and reproducibility. American Journal of Respiratory and Critical Care Medicine, v. 165, n. 8, p.A180, 2002.

BAYDUR, A.; BEHRAKIS, P. K.; ZIN, W. A.; JAEGER, M.; MILIC-EMILI, J. A simple method for assessing the validity of the esophageal balloon technique. American Review of Respiratory Diseases, v. 126, p. 788-791, 1982.

BERGMAN, N. A.; WALTEMATH, C. L. A comparison of some methods for measuring total respiratory resistance. Journal of Applied Physiology, v. 36, n. 1, p. 131-134, 1974.

BERSTEN, A. D. Measurement of overinflation by multiple linear regression analysis in patients with acute lung injury. European Respiratory Journal, v. 12, p. 526-532, 1998.

BIJAOUI, E.; BACONNIER, P. F.; BATES, J. H. T. Mechanical output impedance of the lung determined from cardiogenic oscillations. Journal of Applied Physiology, v. 91, p. 859-865, 2001.

CHARTRAND, D. A.; YE, T. H.; MAAREK, J. M.; CHANG, H. K. Measurement of pleural pressure at low and high frequencies in normal rabbits. Journal of Applied Physiology, v. 63, n. 3, p. 1142-1146, 1987.

D'ANGELO, E. Statics of the respiratory system. In: MILIC-EMILI, J.; LUCANGELO U.; PESENTI, A.; ZIN, W. A.(Ed.) Basics of respiratory mechanics and artificial ventilation. Milan: Springer, 1999. p. 9-19.

DAMBROSIO, M.; ROUPIE, E.; MOLLET, J. J.; ANGLADE, M. C.; VASILE, N.; LEMAIRE, F.; BROCHARD, L. Effects of positive end-expiratory pressure and different tidal volumes on alveolar recruitment and hyperinflation. Anesthesiology, v. 87, n. 3 , p. $495-503,1997$. 
DARÓCZY, B.; HANTOS, Z. Generation of optimum pseudorandom signals for respiratory impedance measurements. International Journal of Biomedical Computing, v. 25, p. 21-31, 1990.

DAVEY, B. L. K.; BATES, J. H. T. Regional lung impedance from forced oscillations through alveolar capsules. Respiration Physiology, v. 91, p. 165-182, 1993.

DECHMAN, G.; SATO, J.; BATES, J. H. T. Factors affecting the accuracy of esophageal balloon measurement of pleural pressure in dogs. Journal of Applied Physiology, v. 72, n. 1, p. 383-388, 1992.

DECHMAN, G.; LAUZON, A.-M.; BATES, J. H. T. Mechanical behaviour of the canine respiratory system at very low lung volumes. Respiration Physiology, v. 95, p. 119-129, 1994.

DRAPER, N. R.; SMITH, H. Applied regression analysis. 3.ed. New York: John Wiley \& Sons, 1998. 706p.

EIDELMAN, D. H.; GHEZZO, H.; BATES, J. H. T. Exponential fitting of pressurevolume curves: confidence limits and sensitivity to noise. Journal of Applied Physiology, v. 69, n. 4, p. 1538-1541, 1990.

FARRE, R.; MANCINI, M.; ROTGER, M.; FERRER, M.; ROCA, J.; NAVAJAS, D. Oscillatory resistance measured during noninvasive proportional assist ventilation. American Journal of Respiratory and Critical Care Medicine., v. 164, n. 5, p. 790-794, 2001.

GATTINONI, L.; D'ANDREA, L.; PELOSI, P.; VITALE, G.; PESENTI, A.; FUMAGALLI, R. Regional effects and mechanism of positive end-expiratory pressure in early respiratory adult distress syndrome. Journal of the American Medical Association, v. 269, n. 16, p. 2122-2127, 1993.

GAVER III, D. P.; SAMSEL, R. W.; SOLWAY, J. Effects of surface tension and viscosity on airway reopening. Journal of Applied Physiology, v. 69, n. 1, p. 74$85,1990$.

GILLIS, H. L.; LUTCHEN, K. R. How heterogeneous bronchoconstriction affects ventilation distribution in human lungs: a morphometric model. Annals of Biomedical Engineering, v. 27, p. 14-22, 1999.

GOMES, R. F. M.; SHEN, X.; RAMCHANDANI, R.; TEPPER, R. S.; BATES, J. H. T. Comparative respiratory system mechanics in rodents. Journal of Applied Physiology, v. 89, n. 3, p. 908-916, 2000.

HAAS, C. Volume-pressure curves during mechanical ventilation. AARC Times, p. 64-67, Fev. 2000. 
HALPERN, D.; GROTBERG, J. B. Surfactant effects on fluid-elastic instabilities of liquid-lined flexible tubes: a model of airway closure. Journal of Biomechanical Engineering, v. 115, p. 271-277, 1993.

HANTOS, Z.; DARÓCZY, B.; KLEBNICZKI, J.; DOMBOS, K.; NAGY, S. Parameter estimation of transpulmonary mechanics by a nonlinear inertive model. Journal of Applied Physiology, v. 52, n. 4, p. 955-963, 1982.

HANTOS, Z.; DARÓCZY, B.; SUKI, B.; GALGÓCZY, G.; CSENDES, T. Forced oscillatory impedance of the respiratory system at low frequencies. Journal of Applied Physiology, v. 60, n. 1, p. 123-132, 1986.

HANTOS, Z.; DARÓCZY, B.; CSENDES, T.; SUKI, B.; NAGY, S. Modeling of low-frequency pulmonary impedance in dogs. Journal of Applied Physiology, v. 68 , n. 3, p. 849-860, 1990.

HANTOS, Z.; DARÓCZY, B.; SUKI, B.; NAGY, S.; FREDBERG, J. J. Input impedance and peripheral inhomogeneity of dog lungs. Journal of Applied Physiology, v. 72, n. 1, p. 168-178, 1992.

HANTOS, Z. Mechanical models of the respiratory system: non-linear and inhomogeneous models. In: MILIC-EMILI, J.; LUCANGELO U.; PESENTI, A.; ZIN, W. A.(Ed.) Basics of respiratory mechanics and artificial ventilation. Milan: Springer, 1999. p. 95-107.

HARRIS, R. S.; HESS, D. R.; VENEGAS, J. G. An objective analysis of the pressure-volume curve in the acute respiratory distress syndrome. American Journal of Respiratory and Critical Care Medicine, v. 161, n. 2, p. 432-439, 2000 .

HICKLING, K. G. The pressure-volume curve is greatly modified by recruitment: a mathematical model of ARDS lungs. American Journal of Respiratory and Critical Care Medicine, v. 158, p. 194-202, 1998.

HICKLING, K. G. Best compliance during a decremental, but not incremental, positive end-expiratory pressure trial is related to open-lung positive end-expiratory pressure: a mathematical model of acute respiratory distress syndrome lungs. American Journal of Respiratory and Critical Care Medicine, v. 163, p. 69-78, 2001 .

HILDEBRANDT, J. Comparison of mathematical models for cat lung and viscoelastic balloon derived by laplace transform methods from pressure-volume data. Bulletin of Mathematical Biophysics, v. 31, p. 651-667, 1969a.

HILDEBRANDT, J. Dynamic properties of air-filled excised cat lung determined by liquid plethysmograph. Journal of Applied Physiology, v. 27, n. 2, p. 246-250, $1969 b$. 
HILDEBRANDT, J. Pressure-volume data of cat lung interpreted by a plastoelastic, linear viscoelastic model. Journal of Applied Physiology, v. 28, n. 3, p. 365-372, 1970.

HIRAI, T.; MCKEOWN, K. A.; GOMES, R. F. M.; BATES, J. H. T. Effects of lung volume on lung and chest wall mechanics in rats. Journal of Applied Physiology, v. 86, n. 1, p. 16-21, 1999.

HORSFIELD, K.; DART, G.; OLSON, D. E.; FILLEY, G. F.; CUMMING, G. Models of the human bronchial tree. Journal of Applied Physiology, v. 31, n. 2, p. 207-217, 1971.

HORSFIELD, K.; KEMP, W.; PHILLIPS, S. An asymmetrical model of the airways of the dog lung. Journal of Applied Physiology, v. 52, n. 1, p. 21-26, 1982.

JONSON, B.; RICHARD, J.-C.; STRAUS, C.; MANCEBO, J.; LEMAIRE, F.; BROCHARD, L. Pressure-volume curves and compliance in acute lung injury: evidence of recruitment above the lower inflection point. American Journal of Respiratory and Critical Care Medicine, v. 159, n. 4, p. 1172-1178, 1999.

KACZKA, D. W.; BARNAS, G. M.; SUKI, B.; LUTCHEN, K. R. Assessment of time-domain analyses for estimation of low-frequency respiratory mechanical properties and impedance spectra. Annals of Biomedical Engineering, v. 23, p. 135-151, 1995.

KACZKA, D. W.; INGENITO, E. P.; SUKI, B.; LUTCHEN, K. R. Partitioning airway and lung tissue resistances in humans: effects of bronchoconstriction. Journal of Applied Physiology, v. 82, n. 5, p. 1531-1541, 1997.

KAMINSKY, D. A.; IRVIN, C. G.; LYNN, M.; MORIYA, H. T.; BATES, J. H. T. Airway and lung tissue mechanics following direct instillation of bronchoactive agents into a wedged subsegment in asthma. American Journal of Respiratory and Critical Care Medicine, v. 163, n. 5, p.A821, 2001.

KAMINSKY, D. A.; IRVIN, C. G. ; MORIYA, H. T.; LYNN, M.; LANG, S.; BATES, J. H. T. Peripheral lung hyperresponsiveness assessed through the wedged brnchoscope by forced oscillations. American Journal of Respiratory and Critical Care Medicine, v. 165, n. 8, p.A255, 2002.

KAMM, R. D.; SCHROTER, R. C. Is airway closure caused by a liquid film instability? Respiration Physiology, v. 75, p. 141-156, 1989.

KANO, S.; LANTERI, C. J.; DUNCAN, A. W.; SLY, P. D. Influence of nonlinearities on estimates of respiratory mechanics using multilinear regression analysis. Journal of Applied Physiology, v. 77, n. 3, p. 1185-1197, 1994. 
KESSLER, V.; MOLS, G.; BERNHARD, H.; HABERTHUR, C.; GUTTMANN, J. Interrupter airway and tissue resistance: errors caused by valve properties and respiratory system compliance. Journal of Applied Physiology, v. 87, n. 4, p. 15461554, 1999.

KONNO, K.; MEAD, J. Measurement of the separate volume changes of rib cage and abdomen during breathing. Journal of Applied Physiology, v. 22, n. 3, p. 407$422,1967$.

KORENBERG, M. J.; HUNTER, I. W. The identification of nonlinear biological systems: Volterra kernel approaches. Annals of Biomedical Engineering, v. 24, p. 250-268, 1996.

KUNST, P. W. A.; DE VRIES, P. M. J. M.; POSTMUS, P. E.; BAKKER, J. Evaluation of electrical impedance tomography in the measurement of PEEP-induced changes in lung volume. Chest, v. 115, n. 4, p. 1102-1106, 1999.

LÁNDSÉR, F. J.; NAGELS, J.; CLÉMENT, J.; VAN DE WOESTIJNE, P. Errors in the measurement of total respiratory resistance and reactance by forced oscillations. Respiration Physiology, v. 28, p. 289-301, 1976.

LAUZON, A.-M.; BATES, J. H. T. Estimation of time-varying respiratory mechanical parameters by recursive least squares. Journal of Applied Physiology, v. 71, n. 3, p. 1159-1165, 1991.

LAUZON, A.-M.; BATES, J. H. T. Kinetics of respiratory system elastance after airway challenge in dogs. Journal of Applied Physiology, v. 89, p. 2023-2029, 2000 .

LICHTWARCK-ASCHOFF, M.; MOLS, G.; HEDLUND, A. J.; KESSLER, V.; MARKSTROM, A. M.; GUTTMANN, J.; HEDENSTIERNA, G.; SJOSTRAND, U. $\mathrm{H}$. Compliance is nonlinear over tidal volume irrespective of positive end-expiratory pressure level in surfactant-depleted piglets. American Journal of Respiratory and Critical Care Medicine, v. 162, n. 6, p. 2125-2133, 2000.

LJUNG, L. System identification: theory for the user. 2.ed. Upper Saddle River: Prentice Hall, 1999. 609p.

LORINO, A. M.; HARF, A. Techniques for measuring respiratory mechanics: an analytic approach with a viscoelastic model. Journal of Applied Physiology, v. 74, n. 5 , p. $2373-2379,1993$.

LUCANGELO, U. Oscillatory mechanics: principles and clinical applications. In: MILIC-EMILI, J.; LUCANGELO U.; PESENTI, A.; ZIN, W. A.(Ed.) Basics of respiratory mechanics and artificial ventilation. Milan: Springer, 1999. p. 59-80. 
LUTCHEN, K. R.; JACKSON, A. C. Statistical measures of parameter estimates from models fit to respiratory impedance data: emphasis on joint variabilities. IEEE Transactions on Biomedical Engineering, v. BME-33, n. 11, p. 1000-1009, 1986.

LUTCHEN, K. R.; SAIDEL, G. M. Estimation of mechanical parameters in multicompartment models applied to normal and obstructed lungs during tidal breathing. IEEE Transactions on Biomedical Engineering, v. BME-33, n. 9, p. 878-887, 1986

LUTCHEN, K. R.; HANTOS, Z.; JACKSON, A. C. Importance of low-frequency impedance data for reliably quantifying parallel inhomogeneities of respiratory mechanics. IEEE Transactions on Biomedical Engineering, v. 35, n. 6, p. 472$481,1988$.

LUTCHEN, K. R.; COSTA, K. D. Physiological interpretations based on lumped element models fit to respiratory impedance data: use of forward-inverse modeling. IEEE Transactions on Biomedical Engineering, v. 37, n. 11, p. 1076-1086, 1990.

LUTCHEN, K. R.; JACKSON, A. C. Confidence bounds on respiratory mechanical properties estimated from transfer versus input impedance in humans versus dogs. IEEE Transactions on Biomedical Engineering, v. 39, n. 6, p. 644-651, 1992.

LUTCHEN, K. R.; KACZKA, D. W.; SUKI, B.; BARNAS, G.; CEVENINI, G.; BARBINI, P. Low-frequency respiratory mechanics using ventilator-driven forced oscillations. Journal of Applied Physiology, v. 75, n. 6, p. 2549-2560, 1993 a.

LUTCHEN, K. R.; YANG, K.; KACZKA, D. W.; SUKI, B. Optimal ventilation waveforms for estimating low-frequency respiratory impedance. Journal of Applied Physiology, v. 75, n. 1, p. 478-488, 1993 b.

MAKSYM, G. N.; BATES, J. H. T. Nonparametric block-structured modeling of rat lung mechanics. Annals of Biomedical Engineering, v. 25, p. 1000-1008, 1997.

MARCHAL, F.; BOUAZIZ, C.; BAEYERT, C.; GALLINA, C.; DUVIVIER, C.; PESLIN, R. Separation of airway and tissue properties by transfer respiratory impedance and thoracic gas volume in reversible airway obstruction. European Respiratory Journal, v. 9, p. 253-261, 1996.

MARTIN-LEFÈVRE， L.; RICARD， J.-D.; ROUPIE， E.; DREYFUSS， D.; SAUMON, G. Significance of the changes in the respiratory system pressurevolume curve during acute lung injury in rats. American Journal of Respiratory and Critical Care Medicine, v. 164, n. 4, p. 627-632, 2001.

MICHAELSON, E. D.; GRASSMAN, E. D.; PETERS, W. R. Pulmonary mechanics by spectral analysis of forced random noise. The Journal of Clinical Investigation, v. 56, p. 1210-1230, 1975. 
MILIC-EMILI, J.; MEAD, J.; TURNER, J. M.; GLAUSER, E. M. Improved technique for estimating pleural pressure from esophageal balloons. Journal of Applied Physiology, v. 19, n. 2, p. 207-211, 1964.

MORIYA, H. T.; MORAES, J. C. T. B.; BATES, J. H. T. Time-domain modeling of respiratory mechanics in the mouse. Annals of Biomedical Engineering, v. 29, p. S-142, 2001. Suplemento. / Apresentado no 2001 Annual Fall Meeting da Biomedical Engineering Society, Durham, NC, EUA, 2001.

MORIYA, H. T.; MORAES, J. C. T. B.; BATES, J. H. T. Nonlinear and frequency dependent mechanical behavior of the mouse respiratory system. Annals of Biomedical Engineering. /no prelo/.

MURAMATSU, K.; YUKITAKE, K.; NAKAMURA, M.; MATSUMOTO, I.; MOTOHIRO, Y. Monitoring of nonlinear respiratory elastance using a multiple linear regression analysis. European Respiratory Journal, v. 17, n. 6, p. 11581166., 2001.

NARUSAWA, U. General characteristics of the sigmoidal model equation representing quasi-static pulmonary P-V curves. Journal of Applied Physiology, v. 91, n. 1, p. 201-210, 2001.

NAVAJAS, D.; MIJAILOVICH, S.; GLASS, G. M.; STAMENOVIC, D.; FREDBERG, J. J. Dynamic response of the isolated passive rat diaphragm strip. Journal of Applied Physiology, v. 73, n. 6, p. 2681-2692, 1992.

NAVAJAS, D.; MAKSYM, G. N.; BATES, J. H. T. Dynamic viscoelastic nonlinearity of lung parenchymal tissue. Journal of Applied Physiology, v. 79, n. 1, p. 348-356, 1995.

NUCCI, G.; MERGONI, M.; BRICCHI, C.; POLESE, G.; COBELLI, C.; ROSSI, A. On-line monitoring of intrinsic PEEP in ventilator-dependent patients. Journal of Applied Physiology, v. 89, n. 3, p. 985-995, 2000.

NUCCI, G.; COBELLI, C. Mathematical models of respiratory mechanics. In: CARSON, E.; COBELLI, C.(Ed.) Modelling methodology for physiology and medicine. London: Academic Press, 2001. p. 279-304.

O'KEEFE, G. E.; GENTILELLO, L. M.; ERFORD, S.; MAIER, R. V. Imprecision in lower "inflection point" estimation from static pressure-volume curves in patients at risk for acute respiratory distress syndrome. The Journal of Trauma: Injury, Infection, and Critical Care, v. 44, n. 6, p. 1064-1068, 1998.

OTIS, A. B. History of respiratory mechanics. In: MACKLEM, P; MEAD, J.(Ed.)

Handbook of Physiology. London: Oxford University, 1986. v. 3. p. 1-12. 
OTIS JR., D. R.; PETAK, F.; HANTOS, Z.; FREDBERG, J. J.; KAMM, R. D. Airway closure and reopening assessed by the alveolar capsule oscillation technique. Journal of Applied Physiology, v. 80, n. 6, p. 2077-2084, 1996.

PARE, P. D.; BROOKS, L. A.; BATES, J.; LAWSON, L. M.; NELEMS, J. M. B.; WRIGHT, J. L.; HOGG, J. C. Exponential analysis of the lung pressure-volume curve as a predictor of pulmonary emphysema. American Review of Respiratory Diseases, v. 126, p. 54-61, 1982.

PELOSI, P.; CROCI, M.; RAVAGNAN, I.; CERISARA, M.; VICARDI, P.; LISSONI, A.; GATTINONI, L. Respiratory system mechanics in sedated, paralyzed, morbidly obese patients. Journal of Applied Physiology, v. 82, n. 3, p. 811-818, 1997.

PERUN, M. L.; GAVER III, D. P. Interaction between airway lining fluid forces and parenchymal tethering during pulmonary airway reopening. Journal of Applied Physiology, v. 79, n. 5, p. 1717-1728, 1995.

PESLIN, R.; JARDIN, P.; DUVIVIER, C.; BEGIN, P. In-phase rejection requirements for measuring respiratory input impedance. Journal of Applied Physiology, v. 56, n. 3, p. 804-809, 1984.

PESLIN, R.; DUVIVIER, C.; BEKKARI, H.; REICHART, E.; GALLINA, C. Stress adaptation and low-frequency impedance of rat lungs. Journal of Applied Physiology, v. 69, n. 3, p. 1080-1086, 1990.

PESLIN, R.; SILVA, J. F.; DUVIVIER, C.; CHABOT, F. Respiratory mechanics studied by forced oscillations during artificial ventilation. European Respiratory Journal, v. 6, p. 772-784, 1993.

PESLIN, R.; SAUNIER, C.; DUVIVIER, C.; MARCHAND, M. Analysis of lowfrequency lung impedance in rabbits with nonlinear models. Journal of Applied Physiology, v. 79, n. 3, p. 771-780, 1995.

PESLIN, R.; FARRE, R.; ROTGER, M.; NAVAJAS, D. Effect of expiratory flow limitation on respiratory mechanical impedance: a model study. Journal of Applied Physiology, v. 81, n. 6, p. 2399-2406, 1996.

PESLIN, R.; FREDBERG, J. J. Oscillation mechanics of the respiratory system. In: MACKLEM, P. T.; MEAD, J.(Ed.) Handbook of physiology. mechanics of breathing. Bethesda: American Physiological Society, 1986. p. 145-177.

PESLIN, R.; DUVIVIER, C. Partitioning of airway and respiratory tissue mechanical impedances by body plethysmography. Journal of Applied Physiology, v. 84, n. 2 , p. $553-561,1998$. 
PETÁK, F.; HANTOS, Z.; ADAMICZA, A.; DARÓCZY, B. Partitioning of pulmonary impedance: modeling vs. alveolar capsule approach. Journal of Applied Physiology, v. 75, n. 2, p. 513-521, 1993.

PETÁK, F.; HABRE, W.; HANTOS, Z.; SLY, P. D.; MOREL, D. R. Effects of pulmonary vascular pressures and flow on airway and parenchymal mechanics in isolated rat lungs. Journal of Applied Physiology, v. 92, n. 1, p. 169-178, 2002.

ROMERO, P. V.; SATO, J.; SHARDONOFSKY, F.; BATES, J. H. T. Highfrequency characteristics of respiratory mechanics determined by flow interruption. Journal of Applied Physiology, v. 69, n. 5, p. 1682-1688, 1990.

SALAZAR, E.; KNOWLES, J. H. An analysis of pressure-volume characteristics of the lungs. Journal of Applied Physiology, v. 19, n. 1, p. 97-104, 1964.

SATO, J.; DAVEY, B. L. K.; SHARDONOFSKY, F.; BATES, J. H. T. Lowfrequency respiratory system resistance in the normal dog during mechanical ventilation. Journal of Applied Physiology, v. 70, n. 4, p. 1536-1543, 1991.

SCHUESSLER, T. F.; BATES, J. H. T. A computer-controlled research ventilator for small animals: design and evaluation. IEEE Transactions on Biomedical Engineering, v. 42, n. 9, p. 860-866, 1995.

SCHUESSLER, T. F.; GOTTFRIED, S. B.; BATES, J. H. T. A model of the spontaneously breathing patient: applications to intrinsic PEEP and work of breathing. Journal of Applied Physiology, v. 82, n. 5, p. 1694-1703, 1997.

SHARDONOFSKY, F. R.; SATO, J.; BATES, J. H. T. Quasi-static pressure-volume hysteresis in the canine respiratory system in vivo. Journal of Applied Physiology, v. 68, n. 5 , p. 2230-2236, 1990.

SIMILOWSKI, T.; BATES, J. H. T. Two-compartment modelling of respiratory system mechanics at low frequencies: gas redistribution or tissue rheology ? European Respiratory Journal, v. 4, p. 353-358, 1991.

SUKI, B.; BATES, J. H. T. A nonlinear viscoelastic model of lung tissue mechanics. Journal of Applied Physiology, v. 71, n. 3, p. 826-833, 1991.

SUKI, B.; HANTOS, Z.; DARÓCZY, B.; ALKAYSI, G.; NAGY, S. Nonlinearity and harmonic distortion of dog lungs measured by low-frequency forced oscillations. Journal of Applied Physiology, v. 71, n. 1, p. 69-75, 1991.

SUKI, B.; LUTCHEN, K. R. Pseudorandom signals to estimate apparent transfer and coherence functions of nonlinear systems: applications to respiratory mechanics. IEEE Transactions on Biomedical Engineering, v. 39, n. 11, p. 1142-1151, 1992.

SUKI, B. Nonlinear phenomena in respiratory mechanical measurements. Journal of Applied Physiology, v. 74, n. 5, p. 2574-2584, 1993. 
SUKI, B.; HABIB, R. H.; JACKSON, A. C. Wave propagation, input impedance, and wall mechanics of the calf trachea from 16 to 1,600 Hz. Journal of Applied Physiology, v. 75, n. 6, p. 2755-2766, 1993.

SUKI, B.; BARABÁSI, A.-L.; LUTCHEN, K. R. Lung tissue viscoelasticity: a mathematical framework and its molecular basis. Journal of Applied Physiology, v. 76, n. 6, p. 2749-2759, 1994a.

SUKI, B.; BARABÁSI, A.-L.; HANTOS, Z.; PETÁK, F.; STANLEY, H. E. Avalanche and power-law behaviour in lung inflation. Nature, v. 368, p. 615-618, 1994b.

SUKI, B.; ZHANG, Q.; LUTCHEN, K. R. Relationship between frequency and amplitude dependence in the lung: a nonlinear block-structured modeling approach. Journal of Applied Physiology, v. 79, n. 2, p. 660-671, 1995.

SUKI, B.; YUAN, H.; ZHANG, Q.; LUTCHEN, K. R. Partitioning of lung tissue response and inhomogeneous airway constriction at the airway opening. Journal of Applied Physiology, v. 82, n. 4, p. 1349-1359, 1997.

SUKI, B.; ALENCAR, A. M.; TOLNAI, J.; ASZTALOS, T.; PETAK, F.; SUJEER, M. K.; PATEL, K.; PATEL, J.; STANLEY, H. E.; HANTOS, Z. Size distribution of recruited alveolar volumes in airway reopening. Journal of Applied Physiology, v. 89 , n. 5, p. 2030-2040, 2000.

SUTER, P. M.; FAIRLEY, H. B.; ISEMBERG, M. D. Effect of tidal volume and positive end-expiratory pressure on compliance during mechanical ventilation. Chest, v. 73, p. 158-162, 1978.

THORPE, C. W.; BATES, J. H. T. Effect of stochastic heterogeneity on lung impedance during acute bronchoconstriction: a model analysis. Journal of Applied Physiology, v. 82, n. 5, p. 1616-1625, 1997.

VASSILAKOPOULOS, T.; ZAKYNTHINOS, S.; ROUSSOS, C. Muscle functions: basic concepts. In: MARINI, J. J.; SLUTSKY, A. S.(Ed.) Physiological basis of ventilatory support. New York: Marcel Dekker, 1998. p. 103-152.

VASSILIOU, M. P.; PETRI, L.; AMYGDALOU, A.; PATRANI, M.; PSARAKIS, C.; NIKOLAKI, D.; GEORGIADIS, G.; BEHRAKIS, P. K. Linear and nonlinear analysis of pressure and flow during mechanical ventilation. Intensive Care Medicine, v. 26, n. 8, p. 1057-1064, 2000.

VENEGAS, J. G.; HARRIS, R. S.; SIMON, B. A. A comprehensive equation for the pulmonary pressure-volume curve. Journal of Applied Physiology, v. 84, n. 1, p. 389-395, 1998. 
WAGERS, S.; LUNDBLAD, L.; MORIYA, H. T.; BATES, J. H. T.; IRVIN, C. G. Nonlinearity of respiratory mechanics during bronchoconstriction in mice with airway inflammation. Journal of Applied Physiology, v. 92, n. 5, p. 1802-1807, 2002.

WRIGHT, P. E.; MARINI, J. J.; BERNARD, G. R. In vitro versus in vivo comparison of endotracheal tube airflow resistance. American Review of Respiratory Diseases, v. 140, p. 10-16, 1989.

YUAN, H.; WESTWICK, D. T.; INGENITO, E. P.; LUTCHEN, K. R.; SUKI, B. Parametric and nonparametric nonlinear system identification of lung tissue strip. Annals of Biomedical Engineering, v. 27, p. 548-562, 1999.

ZHANG, Q.; SUKI, B.; LUTCHEN, K. R. Harmonic distortion from nonlinear systems with broadband inputs: applications to lung mechanics. Annals of Biomedical Engineering, v. 23, p. 672-681, 1995.

ZHANG, Q.; SUKI, B.; WESTWICK, D. T.; LUTCHEN, K. R. Factors affecting Volterra kernel estimation: emphasis on lung tissue viscoelasticity. Annals of Biomedical Engineering, v. 26, p. 103-116, 1998.

ZHANG, Q.; LUTCHEN, K. R.; SUKI, B. A frequency domain approach to nonlinear and structure identification for long memory systems: application to lung mechanics. Annals of Biomedical Engineering, v. 27, p. 1-13, 1999.

ZIN, W. A. Principles of measurement of respiratory mechanics. In: MILIC-EMILI, J.; LUCANGELO U.; PESENTI, A.; ZIN, W. A.(Ed.) Basics of respiratory mechanics and artificial ventilation. Milan: Springer, 1999. p. 3-8.

ZIN, W. A.; GOMES, R. F. M. Mechanical models of the respiratory system: linear models. In: MILIC-EMILI, J.; LUCANGELO U.; PESENTI, A.; ZIN, W. A.(Ed.) Basics of respiratory mechanics and artificial ventilation. Milan: Springer, 1999. p. 87-94. 


\section{APÊNDICE I}

\section{RESULTADOS GERADOS PELO SOFTWARE SigmaStat}

Two Way Repeated Measures ANOVA (Two Factor Repetition)

Data source: Data 1 in Notebook

Balanced Design

Dependent Variable: kd

$\begin{array}{lll}\text { Normality Test: } & \text { Failed } & (\mathrm{P}=0,002) \\ \text { Equal Variance Test: } & \text { Passed } & (\mathrm{P}=0,269)\end{array}$

Source of Variation DF SS

$\begin{array}{llll}\text { Mouse } & 3 & 3,279 & 1,093 \\ \text { PEEP } & 3 & 103,355 & 34,452 \\ \text { PEEP x Mouse } & 9 & 25,135 & 2,793 \\ \text { VT } & 3 & 165,640 & 55,213 \\ \text { VT x Mouse } & 9 & 19,964 & 2,218 \\ \text { PEEP x VT } & 9 & 75,749 & 8,417 \\ \text { Residual } & 27 & 27,567 & 1,021 \\ \text { Total } & 63 & 420,689 & 6,678\end{array}$

sexta-feira, outubro 25, 2002, 10:10:37

The difference in the mean values among the different levels of PEEP is greater than would be expected by chance after allowing for effects of differences in VT. There is a statistically significant difference $(\mathrm{P}=0,002)$. To isolate which group(s) differ from the others use a multiple comparison procedure.

The difference in the mean values among the different levels of VT is greater than would be expected by chance after allowing for effects of differences in PEEP. There is a statistically significant difference $(\mathrm{P}=<0,001)$. To isolate which group(s) differ from the others use a multiple comparison procedure.

The effect of different levels of PEEP depends on what level of VT is present. There is a statistically significant interaction between PEEP and VT. $(\mathrm{P}=<0,001)$

Power of performed test with alpha $=0,0500$ : for PEEP : 0,984

Power of performed test with alpha $=0,0500$ : for VT : 1,000

Power of performed test with alpha $=0,0500$ : for PEEP $\mathrm{x}$ VT : 1,000

Least square means for PEEP :

$\begin{array}{ll}\text { Group } & \text { Mean } \\ 0,000 & 11,006 \\ 3,000 & 12,096 \\ 6,000 & 14,356 \\ 9,000 & 13,396\end{array}$

Std Err of LS Mean = 0,418 
Least square means for VT :

$\begin{array}{ll}\text { Group } & \text { Mean } \\ 0,1000 & 15,378 \\ 0,200 & 11,483 \\ 0,300 & 11,400 \\ 0,400 & 12,593\end{array}$

Std Err of LS Mean =0,372

Least square means for PEEP x VT :

$\begin{array}{ll}\text { Group } & \text { Mean } \\ 0,000 \times 0,100 & 14,802 \\ 0,000 \times 0,200 & 10,549 \\ 0,000 \times 0,300 & 9,755 \\ 0,000 \times 0,400 & 8,920 \\ 3,000 \times 0,100 & 15,591 \\ 3,000 \times 0,200 & 10,985 \\ 3,000 \times 0,300 & 9,823 \\ 3,000 \times 0,400 & 11,988 \\ 6,000 \times 0,100 & 15,037 \\ 6,000 \times 0,200 & 11,934 \\ 6,000 \times 0,300 & 14,798 \\ 6,000 \times 0,400 & 15,657 \\ 9,000 \times 0,100 & 16,083 \\ 9,000 \times 0,200 & 12,467 \\ 9,000 \times 0,300 & 11,226 \\ 9,000 \times 0,400 & 13,808\end{array}$

Std Err of LS Mean =0,505

All Pairwise Multiple Comparison Procedures (Tukey Test):

Comparisons for factor: PEEP

$\begin{array}{llllll}\text { Comparison } & \text { Diff of Means } & \mathbf{p} & \mathbf{q} & \mathbf{P} & \mathbf{P}<\mathbf{0 , 0 5 0} \\ \text { 6,000 vs. } 0,000 & 3,350 & 4 & 8,018 & 0,002 & \text { Yes } \\ 6,000 \text { vs. } 3,000 & 2,260 & 4 & 5,409 & 0,018 & \text { Yes } \\ \text { 6,000 vs. } 9,000 & 0,960 & 4 & 2,299 & 0,413 & \text { No } \\ 9,000 \text { vs. } 0,000 & 2,390 & 4 & 5,720 & 0,013 & \text { Yes } \\ 9,000 \text { vs. } 3,000 & 1,300 & 4 & 3,110 & 0,195 & \text { No } \\ \text { 3,000 vs. } 0,000 & 1,090 & 4 & 2,609 & 0,315 & \text { No }\end{array}$

Comparisons for factor: VT

$\begin{array}{llllll}\text { Comparison } & \text { Diff of Means } & \mathbf{p} & \mathbf{q} & \mathbf{P} & \mathbf{P}<\mathbf{0 , 0 5 0} \\ 0,100 \text { vs. } 0,300 & 3,978 & 4 & 10,684 & <0,001 & \text { Yes } \\ 0,100 \text { vs. } 0,200 & 3,895 & 4 & 10,460 & <0,001 & \text { Yes } \\ 0,100 \text { vs. } 0,400 & 2,785 & 4 & 7,479 & 0,002 & \text { Yes } \\ 0,400 \text { vs. } 0,300 & 1,193 & 4 & 3,204 & 0,178 & \text { No } \\ 0,400 \text { vs. } 0,200 & 1,110 & 4 & 2,981 & 0,222 & \text { Do Not Test } \\ 0,200 \text { vs. } 0,300 & 0,0832 & 4 & 0,223 & 0,999 & \text { Do Not Test }\end{array}$


Comparisons for factor: VT within 0

$\begin{array}{ll}\text { Comparison } & \text { Diff of Means } \\ 0,100 \text { vs. } 0,400 & 5,882 \\ 0,100 \text { vs. } 0,300 & 5,047 \\ 0,100 \text { vs. } 0,200 & 4,254 \\ 0,200 \text { vs. } 0,400 & 1,629 \\ 0,200 \text { vs. } 0,300 & 0,794 \\ 0,300 \text { vs. } 0,400 & 0,835\end{array}$

Comparisons for factor: VT within 3

$\begin{array}{ll}\text { Comparison } & \text { Diff of Means } \\ \text { 0,100 vs. } 0,300 & 5,768 \\ 0,100 \text { vs. } 0,200 & 4,606 \\ 0,100 \text { vs. } 0,400 & 3,603 \\ 0,400 \text { vs. } 0,300 & 2,165 \\ 0,400 \text { vs. } 0,200 & 1,003 \\ 0,200 \text { vs. } 0,300 & 1,162\end{array}$

Comparisons for factor: VT within 6

\section{Comparison Diff of Means p}

0,400 vs. $0,200 \quad 3,723$

0,400 vs. $0,300 \quad 0,859$

0,400 vs. $0,100 \quad 0,620$

0,100 vs. $0,200 \quad 3,103$

0,100 vs. $0,300 \quad 0,239$

0,300 vs. $0,200 \quad 2,864$

Comparisons for factor: VT within 9

$\begin{array}{ll}\text { Comparison } & \text { Diff of Means } \\ 0,100 \text { vs. } 0,300 & 4,858 \\ 0,100 \text { vs. } 0,200 & 3,617 \\ 0,100 \text { vs. } 0,400 & 2,275 \\ 0,400 \text { vs. } 0,300 & 2,583 \\ 0,400 \text { vs. } 0,200 & 1,341 \\ 0,200 \text { vs. } 0,300 & 1,241\end{array}$

Comparisons for factor: PEEP within 0,1

$\begin{array}{llllll}\text { Comparison } & \text { Diff of Means } & \mathbf{p} & \mathbf{q} & \mathbf{P} & \mathbf{P}<\mathbf{0 , 0 5} \\ 9,000 \text { vs. } 0,000 & 1,281 & 4 & 2,118 & 0,452 & \text { No } \\ 9,000 \text { vs. } 6,000 & 1,047 & 4 & 1,730 & 0,618 & \text { Do Not Test } \\ 9,000 \text { vs. } 3,000 & 0,493 & 4 & 0,815 & 0,939 & \text { Do Not Test } \\ \text { 3,000 vs. } 0,000 & 0,788 & 4 & 1,303 & 0,794 & \text { Do Not Test } \\ \text { 3,000 vs. } 6,000 & 0,554 & 4 & 0,916 & 0,916 & \text { Do Not Test } \\ \text { 6,000 vs. } 0,000 & 0,235 & 4 & 0,388 & 0,993 & \text { Do Not Test }\end{array}$

$\begin{array}{lll}\mathbf{q} & \mathbf{P} & \mathbf{P}<\mathbf{0 , 0 5} \\ 10,238 & <0,001 & \text { Yes } \\ 8,785 & <0,001 & \text { Yes } \\ 7,404 & <0,001 & \text { Yes } \\ 2,835 & 0,208 & \text { No } \\ 1,381 & 0,764 & \text { Do Not Test } \\ 1,453 & 0,735 & \text { Do Not Test }\end{array}$

$\begin{array}{lll}\mathbf{q} & \mathbf{P} & \mathbf{P}<\mathbf{0 , 0 5} \\ 10,039 & <0,001 & \text { Yes } \\ 8,017 & <0,001 & \text { Yes } \\ 6,271 & <0,001 & \text { Yes } \\ 3,769 & 0,056 & \text { No } \\ 1,747 & 0,610 & \text { Do Not Test } \\ 2,022 & 0,491 & \text { Do Not Test }\end{array}$

$\begin{array}{lll}\mathbf{q} & \mathbf{P} & \mathbf{P}<\mathbf{0 , 0 5} \\ 6,480 & <0,001 & \text { Yes } \\ 1,495 & 0,718 & \text { No } \\ 1,080 & 0,870 & \text { Do Not Test } \\ 5,401 & 0,003 & \text { Yes } \\ 0,415 & 0,991 & \text { Do Not Test } \\ 4,985 & 0,007 & \text { Yes }\end{array}$

$\begin{array}{lll}\mathbf{q} & \mathbf{P} & \mathbf{P}<\mathbf{0 , 0 5} \\ 8,455 & <0,001 & \text { Yes } \\ 6,295 & <0,001 & \text { Yes } \\ 3,960 & 0,041 & \text { Yes } \\ 4,495 & 0,017 & \text { Yes } \\ 2,335 & 0,366 & \text { No } \\ 2,161 & 0,434 & \text { No }\end{array}$

$0,388 \quad 0,993 \quad$ Do Not Test 
Comparisons for factor: PEEP within 0,2

$\begin{array}{llllll}\text { Comparison } & \text { Diff of Means } & \mathbf{p} & \mathbf{q} & \mathbf{P} & \mathbf{P}<\mathbf{0 , 0 5} \\ 9,000 \text { vs. } 0,000 & 1,918 & 4 & 3,171 & 0,137 & \text { No } \\ 9,000 \text { vs. } 3,000 & 1,482 & 4 & 2,450 & 0,326 & \text { Do Not Test } \\ \text { 9,000 vs. } 6,000 & 0,533 & 4 & 0,881 & 0,924 & \text { Do Not Test } \\ \text { 6,000 vs. } 0,000 & 1,385 & 4 & 2,290 & 0,385 & \text { Do Not Test } \\ \text { 6,000 vs. 3,000 } & 0,949 & 4 & 1,569 & 0,687 & \text { Do Not Test } \\ \text { 3,000 vs. } 0,000 & 0,436 & 4 & 0,721 & 0,956 & \text { Do Not Test }\end{array}$

Comparisons for factor: PEEP within 0,3

$\begin{array}{llllll}\text { Comparison } & \text { Diff of Means } & \mathbf{p} & \mathbf{q} & \mathbf{P} & \mathbf{P}<\mathbf{0 , 0 5} \\ \text { 6,000 vs. } 0,000 & 5,043 & 4 & 8,336 & <0,001 & \text { Yes } \\ 6,000 \text { vs. } 3,000 & 4,975 & 4 & 8,224 & <0,001 & \text { Yes } \\ \text { 6,000 vs. } 9,000 & 3,572 & 4 & 5,905 & 0,002 & \text { Yes } \\ 9,000 \text { vs. } 0,000 & 1,471 & 4 & 2,431 & 0,333 & \text { No } \\ 9,000 \text { vs. } 3,000 & 1,403 & 4 & 2,319 & 0,374 & \text { Do Not Test } \\ 3,000 \text { vs. } 0,000 & 0,0678 & 4 & 0,112 & 1,000 & \text { Do Not Test }\end{array}$

Comparisons for factor: PEEP within 0,4

$\begin{array}{llllll}\text { Comparison } & \text { Diff of Means } & \mathbf{p} & \mathbf{q} & \mathbf{P} & \mathbf{P}<\mathbf{0 , 0 5} \\ \text { 6,000 vs. } 0,000 & 6,737 & 4 & 11,136 & <0,001 & \text { Yes } \\ 6,000 \text { vs. } 3,000 & 3,669 & 4 & 6,065 & 0,001 & \text { Yes } \\ 6,000 \text { vs. } 9,000 & 1,849 & 4 & 3,056 & 0,159 & \text { No } \\ 9,000 \text { vs. } 0,000 & 4,888 & 4 & 8,080 & <0,001 & \text { Yes } \\ 9,000 \text { vs. } 3,000 & 1,820 & 4 & 3,009 & 0,169 & \text { No } \\ \text { 3,000 vs. } 0,000 & 3,068 & 4 & 5,071 & 0,007 & \text { Yes }\end{array}$

A result of "Do Not Test" occurs for a comparison when no significant difference is found between two means that enclose that comparison. For example, if you had four means sorted in order, and found no difference between means 4 vs. 2, then you would not test 4 vs. 3 and 3 vs. 2, but still test 4 vs. 1 and 3 vs. 1 ( 4 vs. 3 and 3 vs. 2 are enclosed by 4 vs. 2: 4321 ). Note that not testing the enclosed means is a procedural rule, and a result of Do Not Test should be treated as if there is no significant difference between the means, even though one may appear to exist. 


\section{APÊNDICE II}

ARTIGO ACEITO PARA PUBLICAÇÃO NA REVISTA ANNALS OF BIOMEDICAL ENGINEERING

\section{NONLINEAR AND FREQUENCY DEPENDENT MECHANICAL BEHAVIOR OF THE MOUSE RESPIRATORY SYSTEM}

Henrique T. Moriya ${ }^{1,2}$, José Carlos T. B. Moraes ${ }^{2}$, and Jason H. T. Bates ${ }^{1}$

${ }^{1}$ Vermont Lung Center, Department of Medicine and Molecular Physiology and Biophysics, University of Vermont, Burlington, VT 05045-0075, and ${ }^{2}$ Biomedical Engineering Laboratory, University of São Paulo, São Paulo, Brazil.

Running title: Mouse respiratory mechanics

Address for correspondence:

Dr. Jason H. T. Bates

University of Vermont

149 Beaumont Ave

Burlington, VT 05405-0075

Tel: (802) 656-8912

Fax: (802) 656-8900

Email: jhtbates@zoo.uvm.edu 


\section{ABSTRACT}

The assessment of the mechanical properties of the respiratory system is typically done by oscillating flow into the lungs via the trachea, measuring the resulting pressure generated at the trachea, and relating the two signals to each other in terms of some suitable mathematical model. If the perturbing flow signal is broadband and not too large in amplitude, linear behavior is usually assumed and the input impedance calculated. Alternatively, some researchers have used flow signals that are narrow band but large in amplitude, and invoked nonlinear lumped-parameter models to account for the relationship between flow and pressure. There has been little attempt, however, to deal with respiratory data that is both broadband and reflective of system nonlinearities. In the present study, we collected such data from mice. To interpret these data, we first developed a time-domain approximation to a widely used model of respiratory input impedance. We then extended this model to include nonlinear resistive and elastic terms. We found that the nonlinear elastic term fit the data better than the linear model or the nonlinear resistance model when amplitudes were large. This model may be useful for detecting overinflation of the lung during mechanical ventilation.

Index terms: input impedance, resistance, elastance, frequency-domain, time-domain 


\section{INTRODUCTION}

The assessment of the mechanical properties of the respiratory system is typically done by oscillating flow into the lungs via the trachea, measuring the resulting pressure generated at the trachea, and relating the two signals to each other in terms of respiratory resistance and elastance ${ }^{1,4,5,9,21,22,29,31}$. Both resistance and elastance depend markedly on the oscillation frequency, and this dependence is most pronounced over the breathing frequency range ${ }^{11,23}$. Consequently, multi-frequency analyses of respiratory mechanics are usually performed in the frequency-domain through the evaluation of the mechanical input impedance $\left(Z_{i n}\right)$ of the respiratory system. $Z_{\text {in }}$ is most often determined by the forced oscillation technique in which the lungs are perturbed with a broadband flow ${ }^{6,7,10-12,23,24,31}$. The determination of $Z_{\text {in }}$ is predicated on the assumption that the respiratory system is linear ${ }^{20,23}$, a requirement which is usually achieved by using small flow amplitudes.

Lutchen and coworkers $^{14,18}$ have developed and applied a specially designed broadband flow waveform that serves the dual purpose of ventilating the lungs in a manner sufficient for maintaining gas exchange, while at the same time allowing $Z_{\text {in }}$ to be determined up to about $8 \mathrm{~Hz}$. To achieve the first purpose, the peak-to-peak amplitude of this optimal ventilator waveform (OVW) cannot be too small. However, this works against the linearity requirement for the calculation of $Z_{i n}$. Fortunately, the harmonic distortion that arises when a nonlinear system is excited by a broadband input can be minimized by having the frequencies present in the perturbing flow waveform satisfy the no-sum-no-difference (NSND) criterion of Suki and Lutchen ${ }^{27}$. However, this means that all the non-NSND frequencies in pressure arising from the 
perturbing flow signal are discarded in the determination of $Z_{i n}$. These harmonics could potentially amount to a significant fraction of the total power in pressure, if the system is highly nonlinear.

Our goal was to develop a means of taking nonlinearities into account when the rather large amplitudes of the OVW are applied to the respiratory system. Although, in principle, such an analysis could be performed in the frequency-domain, this would involve a complicated series of integrals such as the Volterra series ${ }^{16,26,33}$. We therefore undertook our analysis in the time-domain because this allowed us to use anatomically based lumped-parameter models that can account for both the nonlinear and multi-compartmental behavior of the respiratory system.

\section{METHODS}

\section{Experimental procedures}

We studied four normal Balb/c mice weighing $22.4 \pm 0.5 \mathrm{~g}$ (mean $\pm \mathrm{SD}$ ). Each mouse was anesthetized (pentobarbital sodium, $90 \mathrm{mg} / \mathrm{kg}$ ip), paralyzed (pancuronium bromide, $1 \mathrm{mg} / \mathrm{kg}$ ip), tracheostomized (18-gauge metal cannula), and mechanically ventilated with a tidal volume of $0.25 \mathrm{~mL}$ and a breathing frequency of 200 breaths/min using a small animal ventilator (flexiVent, SCIREQ, Montreal, Canada). The flexiVent is a computer-controlled piston pump that can function both as a conventional mechanical ventilator and as a system identification device when its piston is made to follow an appropriate volume displacement waveform ${ }^{3,10,25}$. Positive end-expiratory pressure (PEEP) was set by connecting the expiratory line of the ventilator to a water column. 
The animals were ventilated for 6 min periods against three different levels of PEEP $\left(0,3\right.$, and $\left.6 \mathrm{cmH}_{2} \mathrm{O}\right)$ in random order. At each level of PEEP, the lungs were first inflated twice to a pressure of $25 \mathrm{cmH}_{2} \mathrm{O}$ in order to standardize lung volume history. After an additional minute of regular ventilation, four different amplitudes $(0.1,0.2$, 0.3 and $0.4 \mathrm{~mL}$ ) of the same 8 -s broadband volume perturbation were applied sequentially. The different amplitudes were applied in random order with $1.5 \mathrm{~min}$ of regular ventilation between each perturbation. After the three PEEP trials were complete, the procedure was repeated at a final PEEP level of $9 \mathrm{cmH}_{2} \mathrm{O}$. We applied the PEEP of $9 \mathrm{cmH}_{2} \mathrm{O}$ only at the end of the experiment to prevent any resulting over-inflation damage to the lung from affecting the measurements at the lower PEEP levels.

Each volume perturbation was applied by interruption mechanical ventilation, allowing the animal to expire for $1 \mathrm{~s}$ against the applied PEEP, and then oscillating the ventilator piston according to the volume perturbation signal. During this procedure, the piston volume displacement $\left(V_{c y l}\right)$ and the pressure inside the cylinder $\left(P_{c y l}\right)$ were filtered at $300 \mathrm{~Hz}(6-$ pole Bessel) and sampled at $1024 \mathrm{~Hz}$. The data were then digitally low-pass filtered (6-pole Bessel) at $30 \mathrm{~Hz}$ and decimated to a sampling rate of $128 \mathrm{~Hz}$ prior to subsequent analysis.

\section{Volume perturbation}

An OVW-type volume perturbation was generated along the lines originally developed by Lutchen et al. ${ }^{18}$. First, a set of 50,000 8-s signals was generated. Each signal had the same spectral content; the frequencies of the sinusoidal components spanned the range 0.5 to $10.25 \mathrm{~Hz}$ and were mutually prime ${ }^{7}$, while the amplitudes 
decreased hyperbolically with frequency. The phases of each component were chosen randomly. From this initial set of perturbations we selected only those that crossed the mean value four times, corresponding to two breathing cycles. From this subset of signals, we chose the smoothest as the perturbation signal to be used in the present study. Smoothness was measured as the integral of the absolute value of the second derivative of the signal. Finally, the points in the perturbation signal were cyclically permuted so that it began with its minimum value. This ensured that when the signal was applied to an animal's lungs, the resulting changes in lung volume would occur above the lung volume defined by the level of PEEP. This volume perturbation signal was scaled to have peak-to-peak excursions of $0.1,0.2,0.3$ and $0.4 \mathrm{~mL}$.

\section{Data analysis}

Table 1 lists the symbols and abbreviations used in the following mathematical development. The measured $V_{c y l}$ and $P_{c y l}$ were corrected for gas compressibility within the flexiVent cylinder and for resistive and accelerative losses in the connecting tubing and endotracheal tube as described previously ${ }^{3}$. This yielded the volume $(V)$ and the pressure $\left(P_{a o}\right)$ applied directly at the airway opening of the animal. $V$ was differentiated numerically to yield flow $(\dot{V})$ by fitting line segments to each 3 consecutive points in the signal and taking the slope of the segment as the derivative of the signal at the central point. These data were fit to four models, as follows: (i) the constant-phase model of the lung in the frequency-domain, (ii) a time-domain approximation to the constant-phase model, (iii) a time-domain nonlinear extension of the constant-phase model containing a flow-dependent 
resistance, and (iv) a time-domain nonlinear extension of the constant-phase model containing a volume-dependent elastance.

We also estimated the degree of nonlinearity in the data in terms of the nonlinear index $k_{d}$ used by Zhang et al. ${ }^{32}$ thus

$$
k_{d}=\sqrt{\frac{P_{N I}}{P_{T O T}}}
$$

where $P_{T O T}$ is the total power in the $P_{a o}$ and $P_{N I}$ is the power in $P_{a o}$ at those frequencies not present in the input $\dot{V}$ signal.

\section{Constant-phase model}

The constant-phase model ${ }^{12}$ is described by

$$
Z_{i n}(f)=R+i 2 \pi f I+\frac{G-i H}{(2 \pi f)^{\alpha}}
$$

where $R$ is a Newtonian resistance, $I$ is an inertance, $G$ characterizes viscous dissipation of energy in the lung tissues, $H$ characterizes energy storage in the lung tissues, $i$ is the imaginary unit, $f$ is frequency, and

$$
\alpha=\frac{2}{\pi} \arctan \left(\frac{H}{G}\right)
$$

$R$ has been taken previously to be a useful estimate of overall airway tree resistance $^{10}$, although it may contain a contribution from the chest wall. I reflects mainly the mass of the gas in the central airways ${ }^{23}$. We have shown previously ${ }^{10}$ that $I$ is not discernible in data collected from mice below $10 \mathrm{~Hz}$, so henceforth we will 
neglect the second term in Eq. 2. Although this model was originally proposed specifically to describe the lung ${ }^{12}$, we have also shown that it provides a good description of the entire respiratory system, including the chest wall ${ }^{10}$.

$Z_{\text {in }}$ was calculated as described previously ${ }^{10,25}$. The $8 \mathrm{~s}$ data records were divided into three 4-s blocks that overlapped by $50 \%$. The first block in each record was discarded and the auto- and cross-power spectra of the remaining two blocks were averaged. The cross-power spectra were then divided by the auto-power spectra to yield a transfer function. This transfer function was corrected for the effects of gas compressibility in the ventilator cylinder and the impedance of the channel leading to the animal as described previously ${ }^{25}$. This correction was achieved using dynamic calibration signals of $P_{c y l}$ and $V_{c y l}$ obtained from the flexiVent prior to connecting the animal by applying the volume perturbation through the tracheal cannula first when it was completely closed and then again when it was open to the atmosphere. Finally, the corrected transfer function was divided by $i 2 \pi f$ to yield $Z_{i n}$.

The constant-phase model (Eq. 2) was fit to $Z_{\text {in }}$ using the following iterative scheme. First, the parameter $\alpha$ was set equal to 1.0 , and the remaining parameters $(R, I, G$ and $H$ ) were estimated by multiple linear regression. The values of $G$ and $H$ were then used in Eq. 3 to obtain a new value for $\alpha$. Using this new value for $\alpha$, the parameters $R, I G$ and $H$ were then re-estimated by multiple linear regression, allowing a second re-estimation of $\alpha$, and so on. This procedure was repeated 10 times (we found that the parameter values typically converged to about 4 significant figures within 5 iterations). 
Time-domain approximation to the constant-phase model

The component of Eq. 2 accounting for the mechanical impedance of the tissues is

$$
Z_{t i}(f)=\frac{G-i H}{(2 \pi f)^{\alpha}}
$$

In the time-domain this corresponds to an impulse-response function ${ }^{12,13}$

$$
z_{t i}(t)=A t^{-k} S(t)
$$

where $S(t)$ is the Heaviside step function defined as

$$
\begin{aligned}
S(t)=1 & , t \geq 0 \\
=0 & , t<0
\end{aligned}
$$

$A$ and $k$ are constants and $t$ is time. $G$ and $H$ are related to $A$ and $k$ as follows.

$$
\begin{aligned}
& G=A \Gamma(\alpha) \cos \left(\frac{\alpha \pi}{2}\right) \\
& H=A \Gamma(\alpha) \sin \left(\frac{\alpha \pi}{2}\right) \\
& k=1-\alpha
\end{aligned}
$$

where $\Gamma(\alpha)$ is the gamma function of $\alpha$ defined as $\int_{0}^{\infty} t^{\alpha-1} e^{-t} d t$.

$z_{t i}(t)$ can be rewritten ${ }^{2}$ 


$$
\begin{aligned}
z_{t i}(t) & =A e^{-k \ln (t)} S(t) \\
& =A\left\{1+[-k \ln (t)]+\frac{[-k \ln (t)]^{2}}{2 !}+\cdots+\frac{[-k \ln (t)]^{n}}{n !}+\cdots\right\} S(t) \\
& \approx\{A[1-k \ln (t)]\} S(t)
\end{aligned}
$$

provided the absolute value of $k \ln (t)$ is small compared to unity, where $\ln (t)$ is the natural logarithm of $t$.

In the frequency-domain, the pressure across the tissues due to the applied flow is

$$
P_{t i}(f)=\dot{V}(f) Z_{t i}(f)
$$

so in the time-domain

$$
P_{t i}(t)=\dot{V}(t) \otimes z_{t i}(t)
$$

where $\otimes$ denotes the operation of convolution. Substituting Eq. 10 into Eq. 12 gives

$$
P_{t i}(t)=\dot{V}(t) \otimes\{A[1-k \ln (t)] S(t)\}
$$

But,

$$
\dot{V}(t) \otimes[A S(t)]=A V(t)
$$

and

$$
\dot{V}(t) \otimes[A k \ln (t) S(t)]=A k\{\dot{V}(t) \otimes[\ln (t) S(t)]\}
$$

Therefore,

$$
P_{t i}(t)=A V(t)-A k\{\dot{V}(t) \otimes[\ln (t) S(t)]\}
$$


By adding a term in $R$ to Eq. 16 we obtain a time-domain approximation to the constant-phase model thus:

$$
P_{a o}(t)=R \dot{V}(t)+A V(t)-A k\{\dot{V}(t) \otimes[\ln (t) S(t)]\}
$$

In order to use Eq. 17, the signals cannot begin at $t=0$ because $\ln (0) \rightarrow-\infty$. To avoid this situation, we defined all signals as starting at $t=0.01 \mathrm{~s}$.

A further consideration regarding the use of Eq. 17 is that it is only valid when the magnitude of $k \ln (t)$ is small compared to unity, because only then is the approximation made in the last line of Eq. 10 valid. This obviously is not true in general because $k \ln (t)$ tends to infinity as $t$ tends to infinity and to minus infinity as $t$ tends to zero. Our requirement here is that Eq. 10 hold over the length of our signals, i.e. from $t=0.01 \mathrm{~s}$ to $8.01 \mathrm{~s}$. We tested this by computing $\mathrm{z}_{t i}(t)$ in Eq. 10 over this time scale using both the exact expression (first line of Eq. 10) and its first-order series approximation (last line of Eq. 10), with a representative value for $k$ of 0.1 . We found the two estimates agreed over the $8 \mathrm{~s}$ period to within an average of $1.2 \%$, with a standard deviation of $0.9 \%$. Thus, we conclude that the truncated series approximation for $z_{t i}(t)$ is sufficiently accurate for our purposes.

\section{Time-domain nonlinear extensions of the constant-phase model}

We extended Equation 17 in two ways by the addition of ad hoc nonlinear terms. The first extension was to add a flow-dependent resistance thus:

$$
P_{a o}(t)=R_{1} \dot{V}(t)+R_{2} \dot{V}|\dot{V}|+A V(t)-A k\{\dot{V}(t) \otimes[\ln (t) S(t)]\}
$$


where $|\dot{V}|$ denotes the absolute value of $\dot{V}$ and is required in the above equation because the resistive pressure drop in the lungs reverses sign with a reversal of the direction of $\dot{V}$.

The second extension of the model was to add a volume-dependent elastance term as follows:

$$
P_{a o}(t)=R \dot{V}(t)+E V^{2}(t)+A V(t)-A k\{\dot{V}(t) \otimes[\ln (t) S(t)]\}
$$

Both nonlinear models (Eqs. 18 and 19) were fit to the data using multiple linear regression. The convolution in the final term of each equation was calculated using Euler integration.

\section{Model comparison}

We compared the performances of the time-domain approximation of the constantphase model (Eq. 17) and the original frequency-domain formulation (Eq. 2) in terms of the percentage differences between the parameters $R, G$ and $H$ estimated by the two models.

The estimated noise variance $(E N V)$ was used as an index of the goodness-of-fit of the a model, where

$$
E N V=\frac{1}{n-m} \sum_{i=1}^{n}\left(P_{i}-\hat{P}_{i}\right)^{2}
$$

where $P_{i}$ is the measured pressure, $\hat{P}_{i}$ is the pressure predicted by the model, $n$ is the sample size, and $m$ is the number of free model parameters. The lower the value of 
$E N V$, the better the model fits the data. When two different models are fit to the same set of data, the model of higher order invariably produces a lower value of $E N V$. In order to decide if the reduction in $E N V$ is statistically significant, we calculated the percent improvement in $E N V$ thus:

$$
\Delta E N V=100\left[\frac{E N V_{1}-E N V_{2}}{E N V_{1}}\right]
$$

where $E N V_{l}$ is the larger of the two values of $E N V$. Provided the noise in the data is normally distributed, the ratio of $E N V_{1}$ to $E N V_{2}$ follows an $\mathrm{F}$ distribution whose number of degrees of freedom is determined by $n$ and the number of parameters in the two models. Using the appropriate $\mathrm{F}$ distribution, we determined that if $\triangle E N V$ is greater than about $30 \%$ then it is less than $5 \%$ likely that $E N V_{1}$ and $E N V_{2}$ are estimates of the same population variance. Thus, when $\Delta E N V>30 \%$ we concluded that model 2 gave a significantly better fit to the data than did model 1 . Otherwise, model 2 was taken as no better than model 1 . We must note, however, that the above reasoning is only valid if the residuals between data and model fit are normally distributed. In our case they clearly were not, so we must take the $30 \%$ level quoted above as a nominal discriminatory level. From a practical point of view, then, we are interested in values of $\triangle E N V$ that are either considerably greater than or less than $30 \%$

\section{RESULTS}

Figure 1 shows the nonlinear index $k_{d}$ (Eq. 1) for all the tidal volumes and PEEP levels studied. $k_{d}$ does not depend in any significant way (ANOVA, Tukey post-hoc comparison) on tidal volume or PEEP. 
Table 2 gives the parameter values of the constant-phase model (Eq. 2) obtained by fitting the model to $Z_{\text {in }}(f)$ in the frequency-domain. The percentage differences between the parameters $R, G$ and $H$ estimated by the constant-phase model (Eq. 2) and the time-domain approximation of this model (Eq. 17) were calculated for every combination of tidal volume and PEEP level. The results are shown in Fig. 2. At a tidal volume of $0.4 \mathrm{~mL}$ and a PEEP of $9 \mathrm{cmH}_{2} \mathrm{O}$ we suddenly obtained a dramatic change in the differences in the tissue parameters $G$ and $H$. We suspect this may reflect the onset of overinflation injury, and so we do not consider the data collected under these conditions from now on. For the remainder of the data, the percentage differences in $\mathrm{H}$ go from $0.73 \%$ at an amplitude of $0.3 \mathrm{~mL}$ and PEEP of $9 \mathrm{cmH}_{2} \mathrm{O}$, to $6.56 \%$ at $0.1 \mathrm{~mL}$ and $6 \mathrm{cmH}_{2} \mathrm{O}$. The percentage differences in $G$ go from $5.13 \%$ at $0.2 \mathrm{~mL}$ and $3 \mathrm{cmH}_{2} \mathrm{O}$, to $45.81 \%$ at $0.1 \mathrm{~mL}$ and PEEP of $0 \mathrm{cmH}_{2} \mathrm{O}$. The lowest percentage difference at $R$ is $14.25 \%$ at $0 \mathrm{cmH}_{2} \mathrm{O}$ and $0.1 \mathrm{~mL}$, while the highest percentage difference is $64.43 \%$ at $9 \mathrm{cmH}_{2} \mathrm{O}$ and $0.1 \mathrm{~mL}$.

Figure 3 shows how the addition of a nonlinear resistance term (Eq. 18) and a nonlinear elastance term (Eq. 19) to the time-domain constant-phase model (Eq. 17) improves the goodness of fit. $\triangle E N V$ is shown for each tidal volume and PEEP level investigated. With the nonlinear resistance term (Fig. 3A) most cases yielded a value of $\triangle E N V$ that was far below the nominal $30 \%$ significance level. Only the data from the lowest PEEP level at the highest two tidal volumes approached the $30 \%$ level. In contrast, the addition of a nonlinear elastance term caused many of the data sets to exceed the $30 \% \triangle E N V$ level substantially (Fig. 3B). 


\section{DISCUSSION}

The use of the constant-phase model to interpret measurements of $Z_{\text {in }}$ has gained a wide following recently $6,10,12,24$. However, its use in this regard is predicated on the assumption of linear dynamic behavior from the respiratory system ${ }^{20,23}$. When the imposed oscillations are small, this may be a reasonable assumption. However, nonlinear behavior of respiratory mechanics can become apparent event at normal tidal volumes, especially when PEEP is elevated ${ }^{4,15,21,29,30}$ Thus, to be comfortable with the assumption of small-amplitude linear behavior, one is compelled to use oscillation amplitudes that are considerably smaller than normal $V_{T}$. This constraint can not, of course, be applied to the OVW, which by definition attempts to deliver a normal $V_{T}$. Lutchen et al. ${ }^{18}$ employ a cunning technique for dealing with nonlinearities when using the OVW by having the OVW contain only components satisfying the no-sum-no-difference criterion ${ }^{27}$ and then calculating $Z_{\text {in }}$ only at those frequencies present in the input $\dot{V}$ waveform. This means that any harmonics in $P_{a o}$, produced by passing $\dot{V}$ through a nonlinear system, are discarded. The problem with this approach is that if the nonlinearities are strong, then a significant amount of information about the system is not being used in its assessment.

The parameters of the constant-phase model (Eq. 2) vary with PEEP and tidal volume (Table 2) in characteristic ways. For example, $H$ is minimal at an intermediate PEEP level $\left(3 \mathrm{cmH}_{2} \mathrm{O}\right.$ at three of the tidal volumes investigated and 6 $\mathrm{cmH}_{2} \mathrm{O}$ at the remaining tidal volume). This has been described before ${ }^{10}$ and is thought to be due to strain stiffening of the tissues at higher PEEPs and to some degree of airspace closure at PEEP $0 . G$ shows a somewhat similar pattern, no doubt 
for the same reasons. $R$ shows a more curious pattern of increasing with both PEEP and tidal volume. If $R$ really is a measure of airway resistance, one might expect the opposite to occur as the airways increase in caliber with increasing lung volume. However, it is possible that our $R$ values include some contribution from the chest wall (this might be more apparent in mice than other species, as mice have relatively large airways for their lung size ${ }^{10}$, which could make the effect of their tissues on $R$ relatively more important than in other species).

Our goal was to develop a method for encapsulating the mechanical behavior of the respiratory system in a way that retains at least some of the nonlinear information present in the measured pressure-flow relationships. We could have attempted this in the frequency-domain in terms of a Volterra series ${ }^{16,26,33}$. However, this series can rapidly become intractable, and interpreting its various terms physiologically is generally not possible. Suki et al. ${ }^{28}$ investigated an alternative approach in which they fit block-structured nonlinear models in the time-domain to data from dogs. Maksym and Bates ${ }^{19}$ applied a similar approach to data from rat lungs. Again, however, it is not obvious how to interpret the elements of these models in physiologic terms. Also, the fitting process is somewhat computationally expensive, requiring iteration between the time and frequency domains. Therefore, we decided to develop nonlinear frequency-dependent lumped-parameter models in the timedomain. These models are derived from a linear frequency-domain model whose utility and interpretation are well established ${ }^{10,12,24}$. Also, by expressing the models in terms of a truncated exponential expansion (Eq. 10), we were able to cast them in a form that can be fit to data using multiple linear regression (Eqs. 17, 18, and 19). This poses a relatively low computational burden. Finally, even though the data 
analyzed in the present study were collected under steady-state conditions, Eqs. 17, 18 and 19 can be fit using recursive least squares ${ }^{17}$. This would allow them to be applied to non-stationary data in order to track changing parameter values.

The first step in this process was re-casting the linear constant-phase model in the time-domain. This was not straightforward because the constant-phase model has an impulse response that is infinite at $t=0$. Therefore, we resorted to a time-domain approximation to the constant-phase model that employs convolution with the first two terms of the series expansion for a power series, and we started the impulse response at $t=0.01 \mathrm{~s}$ in order to avoid singularities. We then had to address the issue of how equivalent the two model formulations are. The frequency-domain and timedomain versions of the constant-phase model weight the data differently when estimating the model parameters. That is, minimizing the squared residuals between a predicted and calculated $Z_{\text {in }}$ is not equivalent to minimizing the residuals between measured and estimated $P_{a o}$. Consequently, any errors in either the data or the models would be expected to affect the parameters differently in the two domains. We thus might also expect that differences in model parameter obtained in the two domains should increase with the degree of nonlinearity in the data. At the very highest level of PEEP and tidal volume the parameter differences are opposite in sign to most of the other cases. We suspect this may have been due to a change in the state of the lung induced by overdistension; it was our impression that the mice did not do well being ventilated under these conditions, which is why we always applied the highest PEEP and tidal volume after the other data had been collected. For the remaining data in Fig. 2, there is a suggestion that the parameter differences increase 
with PEEP, however the effect is not marked so we can not draw any firm conclusions.

The parameter $H$, which characterizes energy storage in the tissues, had the lowest percentage differences between the frequency-domain and time-domain models (Fig. 2). This can be explained by the fact that most of the $P$ signal produced by the perturbations reflected stored elastic energy, because most of the power in $V$ was at low frequencies. Consequently, $H$ is most strongly determined by the data and so has the greatest signal-to-noise ratio. In contrast, the highest percentage differences occurred in $R$, which is the asymptotic value of the real part of the impedance as frequency goes to infinity. $R$ is thus the parameter least strongly determined by the data, and so it tends to have the lowest signal-to-noise ratio. Nevertheless, the two models produce parameter values that are at least comparable over the range of conditions we investigated.

The second step in our model development was to add the capacity for the timedomain constant-phase model to account for nonlinearities. Previous studies ${ }^{4,15,21,30}$ have shown that the most important nonlinearity to appear during mechanical ventilation is invariably a volume-dependent elastance. Therefore, we added an ad hoc term in $V^{2}$ to our model (Eq. 19). We then assessed the necessity for this extra term, in any particular case, by examining how much it improved the fit to the data. We found that the fit was improved significantly as both $V_{T}$ and PEEP increased (Fig. 3B). This is explicable on the basis that the respiratory tissues assume progressively stiffening behavior as lung volume is increased, causing their pressurevolume properties to become increasingly nonlinear ${ }^{4,8,15,21,30}$. We also examined the 
effect of adding a flow-dependent resistance term to the time-domain model (Eq. 18). In most cases, this had a minimal effect on $\triangle E N V$ (Fig. 3A). Interestingly, $\triangle E N V$ obtained with the flow-dependent resistance was largest at the two highest tidal volumes and lowest PEEP level (Fig. 3A). This is consistent with the notion that turbulent flow in the airways would most likely occur when the highest gas flows (produced by the high tidal volumes) pass through narrowed airways (i.e. at the lowest lung volume).

In conclusion, our study has shown that in normal mice, ventilation with the OVW produces mechanical behavior that becomes significantly nonlinear as PEEP and $V_{T}$ are increased. Although these nonlinearities can be neglected using a perturbation waveform designed to avoid harmonic distortion, doing so may discard a significant and interesting portion of the data. In particular, keeping track of the appearance of a volume-dependent nonlinearity, one may be able to detect overinflation of the lung, or the onset of pathologies that cause the lung tissues to acquire nonlinear elastic behavior at lower than normal volumes. 


\section{ACKNOWLEDGEMENTS}

This work was supported by NIH grants R01HL62746, R01HL67273 and NCRR

COBRE P20RR15557, and a grant from Conselho Nacional de Desenvolvimento Cientifico e Tecnológico (CNPq), Brazil. 


\section{REFERENCES}

1. Antonaglia, V., A. Peratoner, L. Simoni, A. Gullo, J. Milic-Emili, and W. A. Zin. Bedside assessment of respiratory viscoelastic properties in ventilated patients. Eur. Respir. J. 16: 302-308, 2000.

2. Bates, J. H. T., G. N. Maksym, D. Navajas, and B. Suki. Lung tissue rheology and 1/f noise. Ann. Biomed. Eng. 22: 674-681, 1994.

3. Bates, J. H. T., T. F. Schuessler, C. Dolman, and D. H. Eidelman. Temporal dynamics of acute isovolume bronchoconstriction in the rat. J. Appl. Physiol. 82: 55$62,1997$.

4. Bersten, A. D. Measurement of overinflation by multiple linear regression analysis in patients with acute lung injury. Eur. Respir. J. 12: 526-532, 1998.

5. Bijaoui, E., S. A. Tuck, J. E. Remmers, and J. H. T. Bates. Estimating respiratory mechanics in the presence of flow limitation. J. Appl. Physiol. 86: 418-426, 1999.

6. Bijaoui, E., P. F. Baconnier, and J. H. T. Bates. Mechanical output impedance of the lung determined from cardiogenic oscillations. J. Appl. Physiol. 91: 859-865, 2001.

7. Daróczy, B., and Z. Hantos. Generation of optimum pseudorandom signals for respiratory impedance measurements. Int. J. Biomed. Comput. 25: 21-31, 1990.

8. Dechman, G, A. -M. Lauzon, and J. H. T. Bates. Mechanical behavior of the canine respiratory system at very low lung volumes. Respir. Physiol. 95: 119-129, 
1994.

9. Farré, R., M. Mancini, M. Rotger, M. Ferrer, J. Roca, and D. Navajas. Oscillatory resistance measured during noninvasive proportional assist ventilation. Am. J. Respir. Crit. Care Med. 164: 790-794, 2001.

10. Gomes, R. F. M., X. Shen, R. Ramchandani, R. S. Tepper, and J. H. T. Bates. Comparative respiratory system mechanics in rodents. J. Appl. Physiol. 89: 908-916, 2000.

11. Hantos, Z., B. Daróczy, B. Suki, G. Galgóczy, and T. Csendes. Forced oscillatory impedance of the respiratory system at low frequencies. J. Appl. Physiol. 60: 123$132,1986$.

12. Hantos, Z., B. Daróczy, B. Suki, S. Nagy, and J. J. Fredberg. Input impedance and peripheral inhomogeneity of dog lungs. J. Appl. Physiol. 72: 168-178, 1992.

13. Hildebrandt, J. Comparison of mathematical models for cat lung and viscoelastic balloon derived by Laplace transform methods from pressure-volume data. Bull. Math. Biophys. 31: 651-667, 1969.

14. Kaczka, D.W. , E.P. Ingenito, B. Suki, and K.R. Lutchen. Partitioning airway and lung tissue resistances in humans: effects of bronchoconstriction. J. Appl. Physiol. 82: 1531-1541, 1997.

15. Kano, S., C. J. Lanteri, A. W. Duncan, and P. D. Sly. Influence of nonlinearities on estimates of respiratory mechanics using multilinear regression analysis. J. Appl. Physiol. 77: 1185-1197, 1994. 
16. Korenberg, M. J., and I. W. Hunter. The identification of nonlinear biological systems: Volterra kernel approaches. Ann. Biomed. Eng. 24: 250-268, 1996.

17. Lauzon, A.-M., and J.H.T. Bates. Estimation of time-varying respiratory mechanical parameters by recursive least squares. J. Appl. Physiol. 71: 1159-1165, 1991.

18. Lutchen, K. R., K. Yang, D. W. Kaczka, and B. Suki. Optimal ventilation waveforms for estimating low-frequency respiratory impedance. J. Appl. Physiol. 75: 478-488, 1993.

19. Maksym G.N., and J.H.T. Bates. Nonparametric block-structure modeling of rat lung mechanics. Ann. Biomed. Eng. 25: 1000-1008, 1997

20. Michaelson, E. D., E. D. Grassman, and W. R. Peters. Pulmonary mechanics by spectral analysis of forced random noise. J. Clin. Invest. 56: 1210-1230, 1975.

21. Muramatsu, K., K. Yukitake, M. Nakamura, I. Matsumoto, and Y. Motohiro. Monitoring of nonlinear respiratory elastance using a multiple linear regression analysis. Eur. Respir. J. 17: 1158-1166, 2001.

22. Pelosi, P., M. Croci, I. Ravagnan, M. Cerisara, P. Vicardi, A. Lissoni, and L. Gattinoni. Respiratory system mechanics in sedated, paralyzed, morbidly obese patients. J. Appl. Physiol. 82: 811-818, 1997.

23. Peslin, R., and J. J. Fredberg. "Oscillation mechanics of the respiratory system". In: Handbook of Physiology. Mechanics of Breathing, edited by P. T. Macklem, and J. Mead. Bethesda: American Physiological Society, 1986, pp. 145-177. 
24. Peták, F., W. Habre, Z. Hantos, P. D. Sly, and D. R. Morel. Effects of pulmonary vascular pressures and flow on airway and parenchymal mechanics in isolated rat lungs. J. Appl. Physiol. 92: 169-178, 2002.

25. Schuessler, T. F.; and J. H. T. Bates. A computer-controlled research ventilator for small animals: design and evaluation. IEEE Trans. Biomed. Eng. 42: 860-866, 1995.

26. Suki, B., and J. H. T. Bates. A nonlinear viscoelastic model of lung tissue mechanics. J. Appl. Physiol. 71: 826-833, 1991.

27. Suki, B., and K. R. Lutchen. Pseudorandom signals to estimate apparent transfer and coherence functions of nonlinear systems: applications to respiratory mechanics. IEEE Trans. Biomed. Eng. 39: 1142-1151, 1992.

28. Suki, B., Q. Zhang, and K.R. Lutchen. Relationship between frequency and amplitude dependence in the lung: a nonlinear block-structured modeling approach. J. Appl. Physiol. 79: 660-671, 1995.

29. Vassiliou, M. P., L. Petri, A. Amygdalou, M. Patrani, C. Psarakis, D. Nikolaki, G. Georgiadis, and P. K. Behrakis. Linear and nonlinear analysis of pressure and flow during mechanical ventilation. Intensive Care Med. 26: 1057-1064, 2000.

30. Wagers S., L. Lundblad, H. T. Moriya, J. H. T. Bates, and C. G. Irvin. Nonlinearity of respiratory mechanics during bronchoconstriction in mice with airway inflammation. J. Appl. Physiol. 92: 1802-1807, 2002. 
31. Zerah, F., A. M. Lorino, H. Lorino, A. Harf, and I. Macquin-Mavier. Forced oscillation technique vs spirometry to assess bronchodilatation in patients with asthma and COPD. Chest. 108: 41-47, 1995.

32. Zhang, Q., K. R. Lutchen, and B. Suki. Harmonic distortion from nonlinear systems with broadband inputs: applications to lung mechanics. Ann. Biomed. Eng. 23: 672-681, 1995.

33. Zhang, Q., K. R. Lutchen, and B. Suki. A frequency domain approach to nonlinear and structure identification for long memory systems: application to lung mechanics. Ann. Biomed. Eng. 27: 1-13, 1999. 
Table 1: List of symbols and abbreviations.

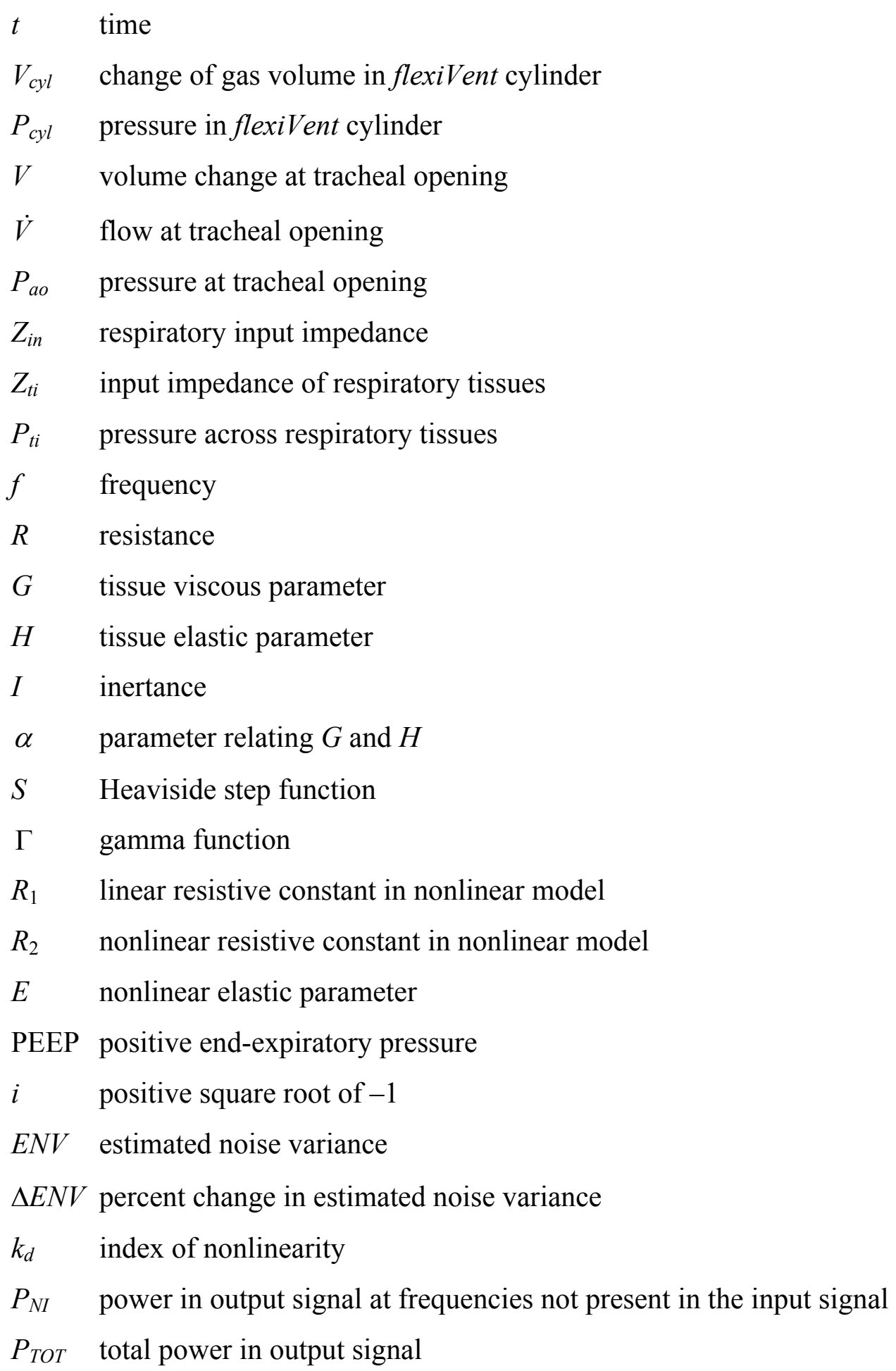


Table 2: Values of $R, G$ and $H$ (mean \pm standard deviation) for the constant-phase model (Eq. 2).

$R\left(\mathrm{cmH}_{2}\right.$ O.S. $\left.m L^{-1}\right)$

\begin{tabular}{|c|c|c|c|c|}
\hline Tidal volume & PEEP 0 & PEEP 3 & PEEP 6 & PEEP 9 \\
\hline $\mathbf{0 . 1} \mathbf{~ m L}$ & $0.296 \pm 0.116$ & $0.388 \pm 0.066$ & $0.349 \pm 0.053$ & $0.464 \pm 0.038$ \\
\hline $\mathbf{0 . 2} \mathbf{~ m L}$ & $0.383 \pm 0.113$ & $0.377 \pm 0.132$ & $0.429 \pm 0.098$ & $0.606 \pm 0.052$ \\
\hline $\mathbf{0 . 3} \mathbf{~} \mathbf{L}$ & $0.498 \pm 0.248$ & $0.415 \pm 0.128$ & $0.509 \pm 0.144$ & $0.676 \pm 0.080$ \\
\hline $\mathbf{0 . 4} \mathbf{~ m L}$ & $0.535 \pm 0.250$ & $0.499 \pm 0.181$ & $0.705 \pm 0.135$ & $0.603 \pm 0.119$ \\
\hline
\end{tabular}

$G\left(\mathrm{cmH}_{2}\right.$ O.s. $\left.\mathrm{mL}^{-(1+\alpha)}\right)$

\begin{tabular}{|c|c|c|c|c|}
\hline $\mathbf{0 . 1} \mathbf{~ m L}$ & $5.174 \pm 1.211$ & $3.711 \pm 0.678$ & $3.326 \pm 0.199$ & $4.807 \pm 0.111$ \\
\hline $\mathbf{0 . 2} \mathbf{~ m L}$ & $4.331 \pm 0.878$ & $3.030 \pm 0.678$ & $2.731 \pm 0.370$ & $4.324 \pm 0.361$ \\
\hline $\mathbf{0 . 3} \mathbf{~} \mathbf{L}$ & $3.630 \pm 0.632$ & $2.689 \pm 0.669$ & $2.022 \pm 0.489$ & $3.883 \pm 0.228$ \\
\hline $\mathbf{0 . 4} \mathbf{~ m L}$ & $3.433 \pm 0.844$ & $2.391 \pm 0.601$ & $1.019 \pm 0.590$ & $6.027 \pm 0.959$ \\
\hline
\end{tabular}

$\mathrm{H}\left(\mathrm{cmH}_{2}\right.$ O.S. $\left.\mathrm{mL}^{-(1+\alpha)}\right)$

\begin{tabular}{|c|l|l|l|l|}
\hline $\mathbf{0 . 1} \mathbf{~ m L}$ & $32.136 \pm 9.088$ & $22.678 \pm 6.882$ & $20.293 \pm 2.406$ & $45.737 \pm 4.858$ \\
\hline $\mathbf{0 . 2} \mathbf{~ m L}$ & $26.043 \pm 4.947$ & $21.735 \pm 6.312$ & $23.208 \pm 1.979$ & $64.085 \pm 7.783$ \\
\hline $\mathbf{0 . 3} \mathbf{~ m L}$ & $24.673 \pm 3.999$ & $21.548 \pm 6.419$ & $31.956 \pm 6.787$ & $77.762 \pm 9.179$ \\
\hline $\mathbf{0 . 4} \mathbf{~ m L}$ & $25.012 \pm 8.181$ & $25.144 \pm 9.541$ & $47.461 \pm 7.825$ & $78.864 \pm 7.107$ \\
\hline
\end{tabular}




\section{FIGURE CAPTIONS}

$\underline{\text { Figure } 1} \quad$ Nonlinear index $k_{d}$ (Eq. 1)

Figure 2 Percentage difference between the parameters estimated by the constant-phase model in the frequency domain and the approximation of the constant-phase model in the time domain.

Figure 3 Improvement in fit $(\triangle E N V)$ with the addition of a nonlinear elastance term to the time-domain approximation of the constant-phase model. The horizontal dashed line shows the nominal level above which a value of $\triangle E N V$ indicates that the nonlinear term produced a significant improvement in the goodness-of-fit of the model. 


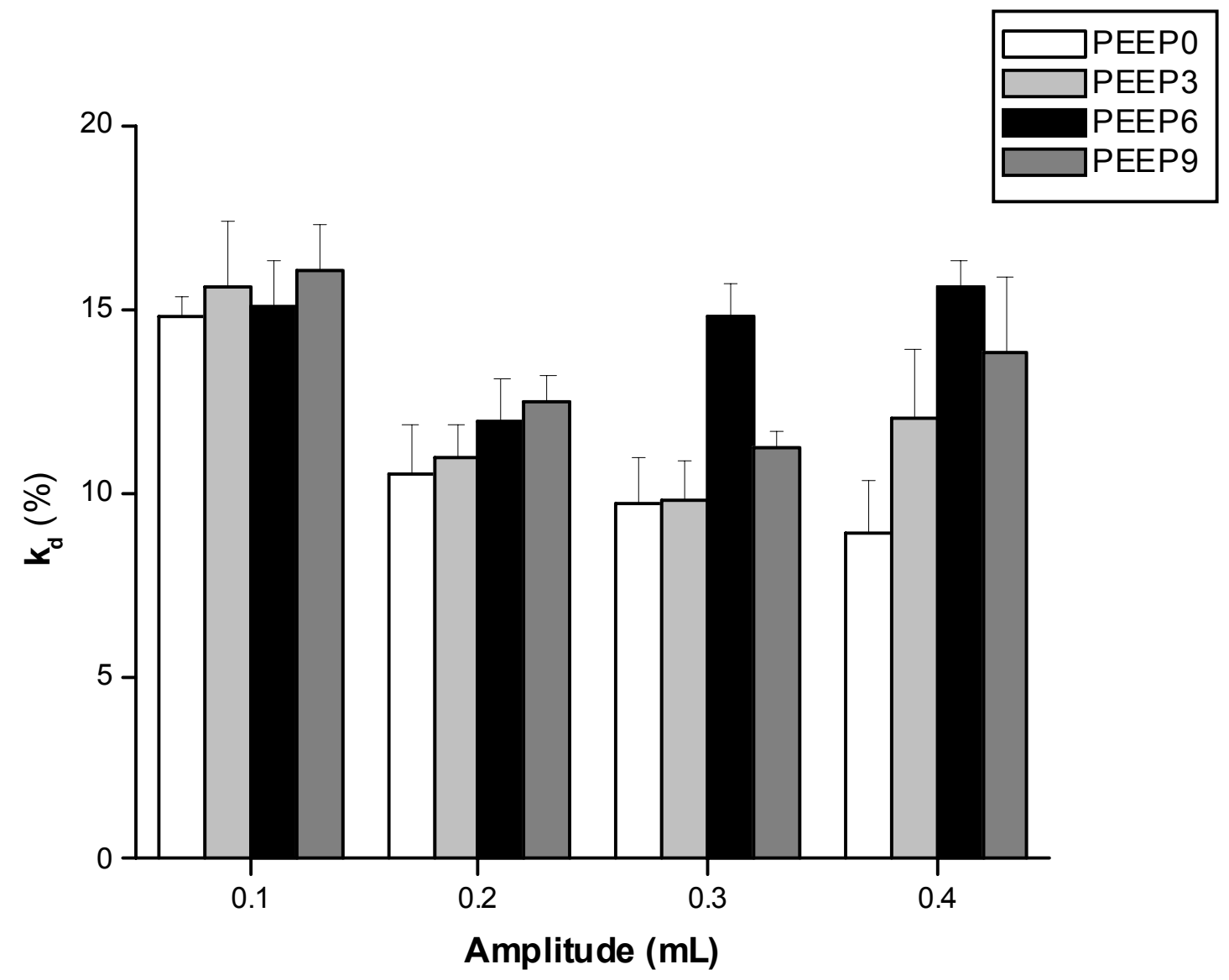

Figure $1 \quad$ Nonlinear index $k_{d}$ (Eq. 1) 

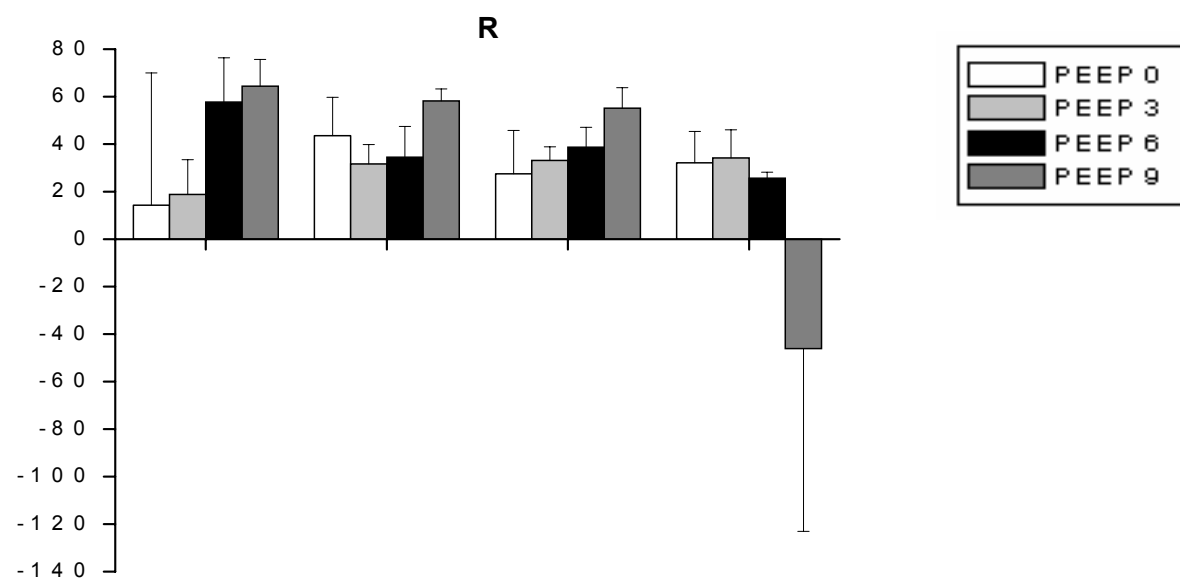

$\frac{O}{0}$
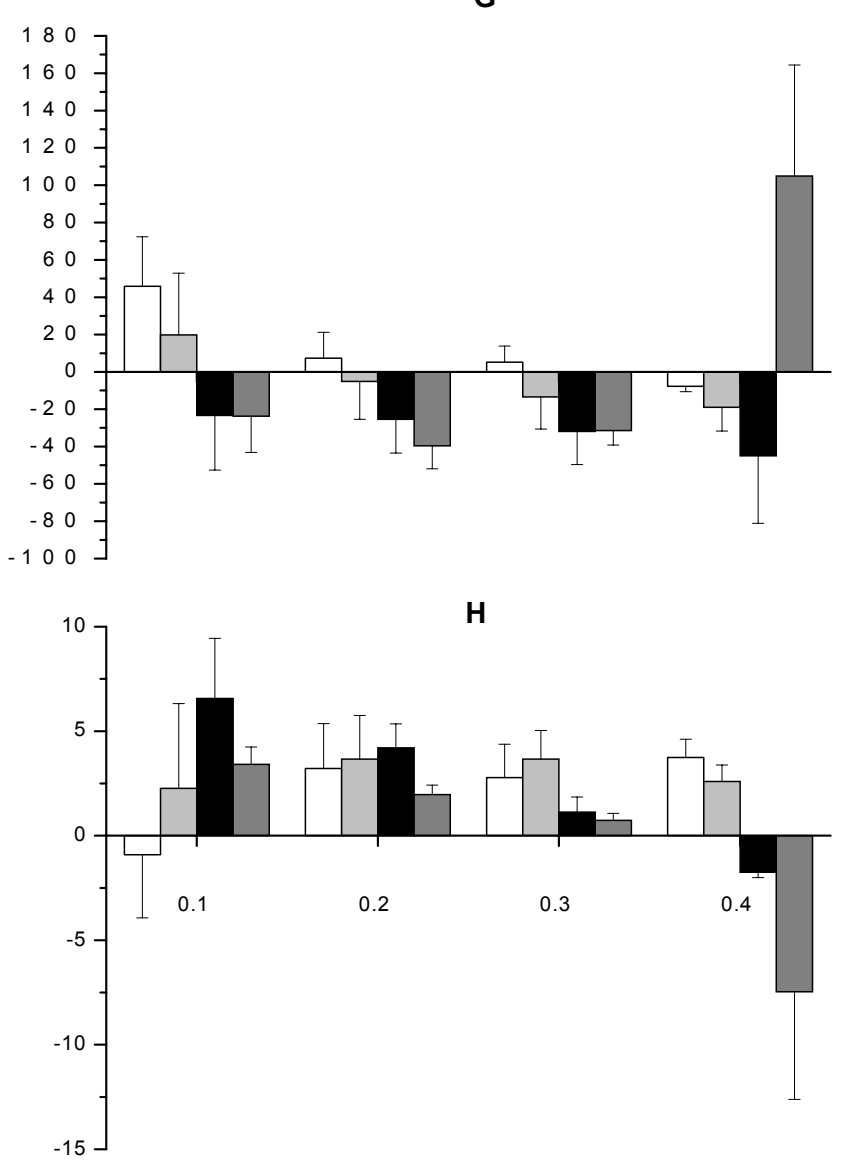

\section{Amplitude (mL)}

Figure 2 Percentage difference between the parameters estimated by the constant-phase model in the frequency domain and the approximation of the constant-phase model in the time domain. 

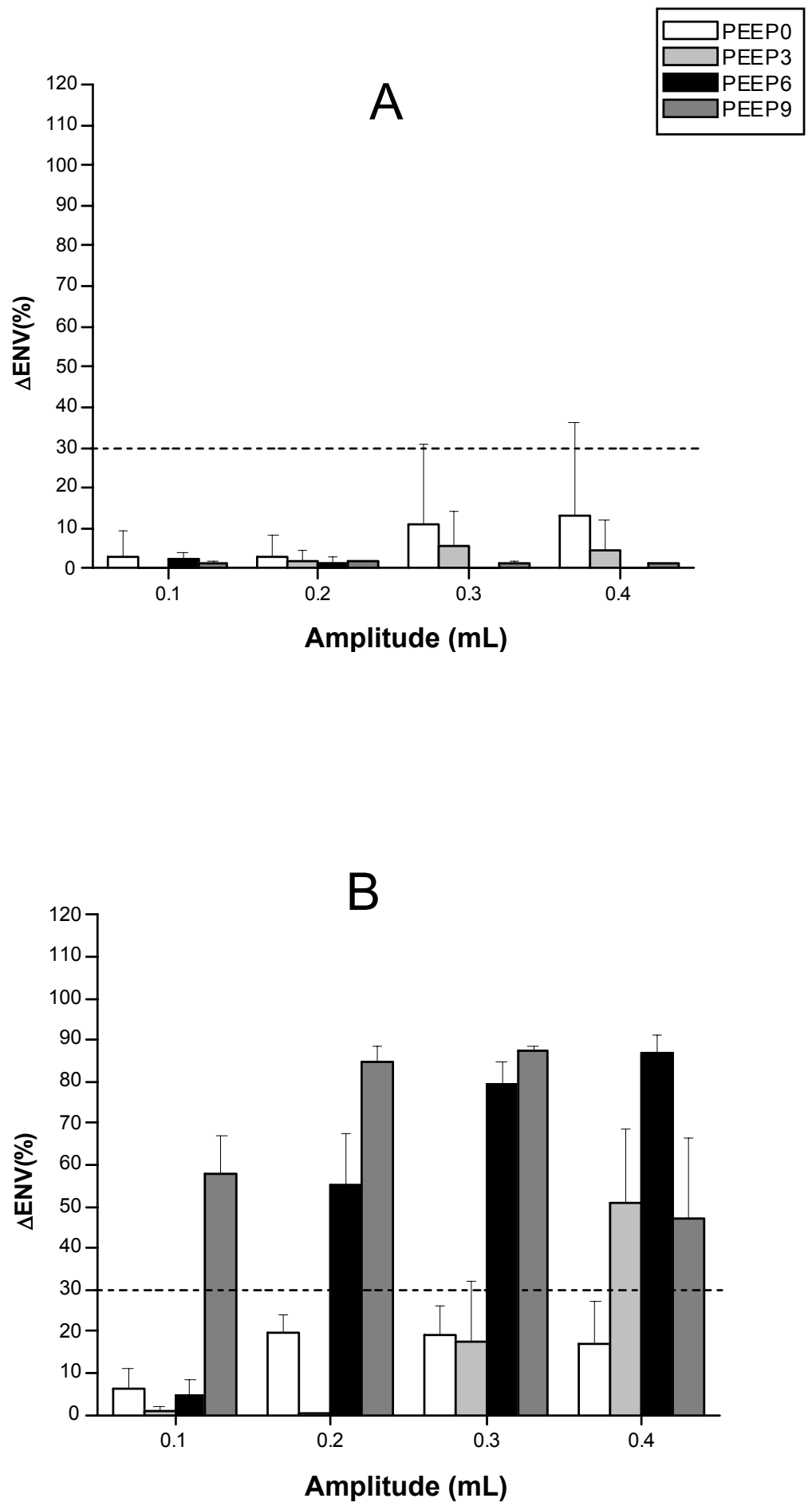

Figure 3 Improvement in fit $(\triangle E N V)$ with the addition of a nonlinear resistance term (A) and a nonlinear elastance term (B) to the time-domain approximation of the constant-phase model. The horizontal dashed line shows the nominal level above which a value of $\triangle E N V$ indicates that the nonlinear term produced a significant improvement in the goodness-of-fit of the model. 